FABIO CARDOSO ALMEIDA

\title{
ANÁLISE DAS FORÇAS DE CONTATO E COMPORTAMENTO DINÂMICO DE RODEIRO FERROVIÁRIO
}

Dissertação apresentada à Escola Politécnica da Universidade de São Paulo para obtenção de título de Mestre em Engenharia

Área de Concentração:

Engenharia de Controle e Automação

São Paulo

2006 
FABIO CARDOSO ALMEIDA

\section{ANÁLISE DAS FORÇAS DE CONTATO E COMPORTAMENTO DINÂMICO DE RODEIRO FERROVIÁRIO}


Este exemplar foi revisado e alterado em relação à versão original, sob responsabilidade única do autor e com a anuência de seu orientador.

São Paulo, .... de .........de 200...

Assinatura do autor

Assinatura do orientador

FICHA CATALOGRÁFICA

Almeida, Fabio Cardoso

Análise das forças de contato e comportamento dinâmico do rodeiro ferroviário / Fabio Cardoso Almeida. -- São Paulo, 2006. 132 p.

Dissertação (Mestrado) - Escola Politécnica da

Universidade de São Paulo. Departamento de Engenharia Mecânica.

1. Dinâmica veicular 2. Contato roda-trilho 3. Força de contato 4. Ferrovia 5. Sistemas multicorpos I. 
DEDICATÓRIA: Aos meus pais, esposa e comunidade acadêmica. 


\section{AGRADECIMENTOS}

Durante os momentos que se passaram desde o início do curso de mestrado, os momentos difíceis foram muitos. Em todos eles, contei com a ajuda de Deus. Por isso, em primeiro lugar, agradeço a Ele. Em segundo, a meu pai Carlos Alberto Cardoso Almeida, pessoa que sem seu exemplo, não teria alcançado tudo isso. A minha mãe agradeço por todo amor, carinho e fé sempre presentes.

Agradeço à empresa Alstom Transport principalmente na pessoa do Sr. Luiz Carlos Fernandez Cano e a toda sua equipe, em especial, ao pessoal do Laboratório de Cálculo de Estruturas.

Esse trabalho existe graças à insistência e confiança depositadas pelo professor Dr. Roberto Barbosa Spinola. A área de dinâmica veicular ferroviária me assustou por sua grandiosidade. Quando olhava de fora, acreditava que alguns meses de trabalho duro bastavam para a criação de uma dissertação. Precisava mais que isso. Diria que não meses mas anos. Diria que mais que dedicação, a orientação certa, e essa base, com o professor Spinola eu tive.

À pessoa que acompanhou minhas dificuldades abrindo mão de um tempo ao meu lado e permitindo que minha dedicação, fora da empresa, fosse quase que exclusiva à dissertação, Isabela.

E por fim, à Universidade do Estado de São Paulo que me acolheu, e me serviu do conhecimento e infra-estrutura necessários para a completa realização dessa dissertação. 


\section{RESUMO}

Sistemas dinâmicos ferroviários são modelados levando-se em consideração as forças de contato roda trilho. As equações de movimento são fortemente influenciadas pela determinação dessas forças, o que requer o conhecimento da mecânica de contato, ferramenta imprescindível na previsão do comportamento de uma composição ferroviária. O rodeiro é responsável por receber as excitações na forma de irregularidades e imperfeições da via e transferi-la para a suspensão primária.

A proposta dessa dissertação consiste em realizar simulações no domínio do tempo, da resposta do comportamento dinâmico do rodeiro ferroviário de 2 graus de liberdade. $\mathrm{O}$ modelo matemático equivalente é desenvolvido. A rigidez de contato e a conicidade são linearizados em torno de um ponto de operação, próximo ao centro da via. É apresentada a influência da velocidade na estabilidade para o modelo linearizado e para a conicidade variando de 0.1 a 1.0. Os respectivos modos de vibrar também são apresentados.

Em seguida, o modelo matemático não linear do rodeiro ferroviário é gerado por software especializado na criação de sistemas de multicorpos, VAMPIRE, que permite a criação das equações de movimento através da topologia do sistema. O modelo é criado seguindo a proposta do benchmarck apresentada pela International Association of Vehicle System Dynamics (IAVSD). O rodeiro recebe uma força lateral crescente que se estabiliza em $20 \mathrm{kN}$. O rodeiro é excitado com a aplicação de outra força lateral a uma taxa de $50 \mathrm{kN} / \mathrm{s}$ até o descarrilamento. As forças longitudinais, laterais que aparecem no contato, o ângulo do plano de contato, ângulo de yaw e afastamento lateral são comparados com o benchmarck e outros autores. 


\begin{abstract}
CARDOSO, F. A. Analysis of Creep Forces and the Dynamic Behavior of wheel-set, São Paulo. (2006). 132p. Dissertação de Mestrado - Escola Politécnica de São Paulo, Universidade de São Paulo, Brasil

Railway dynamics systems are modeled regarding the creep forces between wheel-rail. The equations of movement are strongly influenced by these forces, what requests the knowledge of the theory in mechanical of contact, necessary tool to foresee the behavior of a railway vehicle. The wheelset is responsible by receiving the perturbations of irregularities and transfer them to the primary suspension. A railway vehicle is composed by primary and secondary suspensions.

The proposal is based on performing simulations in the time domain, dynamic response of a railway wheelset of two degrees of freedom. The mathematical model is developed. The stiffness of contact and conicity are linearized around an operation point, near to track center. The influence of speed is determined to linearized model and to a range of 0.1 to 1.0 in the conicity. The eigenvectors are presented.

In the following, the non linear model of the wheelset is generated using a specialized package of multi body system, VAMPIRE. The package creates equations of movement after the generation of the topology. The non linear mathematical model are defined by the benchmark proposed by International Association of Vehicle System Dynamics (IAVSD). The wheelset is submitted to $20 \mathrm{kN}$ at the rail level. In a second case, the wheelset is submitted to a rate of $50 \mathrm{kN} / \mathrm{s}$ of lateral force until derailing. The determined longitudinal and lateral forces on contact, yaw angle and displacement of the center of gravity of the wheelset, contact angle are compared with the benchmark results and other authors.
\end{abstract}




\section{SUMÁRIO}

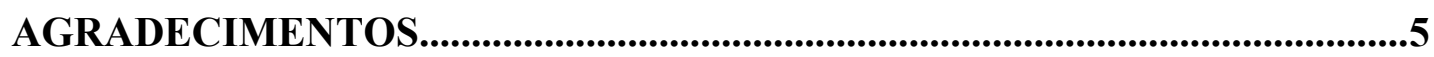

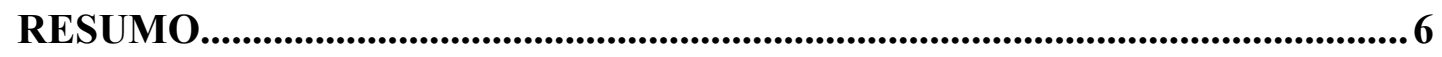

ABSTRACT

LISTA DE SÍMBOLOS..............................................................................13

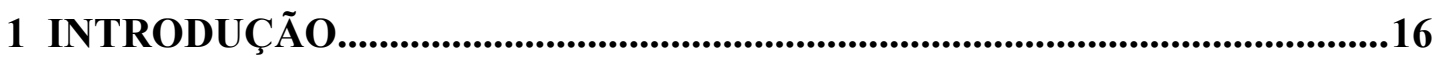

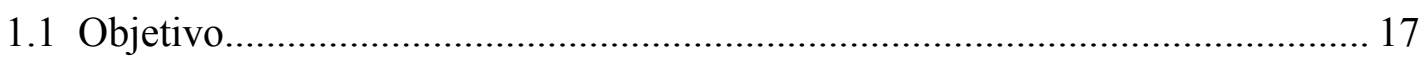

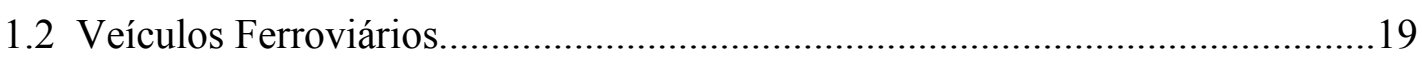

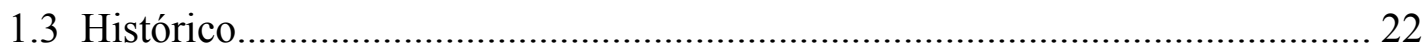

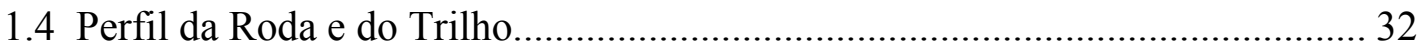

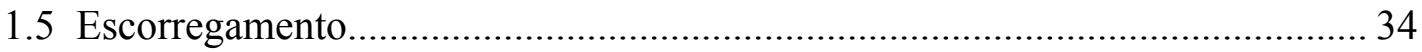

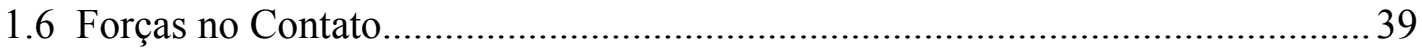

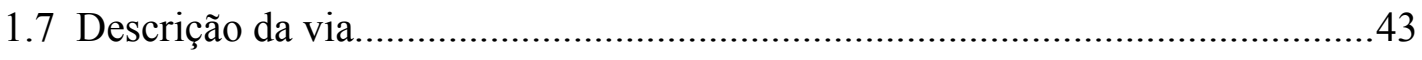

2 MODELO MATEMÁTICO..........................................................................49

2.1 Solução das equações de movimento............................................................. 52

2.2 Desacoplamento das Equações..........................................................................5

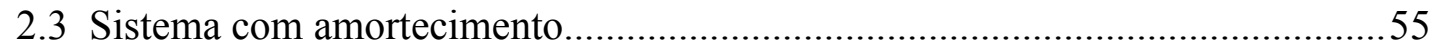

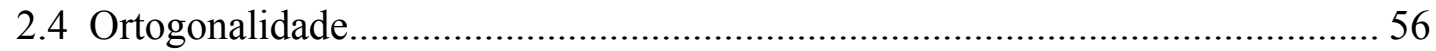

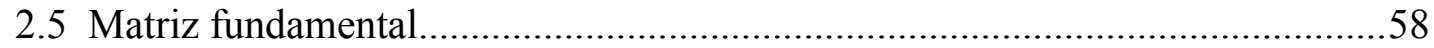

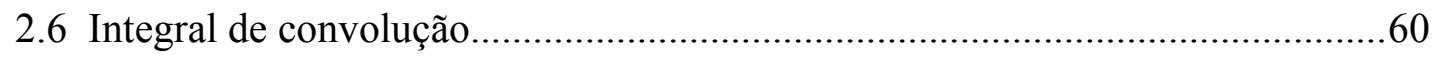

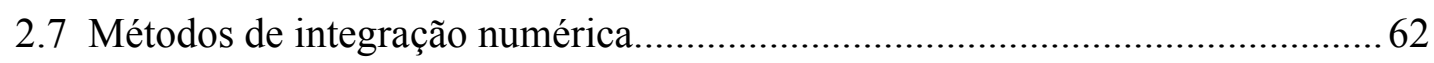

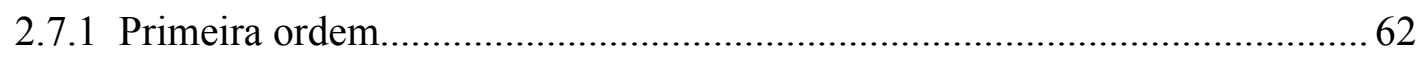

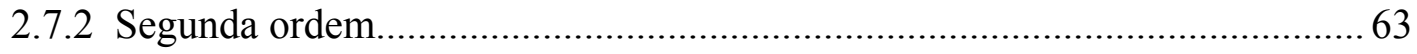

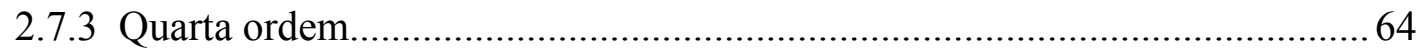

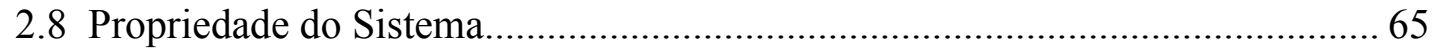

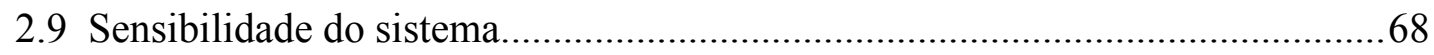

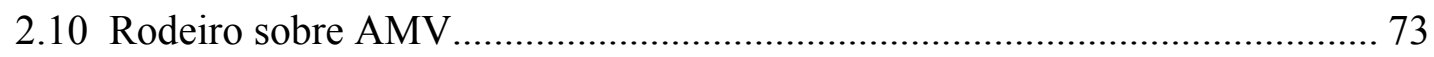

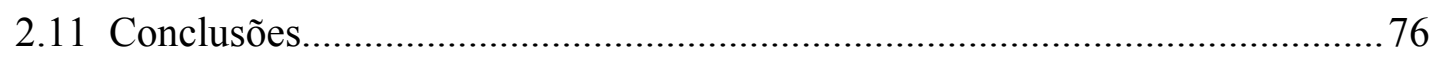

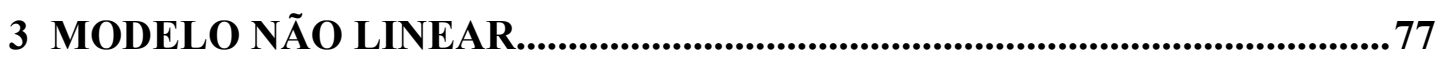


3.1 Disposição espacial da geometria do modelo.................................................. 77

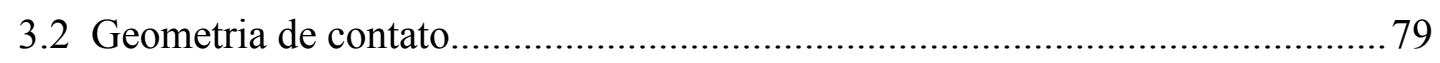

3.2.1 Análise da deformação elástica no contato................................................ 81

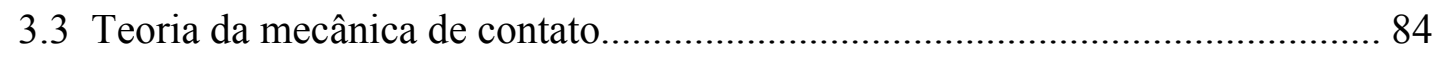

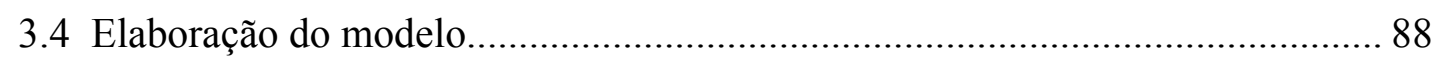

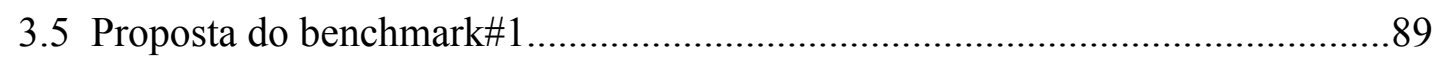

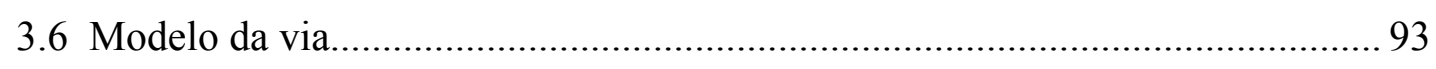

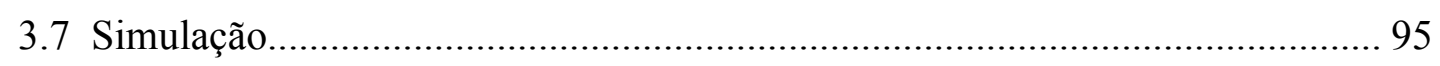

3.8 Descrição do programa de multicorpos.......................................................... 96

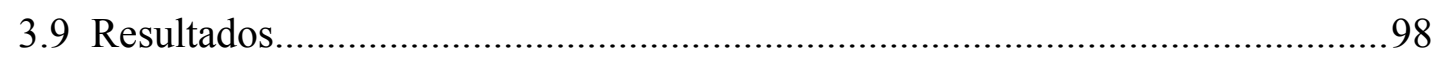

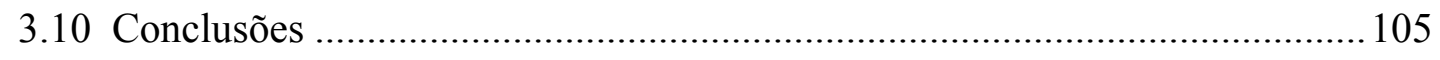

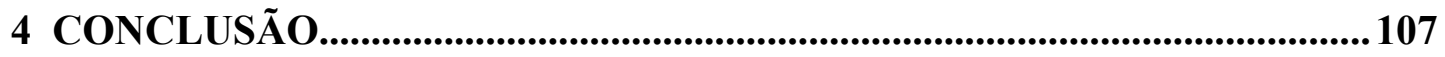

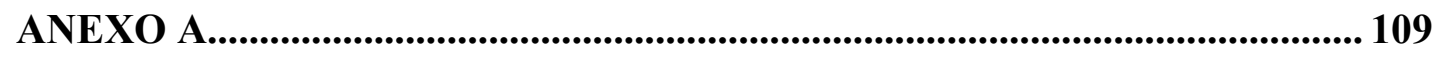

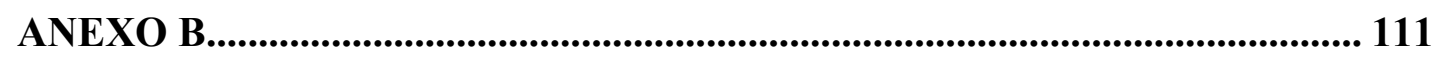

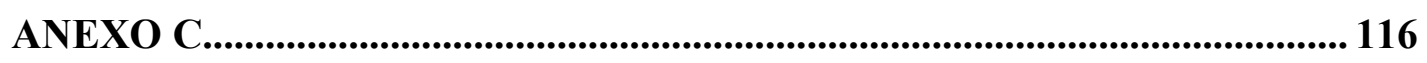

REFERÊNCIA BIBLIOGRÁFICA............................................................. 125 


\section{ÍNDICE DE FIGURAS}

Figura 1: Modelo simplificado da ligação da suspensão primária no truque.............. 21

Figura 2: Modelo simplificado da ligação de um rodeiro ao truque............................22

Figura 3: Deformação do contato na roda direita e raio de curvatura do trilho...........24

Figura 4: Elipse de escorregamento e saturação no contato - Carter (1926).............. 25

Figura 5: Área de contato de acordo com a teoria de Johnson e Vermeulen...............26

Figura 6:Teoria da tira - Halling, Haines e Ollerton (1963)...................................... 27

Figura 7: Escorregamento de pivotamento............................................................. 28

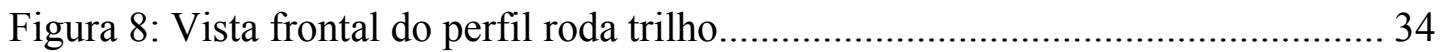

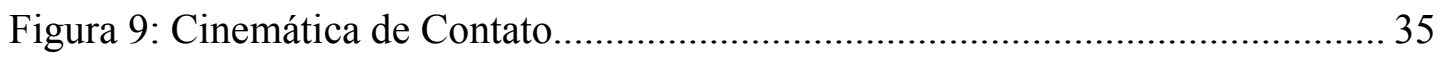

Figura 10: Descrição da geometria envolvida no modelo do rodeiro...........................36

Figura 11: Rijezas e escorregamentos no contato..................................................40

Figura 12: Curva de saturação das forças tangenciais (Barbosa, 1999)..................... 41

Figura 13: Exemplos de mudança de via.................................................................. 44

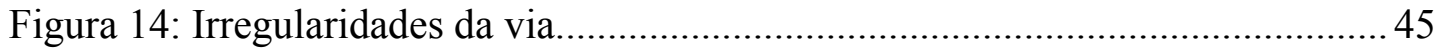

Figura 15: Curva de transição de vias (Barbosa, 1999)..................................................46

Figura 16: Rodeiro ligado à caixa de rolamento e a suspensão primária....................47

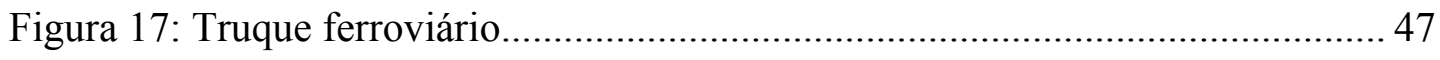

Figura 18: Modo de movimento lateral e angular (Yaw)...................................... 50

Figura 19: Forças de contato e vista superior do rodeiro simplificado........................51

Figura 20: Gráfico lugar das raízes do primeiro (gráfico superior) e segundo modos

Figura 21: Freqüência amortecida do primeiro e segundo modos 66

Figura 22: Fator de amortecimento (gráfico superior) e módulo da freqüência do primeiro modo.

Figura 23: Fator de amortecimento (gráfico superior) e módulo da freqüência do segundo modo. 68

Figura 24: Comportamento dos autovalores do primeiro (em azul) e segundo (em vermelho) modos para conicidade crescente. 
Figura 25: Comportamento da freqüência amortecida do primeiro (em azul) e segundo (em vermelho) modos para conicidade crescente 70

Figura 26: Comportamento do fator de amortecimento (em azul) e módulos de autovalores (em vermelho) do primeiro modo. .71

Figura 27: Comportamento do fator de amortecimento (em azul) e módulos de autovalores (em vermelho) do segundo modo...................................................... 72

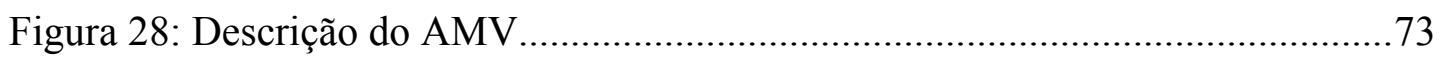

Figura 29: Resultado da simulação numérica do rodeiro..........................................75

Figura 30: Identificação das referências Global e Local e região de contato roda trilho. .78

Figura 31: Disposição do rodeiro na via...... 79

Figura 32: Representação lógica para cálculo das propriedades de contato (Barbosa, 1999). 81

Figura 33: Detalhes das deformações nas regiões de contato (Barbosa, 1999).......... 82

Figura 34: Diferença entre os raios de rolamento.................................................. 83

Figura 35: Relação entre as dimensões da elipse de contato..................................... 84

Figura 36: Discretização da elipse de contato (Barbosa, 1999)..................................86

Figura 37: Distribuição de tensões tangenciais (Barbosa, 1999)................................. 87

Figura 38: Forças no contato e referências global e local (via)................................. 90

Figura 39: Rotina seguida no cálculo das forças de contato (Barbosa, 1999)............ 90

Figura 40: Ilustração do modelo proposto pela IAVSD............................................ 93

Figura 41: Disposição da via (Barbosa, 1999)..........................................................94

Figura 42: Localização de uma trajetória (Barbosa, 1999)..........................................95

Figura 43: Diagrama do bloco do integrador(Barbosa, 1999)..................................98

Figura 44: Forças no Descarrilamento para coeficiente de atrito de 0.3 _................ 102

Figura 45: Forças no Descarrilamento para coeficiente de atrito de 1..................... 103

Figura 46: Comportamento do ângulo do plano de contato $(\mathrm{Mu}=1)$......................... 104

Figura 47: Máximas forcas e ralação L/V na iminência ao descarrilamento............ 105

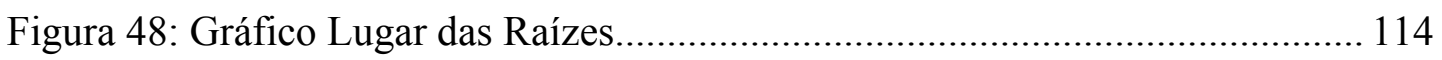




\section{ÍNDICE DE TABELAS}

Tabela 1: Dados de entrada do modelo do benchmarck\#1 ....................................... 92

Tabela 2: Resultados para força lateral de $20 \mathrm{kN}$....................................................... 99

Tabela 3: Resultados da tabela 1 para 0.3 de atrito....................................................100

Tabela 4: Comparação percentual da Reação Vertical, Fx, Fy, e Força de contato. 101 


\section{LISTA DE SÍMBOLOS}

\begin{tabular}{|c|c|}
\hline$a, b, c$ & escalares \\
\hline$a$ & semi-eixo da elipse de contato na direção de rolamento \\
\hline $\boldsymbol{b}$ & semi-eixo da elipse de contato na direção lateral \\
\hline$f$ & função \\
\hline$V_{c}$ & velocidade circunferencial da roda no centro da via \\
\hline$V_{t}$ & velocidade de translação da roda no centro da via \\
\hline $\mathbf{N}$ & Força normal no contato \\
\hline$R_{f}$ & raio de rolamento da roda fora da região de contato \\
\hline$R_{e, d}$ & raios de rolamento das rodas esquerda e direita \\
\hline$R_{d}$ & raio de rolamento da roda na região de contato \\
\hline$E_{r}, E_{t}$ & módulo de elasticidade dos materiais da roda e do trilho \\
\hline$v_{x}, v_{y}, v_{s p}$ & escorregamentos longitudinal, lateral, e de pivotamento \\
\hline$k_{x, y}$ & rijezas de contato nas direções $\mathrm{x}$ e $\mathrm{y}$ \\
\hline$C_{x, y}$ & rijezas das molas nas direções x e y \\
\hline$\alpha$ & inclinação da via (subida ou descida) \\
\hline$\beta$ & ângulo de agulha \\
\hline$\gamma$ & sobrelevação da via, diferença de altura entre os trilhos \\
\hline $\mathbf{G}$ & módulo de cisalhamento do material \\
\hline GL & Graus de liberdade \\
\hline$C_{i, j}$ & coeficientes de Kalker \\
\hline$e, d$ & distâncias \\
\hline$e_{1,} e_{2}$ & vetores correspondentes às direções longitudinais e laterais \\
\hline$F_{x}, F_{y}, F_{z}$ & forças nas direções $x, y, z$ \\
\hline$\lambda_{r, j}$ & autovalores $\mathrm{r}$ e j \\
\hline $\mathbf{n}$ & quantidade de elementos, ordem do sistema \\
\hline $\mathrm{m}$ & massa do rodeiro \\
\hline$\Theta$ & momento de inércia do rodeiro \\
\hline$\Omega$ & velocidade angular do eixo do rodeiro \\
\hline
\end{tabular}




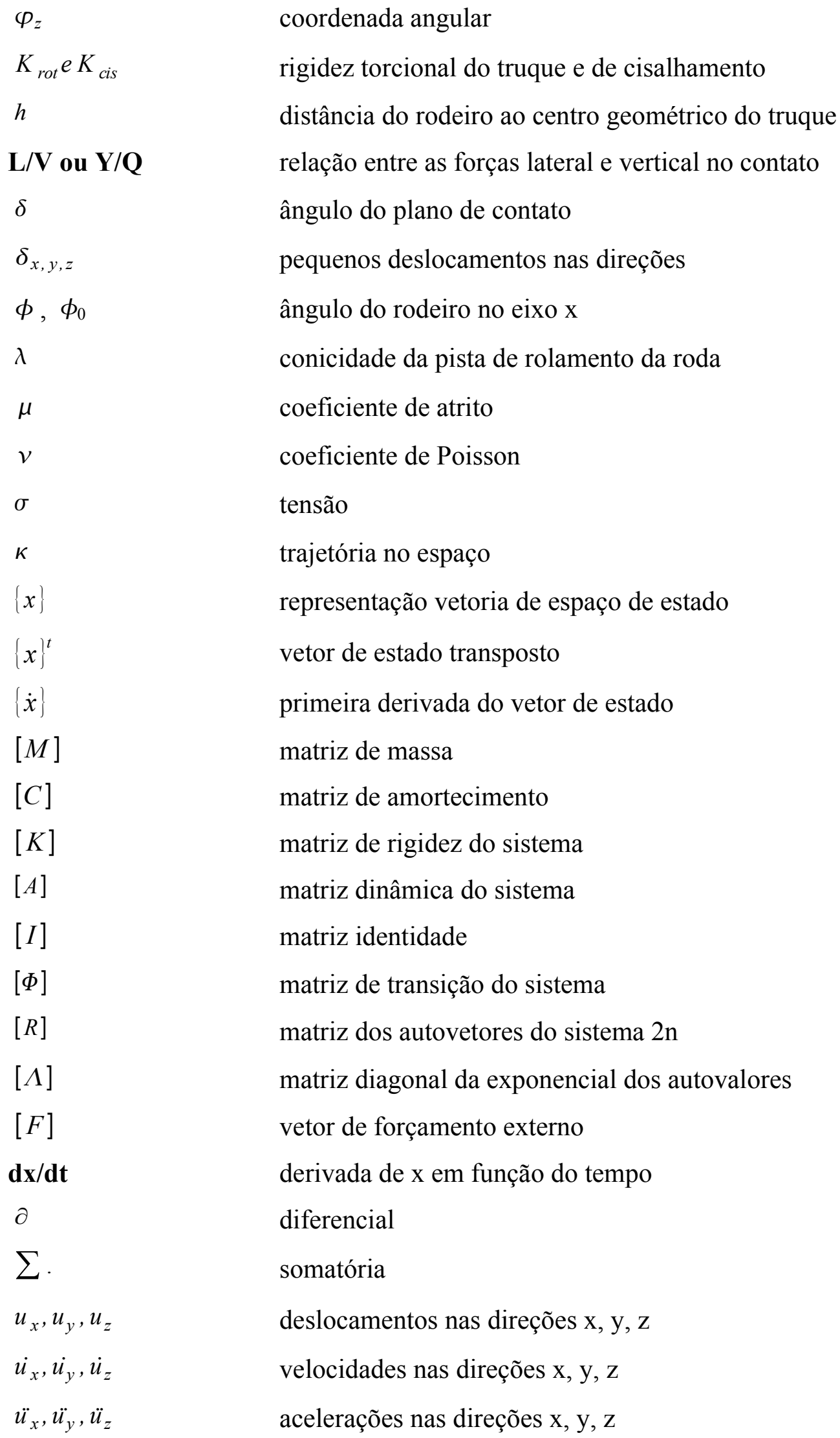




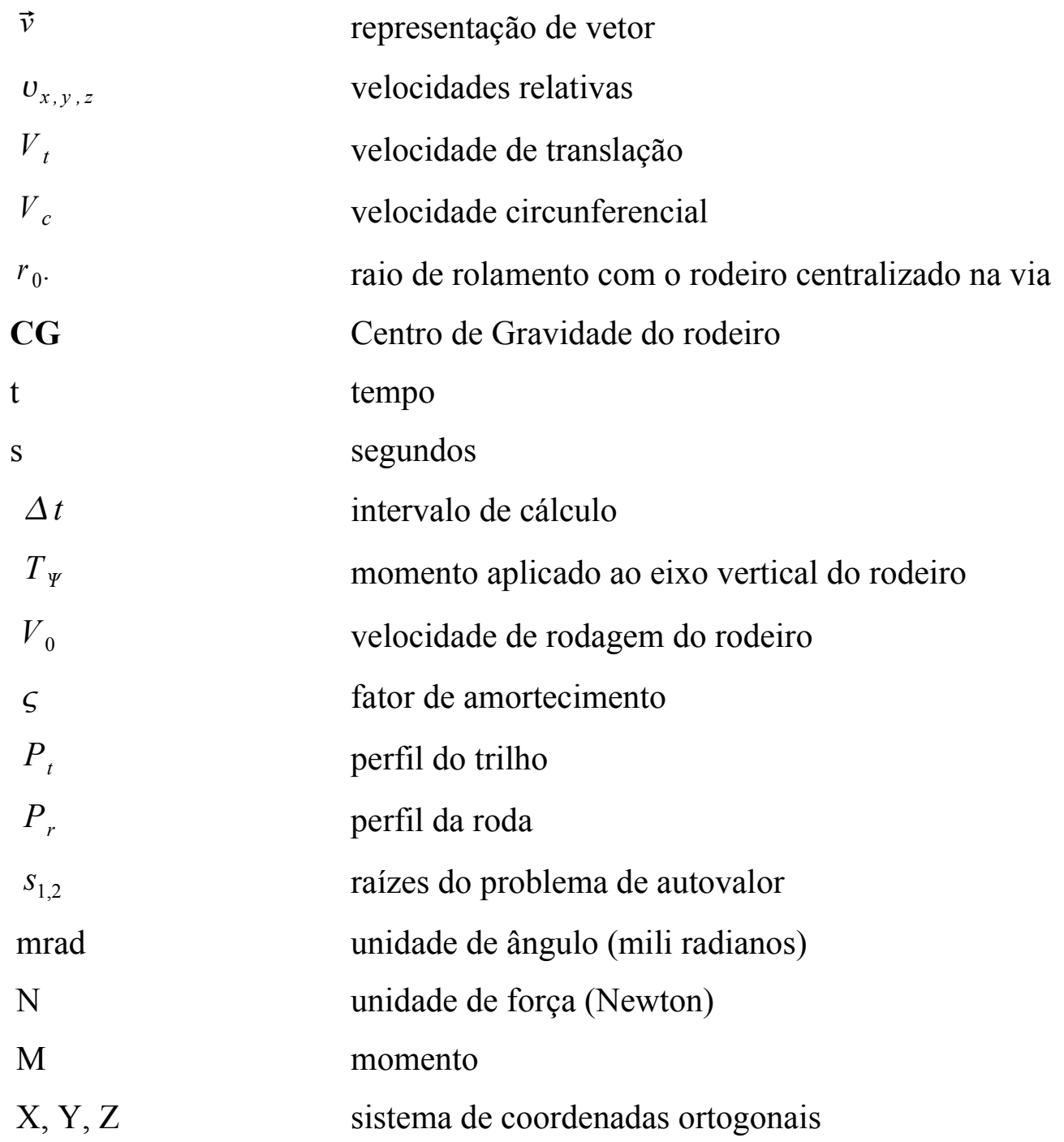

As definições nesta lista são de ordem geral, podendo ser modificada se existir alguma indicação local. 


\section{INTRODUÇÃ̃O}

A combinação homem e máquina no transporte rodoviário impulsionaram a distribuição de mercadorias e o acesso das pessoas a outras regiões. Sobre uma estrutura mais robusta, com maior capacidade de transporte de carga por eixo, o veículo ferroviário, objeto dessa dissertação, pode ampliar o transporte de cargas bem como de pessoas, ampliando a capacidade de escoamento da malha de transporte, barateando o custo da produção e acelerando o desenvolvimento de regiões.

Esse barateamento do transporte é justificado pela maior capacidade de carga transportada por eixo e velocidade empregada para se entregar à mercadoria no seu devido destino. Para suprir essa necessidade, o desempenho de rodagem está relacionada à construção de novas linhas, adaptadas para que a composição de um trem possa atingir maiores velocidades.

O aumento da velocidade gera oscilação lateral que pode se tornar instável. As elevadas cargas transportadas elevam os danos provocados pelas solicitações no contato entre a roda e o trilho. O desenvolvimento de um tráfego seguro e estável está relacionado à melhoria das propriedades de guiagem, com conseqüente acréscimo na redução do desgaste roda/trilho e agressão à guia de rodagem. O perfil do rodeiro e o dimensionamento da região de contato ganham importância à medida que os mesmos influenciam no amortecimento lateral.

As primeiras rodas ferroviárias, de que se tem notícia, não tinham borda e rodavam em eixos independentes (IWNICKI, 2003). A primeira locomotiva registrada, criada por Richard Trevithick, carregava o minério de ferro em Pen-yDarren, situada no País de Gales, no ano de 1804.

Inicialmente, as locomotivas possuíam rodas planas e eram capazes de utilizar estradas, bem como os trilhos. Buscando economia de material e melhoria da dirigibilidade, adaptaram-se as bordas para as rodas. Nascia uma história de casamento entre roda e trilho, uma vez que as mesmas rodas agora com friso já não se adaptariam mais as estradas. Com o avanço e advento de mais inovações as rodas deixaram de ser independentes e passaram a serem interligadas por um eixo. A parte 
externa à borda deixou de ser plana. Essa inclinação permitiu ao então rodeiro, como foi rebatizado o conjunto de duas rodas unidas pelo mesmo eixo, realizar curvas. Com a mesma velocidade angular específica, a diferença de raio de giro entre as rodas de cada lado gera momento de giro variando a direção do rodeiro.

As vantagens dessas mudanças podem ser vistas por meio da dirigibilidade que o rodeiro adquire frente ao forçamento externo. O friso, por sua vez, estabelece um limite para o deslocamento externo do rodeiro quando os esforços superam toda resistência gerada pela inclinação do contato entre os perfis.

Essa realidade tem seu preço, uma vez estabelecidas às geometrias em que se espera que seja submetido o sistema mecânico do rodeiro sobre os trilhos, qualquer mudança implicará em um funcionamento fora das previsões calculadas em projeto. Coeficientes de atrito, propriedades mecânicas das superfícies de contato e desgaste no contato determinam as velocidades máximas de funcionamento do sistema numa importância maior que a encontrada, por exemplo, em veículos de passeio. Em uma unidade de trem urbano (UTU), o maquinista está sujeito ao passeio lateral máximo do rodeiro para realizar a curva.

A restituição do rodeiro à posição central aparece devido às forças laterais, geradas pela inclinação do contato da roda com o trilho e mudança do ângulo de direção longitudinal yaw. A presença dessas forças diminui o deslocamento lateral e retorna o rodeiro. Em condições extremas, em que as forças de contato não conseguem retornar o rodeiro, a borda da roda ou friso gera a força resistente ao deslocamento lateral.

\subsection{Objetivo}

O objetivo consiste no entendimento dos parâmetros que influenciam a estabilidade de todo o sistema suspenso pelo rodeiro criando condições para otimização do projeto de um veículo ferroviário. Como a estabilidade depende não somente de um parâmetro, mas da interação de diversos parâmetros (velocidade, conicidade, irregularidades, etc..), a presente obra divide a abordagem do assunto em 
uma análise cuidadosa de cada parâmetro, e seu impacto nas propriedades do sistema mecânico. Segue como essa análise foi dividida:

- Influência da velocidade na estabilidade do sistema;

- Influência da conicidade na estabilidade do sistema;

- Análise dinâmica do rodeiro ao atravessar o AMV;

Os parâmetros para simulação da influência da velocidade na estabilidade são obtidos e comparados com o artigo publicado por Barbosa (1996). Para a simulação da influência da conicidade, utiliza-se do mesmo modelo, contudo a conicidade varia de 0.1 a 1 dentro da mesma proposta de intervalo da velocidade de rodagem de 2 a $62 \mathrm{~m} / \mathrm{s}$.

O passeio lateral do rodeiro ao longo de toda extensão do contato roda-trilho está intimamente ligado à variação das propriedades de contato, principalmente quando o friso da roda toca o boleto do trilho. Essa é uma região cuja representação dos esforços exige a determinação do centro instantâneo de rolamento. Dependendo do software numérico, a solução será dada com base no número de pontos de contato de rolamento. O Vampire utiliza uma abordagem que considera dois pontos de contato, diferente do Vocodym, por exemplo, que considera seis pontos de contato. A presente obra, em uma segunda e última fase, simula o rodeiro conforme a proposta do benchmark to test wheel/rail contact forces para:

- Determinar na posição de equilíbrio atingida pelo modelo através da aplicação de uma força externa de $20 \mathrm{kN}$ as forças no contato, reações verticais e deslocamentos lateral e abertura do ângulo de yaw para diversos coeficientes de atrito da via;

- Simular a aplicação da força lateral variável (taxa de $50 \mathrm{kN} / \mathrm{s}$ ) até o descarrilamento;

- Verificar as relações $\mathrm{L} / \mathrm{V}$, máxima força de contato lateral e máxima força transversal nos trilhos para os diversos coeficientes de atrito da via.

\subsection{Veículos Ferroviários}


O sistema de guiagem de veículos é caracterizado pela presença de dois grupos. O primeiro grupo, conhecido como veículo autônomo direcionado, se caracteriza no veículo que possui sua trajetória definida pelo motorista. O segundo, conhecido como veículo autônomo guiado, possui sua trajetória pré-estabelecida e o motorista não possui liberdade para alterar a trajetória.

O veículo autônomo direcionado muda de direção de duas formas. A primeira forma é através da aplicação de um ângulo de esterçamento nas rodas, o que gera força lateral. É o mais conhecido devido ao fato de ser utilizado em carros de passeio, ou caminhões de carga, entre outros. A outra forma, através da aplicação de tração e frenagem entre as rodas de lados distintos, gera mudança do ângulo da direção. Esta é usada em veículos com esteira, como tratores e guindastes. Os dois casos de veículo autônomo precisam gerar força lateral para produzir uma variação no ângulo da trajetória.

O grupo de veículos guiados possui movimento direcionado pela via. Sua trajetória já é pré-definida, impedindo que o motorista possa alterá-la. O veículo percorre um caminho imposto por uma guia, e em curvas, por exemplo, desenvolve forças laterais dependentes do escorregamento no contato. $\mathrm{O}$ sistema ferroviário é formado por uma via com trilhos, rodas cônicas que são direcionadas por forças no contato e veículo de duas suspensões. A teoria utilizada para cálculo de forças de contato (mecânica de contato) em rodas de borracha (pneu/pavimento) ou rodas metálicas (roda/trilho) é a mesma, diferenciando pela ordem da rigidez tangencial de contato das rodas metálicas, que é 100 vezes maior (Barbosa, 1999).

O sistema de direcionamento do rodeiro permite a centralização do rodeiro na via e a inscrição em curvas, porém, estabelece velocidade crítica de rolamento provocada pelo balanço lateral. O truque, conjunto formado por dois rodeiros presos por suspensão primária ao esqueleto (bogie), comporta os movimentos relativos das suspensões primária e secundária. Autores como Wickens, apresentaram muitas publicações no assunto em conjunto com Technical Centre of British Railway (Derby, Reino Unido). Equações básicas de movimento para o rodeiro, determinação das tabelas de contato para diversos perfis e comparações experimentais deram-lhe condições de publicar artigos sobre a instabilidade lateral de truques. Essa 
instabilidade é causada pela ação da conicidade da roda e das forças de contato combinadas. Uma forma de resolver esse problema é através da conexão dos rodeiros por braços de articulações em cisalhamento (Wickens, 1991). Essa solução deu origem ao truque do tipo direcionado (steering).

Uma adequada inscrição em curvas e a estabilidade do veículo estão relacionadas com a forma do perfil da roda (Wickens, 1991). A análise desses dois parâmetros se estendeu até a determinação que a presença de valores baixos de conicidade e pequena rigidez de contato também ajudam na estabilidade de um truque ferroviário. Dispondo de truques posicionados de forma assimétrica com auxílio de conexões elásticas entre os rodeiros, abriu-se caminho para uma nova forma de avaliar projetos ferroviários (Wickens, 1996b).

$\mathrm{O}$ projeto de um veículo ferroviário, quando atende a alguns requisitos mínimos de desempenho, colabora para um transporte confortável e seguro. Ao se percorrer uma trajetória com boa qualidade de tráfego, a presença de excitação lateral diminui, ajudando na inscrição em curvas e no desempenho do veículo. Também, ao se diminuir a intensidade dos esforços presentes entre a via e a roda, o desgaste de ambas diminui com conseqüente redução da manutenção do sistema. Conceitos modernos sugerem que o desgaste das partes rolantes está relacionado à massa não suspensa. Ao se utilizar massa não suspensa reduzida, o grau de agressão cai drasticamente a favor da conservação do sistema.

Os truques são desenvolvidos em função de sua aplicação, prevalecendo nos veículos de passageiros algumas características que não estão presentes nos veículos de transporte de carga. Assim, nos veículos de passageiros, os truques na forma de $\mathrm{H}$ rígido possuem uma estrutura bastante diferenciada dos truques de travessas central e lateral. No truque em $\mathrm{H}$ rígido, os rolamentos dos rodeiros se ligam à parte em $\mathrm{H}$ por mecanismos elásticos (molas). Nos truques de carga, o rolamento de rodeiro está diretamente ligado ao esqueleto do truque (bogie), sendo mantida a interface com elementos elásticos apenas nos movimentos verticais da conexão. Em ambos os sistemas mecânicos, a estabilidade depende da rigidez horizontal da suspensão, representada pela rigidez rotacional e de cisalhamento. A rigidez rotacional é 
responsável pela defasagem dos movimentos angulares dos rodeiros, enquanto a de cisalhamento, pela defasagem do movimento lateral (Wickens, 1991)

As relações de equivalência entre rigidez torcional e de cisalhamento para truques do tipo rígido $\mathrm{H}$ e suspensão primária são apresentados a seguir:

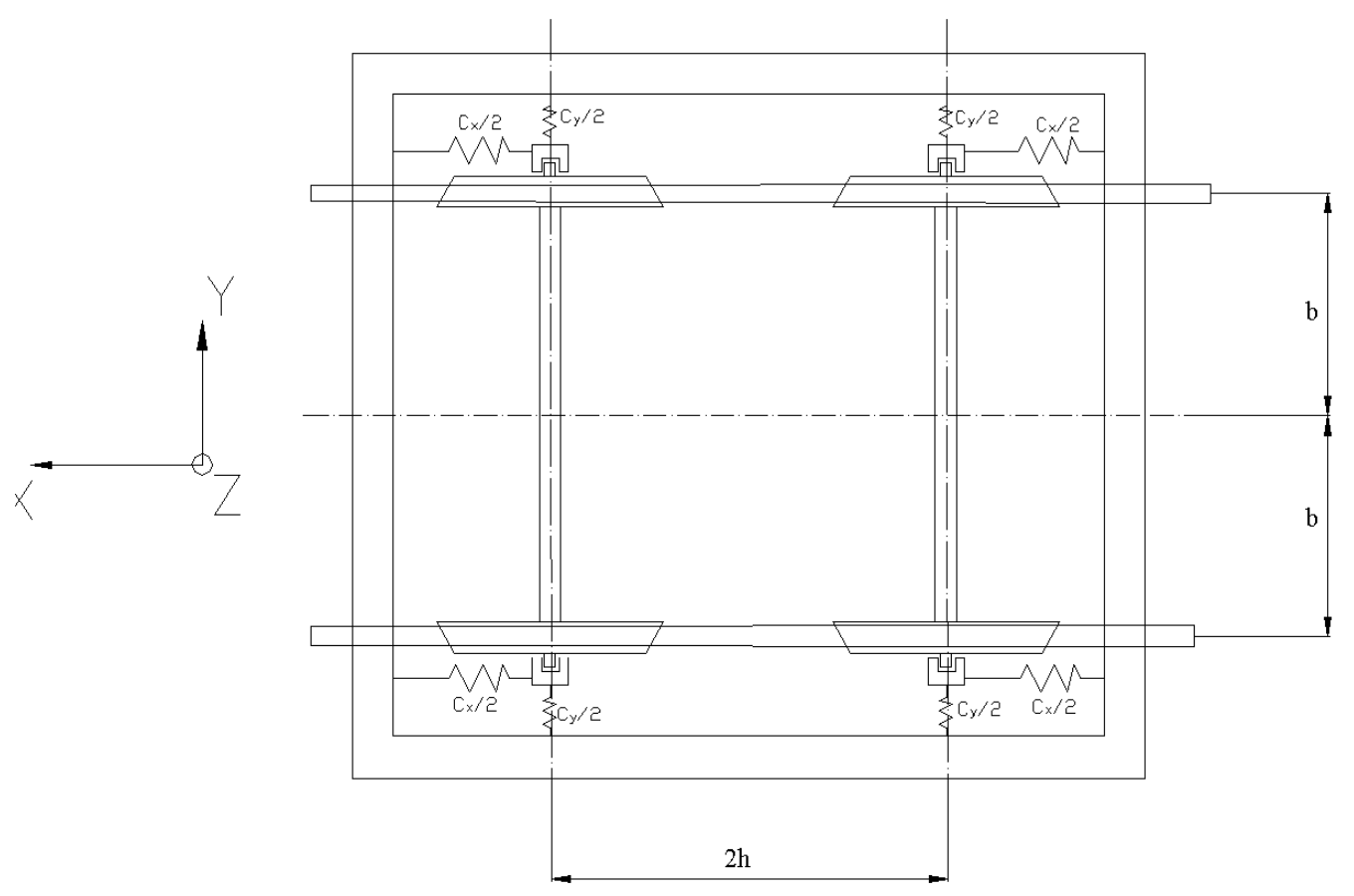

Figura 1: Modelo simplificado da ligação da suspensão primária no truque

Esse sistema possui um afastamento entre os rodeiros de $u_{x}$ e entre as suspensões primárias (lados opostos) igual a 2e. Esse afastamento é suficiente para garantir o bom compromisso entre estabilidade e inscrição em curvas. Cada rodeiro desenvolve seu movimento ao longo da via de rolamento e a interação de ambos os movimentos dos rodeiros será analisada como comportamento dinâmico do truque. No entanto, as relações entre ângulo do plano de contato e rigidez de contato com os autovalores dos modos de passeio do rodeiro são igualmente importantes, pois determinam as limitações individuais dos rodeiros. Para obter os resultados individuais do comportamento do rodeiro, o modelo do truque foi simplificado para uma composição de apenas um rodeiro.

Dessa forma, a composição simplificada do truque pode ser apresentada como: 


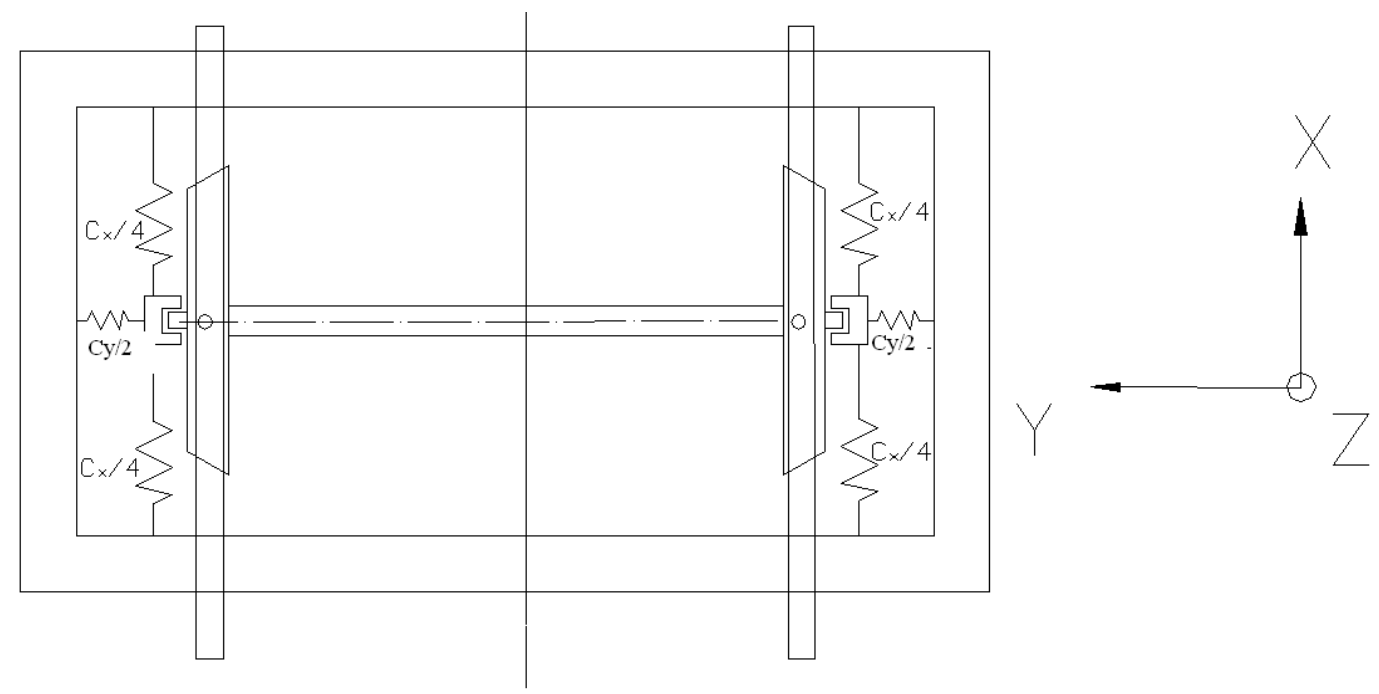

Figura 2: Modelo simplificado da ligação de um rodeiro ao truque

A análise do comportamento do rodeiro, isolado em uma estrutura igual à apresentada na figura 2, e com apenas um rodeiro, para determinação da velocidade crítica de rolamento, comprimento da onda do movimento de Lacet e relação dos autovalores do segundo modo com a constante de rigidez de contato, pode ser realizada uma vez que as mesmas condições geométricas da distribuição dos elementos elásticos, bem como bitola, raio de giração, inclinação do ponto de contato do rodeiro.

\section{3 Histórico}

Nas décadas de 1970 e 1980, o problema de contato de rolamento entre roda e trilho passou a ser estudado mais intensamente. Várias teorias de contato de rolamento foram desenvolvidas com o objetivo de expressar com maior fidelidade à dinâmica ferroviária. Uma breve discussão dessas teorias mostrará suas aplicações e suas limitações.

O comportamento dinâmico de um veículo ferroviário é consideravelmente afetado por forças de interação entre roda e trilho. Essas forças dependem da adesão, escorregamento e de características de uso. A geometria da roda e do trilho afeta a 
adesão, escorregamento e as características de uso, tanto quanto o comportamento dinâmico do veículo, uma vez que as forças de escorregamento são influenciadas pelas áreas de contato e pelas tensões de contato entre a roda e o trilho. A rugosidade da superfície, os materiais das rodas e do trilho ou mesmo as condições do ambiente tais como contaminação por água, óleo, sujeira, entre outros também influenciam a adesão.

O fenômeno de escorregamento aparece quando dois corpos rígidos são pressionados um contra o outro e a pressão de contato não suporta a deformação, o que cria um escorregamento entre as partes. A região de contato é formada quando os corpos se tocam gerando o atrito. As relações das forças de contato e do atrito seco foram inicialmente observadas por Charles Coulomb (1736-1806).

De acordo com a teoria elástica, a região de contato é elíptica e a razão do semi-eixo (a / b) pode ser calculada através do conhecimento do raio principal de curvatura dos corpos rolantes. Com o objetivo de calcular as dimensões a e b da elipse de contato, os raios de contato precisam ser conhecidos.

Em geral, as velocidades cincunferenciais dos dois corpos rolantes não são iguais. O termo escorregamento ou simplesmente contato é usado para definir esse desvio do movimento do rolamento puro dos dois corpos, em ambas as direções longitudinal e lateral. Carter (1926) foi o primeiro a reconhecer a importância do escorregamento para aplicações na dinâmica ferroviária. Carter definiu o escorregamento longitudinal e lateral.

As forças de escorregamento se desenvolvem por causa da diferença na taxa de deformação dos dois corpos na região de contato. Como mostrado na figura $3 \mathrm{com}$ o raio na região deformada $\left(R_{d}\right)$ ou de contato menor que o raio final ou fora da região de contato $\left(\mathrm{R}_{\mathrm{f}}\right)$. Com o objetivo de se calcular as forças laterais e longitudinais e o momento de pivotamento na interface roda trilho, o entendimento da região de contato é essencial para estabelecer as necessárias relações entre os escorregamentos lateral, longitudinal, e de pivotamento. 


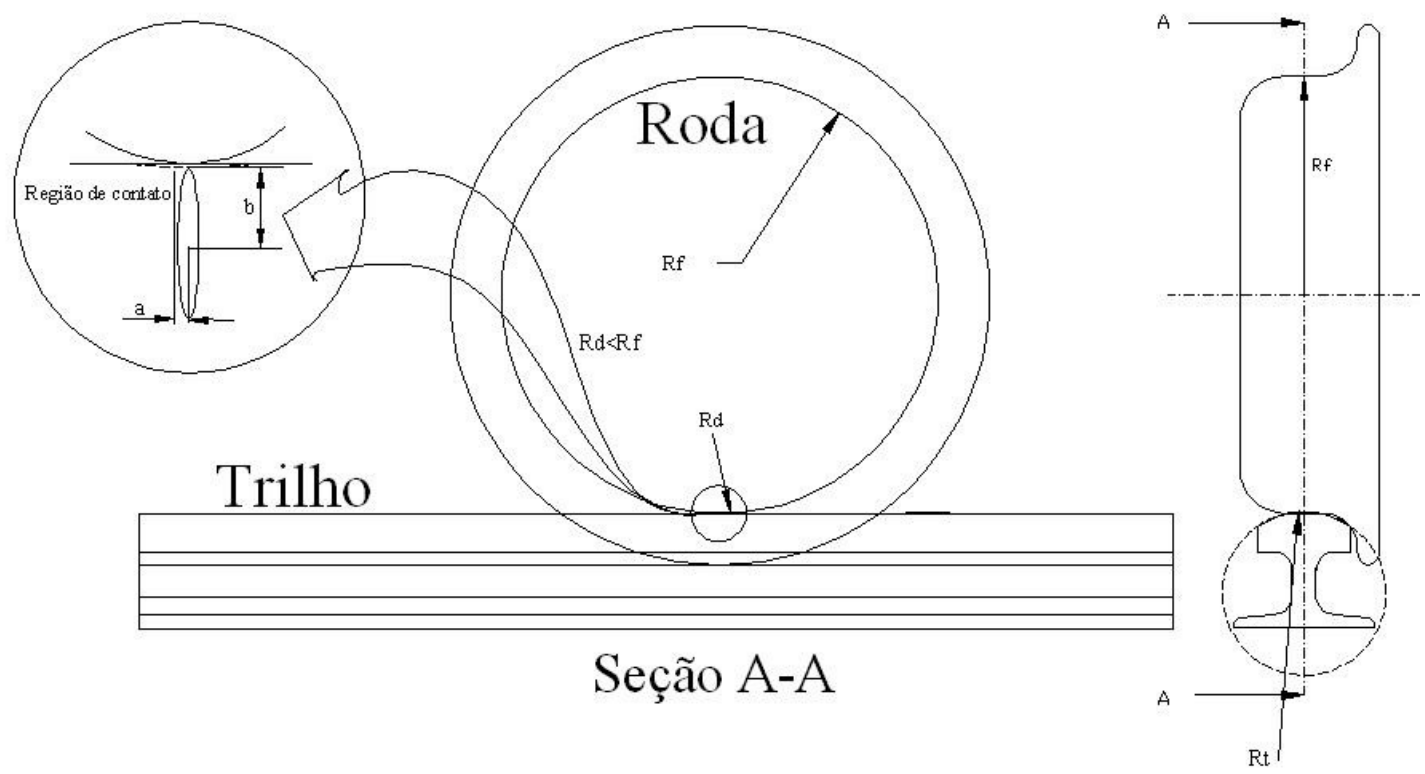

Figura 3: Deformação do contato na roda direita e raio de curvatura do trilho

Em 1926, Carter desenvolveu a teoria bidimensional de contato de rolamento com atrito para análise dos fenômenos de frenagem e aceleração em situação que as forças tangenciais são elevadas. Carter forneceu uma forma de solução para a relação entre escorregamento longitudinal e força tangencial. A área de contato entre roda $\mathrm{e}$ trilho depende significativamente da extensão do perfil da roda sobre o boleto do trilho. Contudo, como a roda e o perfil da cabeça do trilho se desgastam com o tempo, a forma para a área de contato pode ser aproximada por uma tira retangular uniforme bidimensional lateral com relação à direção do trilho. Carter considerou a roda como um cilindro e o trilho como uma chapa espessa, além de um raio realmente largo em comparação com o comprimento da circunferência da área de contato. O problema foi então tratado como uma área de um plano limitado e que sofria uma distribuição de pressão e tração tangencial. O meio espaço considerado foi usado e somente o escorregamento longitudinal foi considerado.

Uma típica distribuição de tração local é mostrada na figura 4, 4(a), e a lei de força de contato é ilustrada na figura 4, 4(b). A área OAA' mostra a região de contato das duas superfícies. A curva $\mathrm{ABCA}^{\prime}$ representa a curva que limita a área de tração dentro da região de contato de rolamento entre as rodas. A curva que limita a zona de 
tração tangencial é a ADCA'. Essa curva, embora comece no ponto A, não excede a curva $\mathrm{ABCA}^{\prime}$. A porção da área de contato que se encontra aderida é a região ADCE.

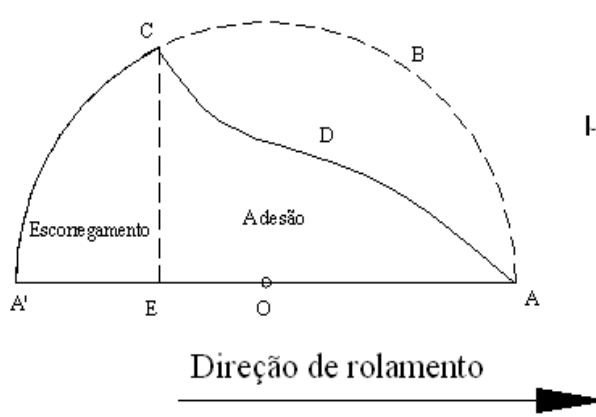

(a)

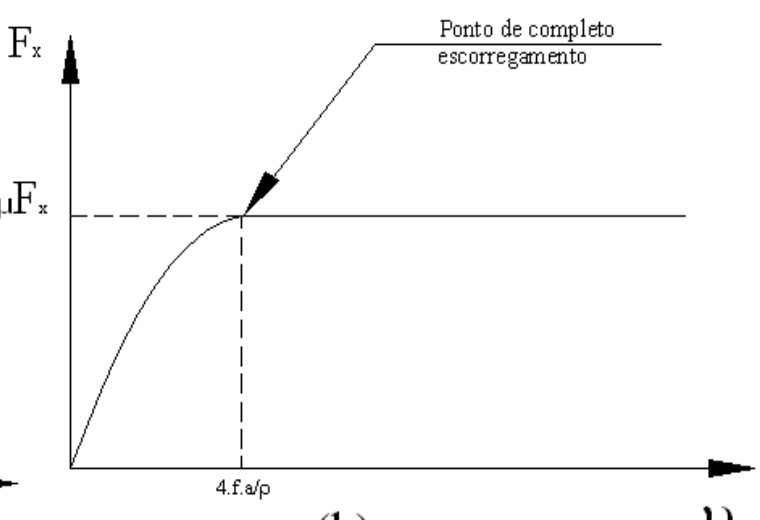

(b)

Figura 4: Elipse de escorregamento e saturação no contato - Carter (1926)

Em função do contorno de contato não ter movimento relativo, qualquer variação de deformação no trilho requer uma variação de deformação nas rodas igual e oposta. A deformação na superfície é de certa forma constante (Carter, 1926 apud Garg, 1984). A pressão entre as superfícies no contato não é suficiente para suportar a deformação, o que acarreta o escorregamento entre as superfícies na área de tração tangencial. A área abaixo da curva ADC equivale à adesão enquanto à área abaixo da linha $\mathrm{CA}^{\prime} \mathrm{E}$ ao escorregamento.

Dessa forma, o grande ganho dessa teoria foi estabelecer uma relação entre a pressão de contato e a força tangencial gerada por ela. Outro ponto relevante, é que a área de contato é formada por uma área de adesão e outra de escorregamento, sendo a relação dessas áreas dependentes da Lei de Coulomb.

Em 1967, Fromm também desenvolveu a mesma solução exata. Kalker, da Universidade de Tecnologia de Delfi, incluiu ambos escorregamentos longitudinal e lateral, mas sem pivotamento, e desenvolveu uma solução aproximada simples que foi similar à solução de Carter (Garg, 1984). Em 1967, Heinrich e Desoyer derivaram uma solução exata, mas complicada para o mesmo problema. 
Em 1958, Johnson estendeu a teoria bidimensional do caso de duas esferas rolantes no qual os escorregamentos longitudinal e lateral foram inclusos, mas sem o escorregamento de pivotamento (spin). Em 1964, Johnson e Vermeulen estenderam a teoria para os meios espaços lisos arbitrários para escorregamento puro sem contato de pivotamento (Barbosa, 1999). A superfície de contato entre os corpos rolantes transmitindo uma força tangencial foi dividida de forma não simétrica dentro de duas regiões distintas: a região de escorregamento e a de adesão.

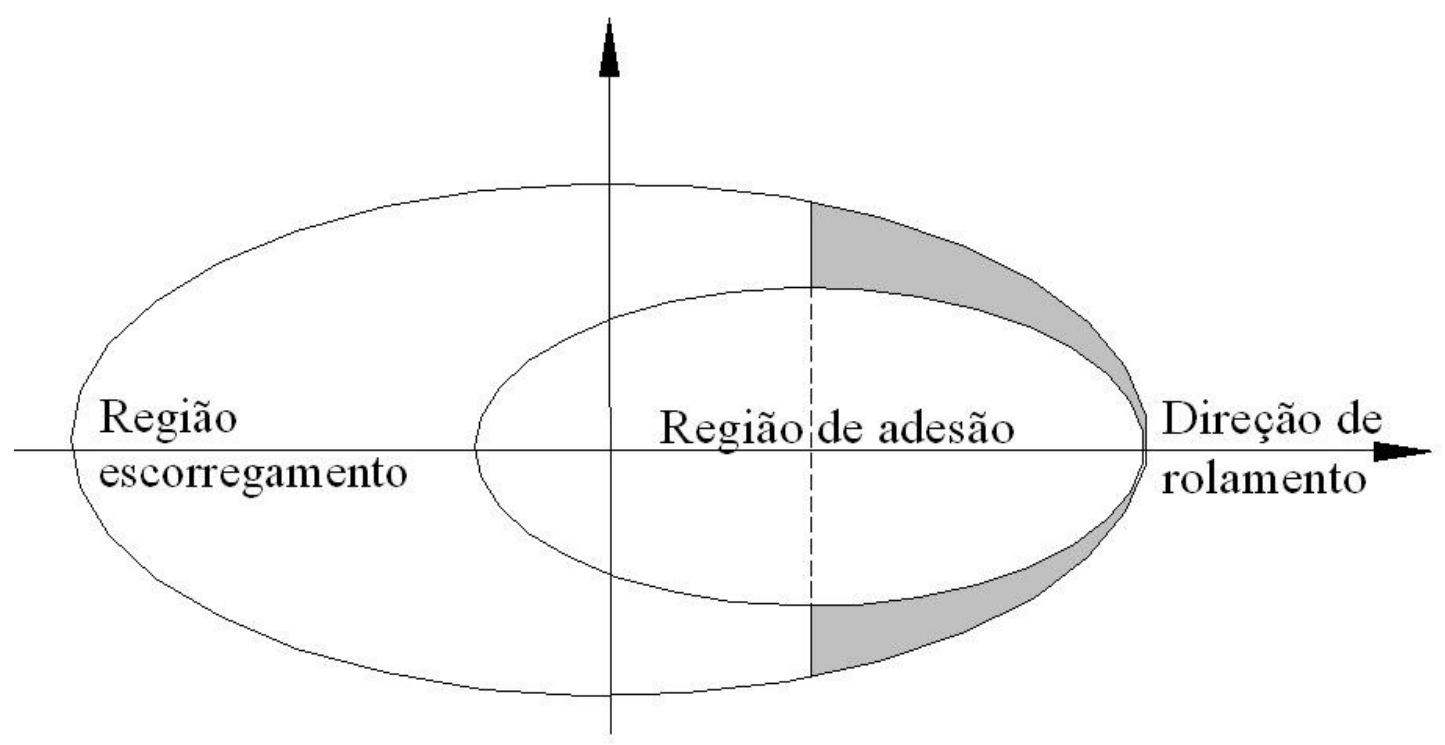

Figura 5: Área de contato de acordo com a teoria de Johnson e Vermeulen

A área de adesão foi assumida ser uma elipse que estava apenas tocando a margem dianteira da elipse de contato, conforme a região escura da figura 5. A tração tangencial semi-elipsoidal age em cada elipse, e a tração tangencial total pode ser obtida por tomar a diferença. Resultados experimentais dados por Jonhson e Vermeulen mostraram que o erro na força de contato resultante era menor que $25 \%$, atribuído ao formato da região de adesão elíptica considerada.

A força tangencial resultante pode ser formulada como segue. Sendo $\boldsymbol{a}$ o semi-eixo na direção de rolamento e $\boldsymbol{b}$ na direção lateral da elipse de contato dentro do plano de contato. A teoria de Johnson e Vermeulen, a qual é uma extensão da 
teoria de Carter, é dessa forma restrita ao caso de escorregamento longitudinal e lateral puros, sendo o pivotamento nulo.

Em 1963, Halling, Haines e Ollerton colocaram adiante uma teoria aproximada para o caso de contato elíptico com escorregamento longitudinal. A área de contato foi dividida em um número de tiras paralelas $\left(u_{x_{0}}, u_{x_{1}}, u_{x_{2}}\right)$ para a direção de rolamento, e cada tira foi então estudada por uma extensão da teoria bidimensional de Carter (Figura 6). A interação entre as tiras individuais foi completamente ignorada (Garg, 1984). Nessa base, para cada pedaço com uma constante y, a solução de Carter é válida e não é afetada pela solução em outros valores de $y$.

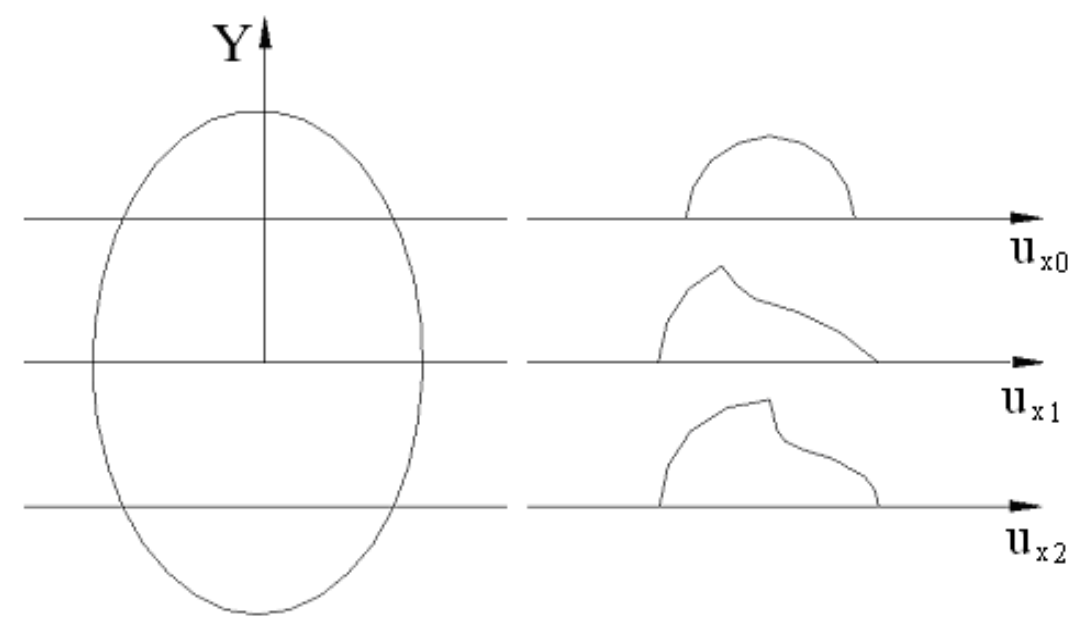

Figura 6:Teoria da tira - Halling, Haines e Ollerton (1963)

A teoria foi apoiada por uma investigação que usou uma técnica de tensão fotoelástica e mostrou que a forma da adesão era próxima daquela assumida. Essa teoria é conhecida como teoria da tira e é restrita ao escorregamento longitudinal. Em 1967, Kalker estendeu a teoria da tira para um caso geral e incluiu escorregamentos longitudinais e laterais, além de um escorregamento de pivotamento (Barbosa, 1999).

$\mathrm{O}$ escorregamento de pivotamento é definido pela velocidade de giro da roda no plano de contato com relação à velocidade nominal do rodeiro. A indicação das direções dos vetores está na figura 7. A teoria da tira é limitada a longas elipses de contato na direção lateral com pequenas quantidades de giro. Dessa forma, a teoria 
da tira tem uso limitado na dinâmica veicular ferroviária. Contudo, a teoria da tira mostra as áreas de adesão e de escorregamento.

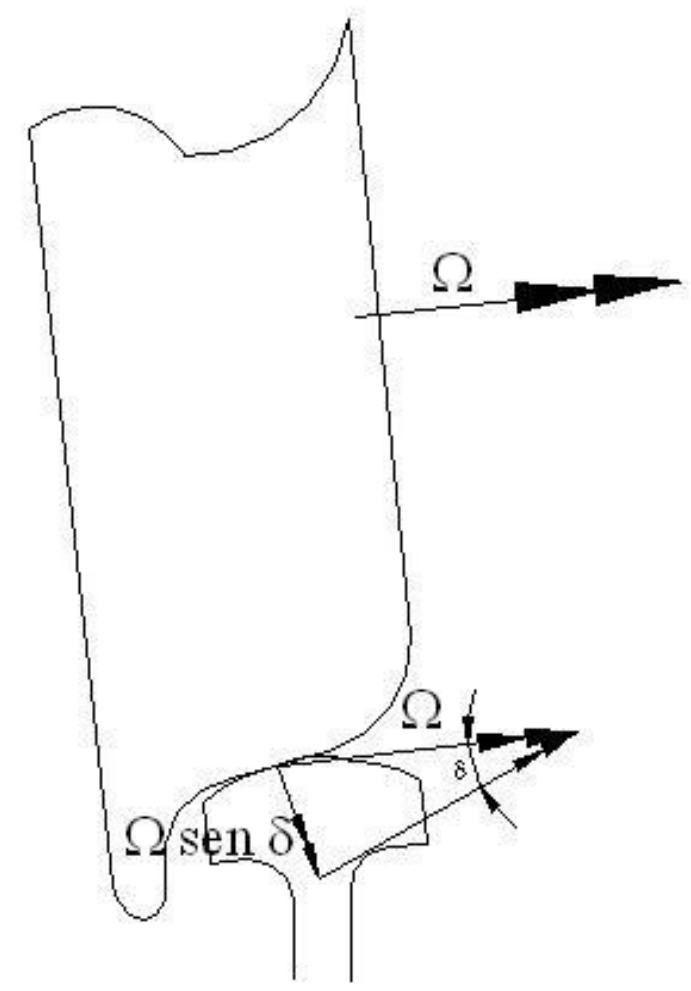

Figura 7: Escorregamento de pivotamento

Kalker, segundo Barbosa (1999), desenvolveu a teoria linear de contato de rolamento que foi baseada na idéia proposta por De Pater, a qual sugeria que para pequenos escorregamentos laterais, longitudinais e de pivotamento, a área de escorregamento é muito pequena. A zona de adesão, dessa forma, pode ser considerada cobrindo a área inteira do contato.

As condições de contorno dentro da área de contato para a condição de rolamento no estado permanente são apresentadas a seguir:

$$
0=\dot{w}=V_{0}\left[\left(v_{x}-v_{s p} u_{y}\right) i+\left(v_{y}+v_{s p} u_{x}\right) j\right]-V_{0} \frac{\partial u}{\partial x}
$$

E fora da área de contato, a resultante é nula. A integração de (1) com respeito ao deslocamento $u_{x}$ leva a :

$$
-V_{0} u+V_{0}\left[\left(v_{x} u_{x}-v_{s p} u_{x} u_{y}\right) i+\left(v_{y} u_{x}+\frac{1}{2} v_{s p} u_{x}^{2}\right) j\right]=g\left(u_{y}\right)
$$


em que $g\left(u_{y}\right)$ é uma função arbitrária determinada para considerar que a tração é contínua na área em que o material entra na região de contato. De acordo com essa teoria, a existe tração quando não há diferença de velocidade entre as superfícies. As partículas finalmente deixam o contato e a tração se anula. As relações lineares de contato-escorregamento de Kalker são dadas para a força de contato longitudinal $F_{x}$ como:

$$
F_{x}=-f_{11} v_{x}
$$

Para a força de contato lateral $F_{y}$ como:

$$
F_{y}=-f_{22} v_{y}-f_{23} v_{s p}
$$

E para o momento $M_{z}$ de contato de pivotamento como:

$$
M_{z}=-f_{23} v_{y}-f_{33} v_{s p}
$$

Das equações acima, tem-se que os valores dos coeficientes de contato são dados a seguir:

$$
\begin{gathered}
f_{11}=a b G C_{11} \quad f_{12}=(a b)^{3 / 2} G C_{23} \\
f_{22}=a b G C_{22} \quad f_{23}=(a b)^{3 / 2} G C_{23} \quad f_{33}=(a b) G C_{33}
\end{gathered}
$$

Perceba que $F_{x}$ é independente do escorregamento lateral e de pivotamento, enquanto que o momento e a força lateral dependem dos escorregamentos lateral e de pivotamento. A teoria de contato linear de Kalker é largamente usada em dinâmica veicular ferroviária para determinar a estabilidade lateral.

A teoria de Jonhson e Vermeulen é restrita ao caso sem efeito de pivotamento. A teoria da tira é limitada a áreas de contato pequenas e pequeno pivotamento. A teoria linear de Kalker é aplicável para pequenos escorregamentos e pivotamento. Kalker (1979a) apresenta três soluções não lineares que não possuem as limitações acima mencionadas, mas que requerem soluções numéricas.

Todas as teorias de contato não lineares de três dimensões, para os escorregamentos lateral, longitudinal e de pivotamento são baseados no princípio que a tração tangencial satisfaz a inequação de Coulomb $\left|F_{\tau}\right| \leqslant \mu F_{z}$.

O programa de solução numérica DUVOROL é baseado na teoria de Duvault e Lions, conforme Garg (1984), o qual foi desenvolvido por Tjoeng e Kalker (1980). Em função do processo incremental, a solução de estado permanente é alcançada 
como o limite do contato de rolamento, na qual o escorregamento rígido no contato é mantido constante.

Johnson e Vermeulen proporam uma fórmula que é vista como uma extensão da teoria bidimensional de Carter para o contato elíptico bidimensional (Spinola, 1999). Essa teoria aplica-se para escorregamentos $v_{x} \mathrm{e} v_{y} \mathrm{e}$ considera o escorregamento de pivotamento nulo:

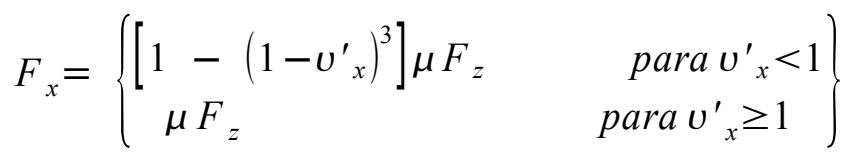

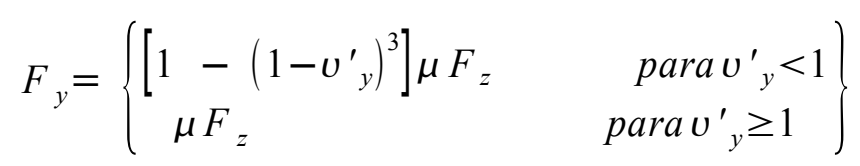

onde $v^{\prime}{ }_{x}=-\frac{G a b C_{11} v_{x}}{3 \mu F_{z}}, \quad v_{y}^{\prime}=-\frac{G a b C_{22} v_{y}}{3 \mu F_{z}}$.

Os resultados dos experimentos de Johnson concordam com a curva empírica até $v=0.4$. Para $u>0.4$ os resultados experimentais se encontram abaixo da curva empírica (Garg, 1984).

Análise das forças de interação roda trilho, por White (1978) apud Garg (1984), mostraram a necessidade de modelos mais sofisticados de interação. Em particular, as não linearidades seguintes estão inclusas: (1) funções geométricas não lineares roda-trilho acontecendo entre os perfis roda e trilho, (2) limites de adesão nas relações das forças de contato-escorregamento. A teoria de Jonhson e Vermeulen, apesar de confirmada por experimentos em laboratório, não incluem escorregamento de pivotamento. Esses efeitos de escorregamento de pivotamento são significativos, especialmente na região do contato friso/trilho. Kalker formulou duas leis de contato não lineares para incorporar os efeitos de escorregamento de pivotamento. Elas são conhecidas como a teoria simplificada de contato de rolamento e teoria numérica de contato de rolamento. A diferença entre as duas se encontra nas definições assumidas sobre as relações de deslocamento-tensão tangenciais e distribuição de tensão normal na superfície de contato. 
Três programas se tornaram disponíveis para computar as forças de contato e os momentos de giro para corpos rolantes. Eles foram desenvolvidos na base da teoria simplificada de contato de rolamento de Kalker e são chamados SIMROL, ROLCON, e FASTSIM. A teoria simplificada é popular porque é de fácil interpretação e necessita de baixos custos computacionais (Garg, 1984).

O programa SIMROL foi originalmente escrito por Kalker em AlGOL-60 e em seguida traduzido para a linguagem FORTRAN-IV por Goree. O programa FASTSIM foi escrito por Kalker em 1980. É simples e extremamente rápido, cerca de 25 vezes mais rápido que SIMROL (Garg, 1984).

Ocorreram tentativas baseadas no intuito de verificar a proximidade dos resultados experimental e analítico para a lei de força de contato. A mais velha dessas tentativas é a de Levi (1935), a qual foi mais tarde modificada por Charter (1950) apud Garg (1984).

Em 1980, Jackinski mostrou que é possível encontrar funções matemáticas que descrevam as leis de força de contato não lineares para as forças de contato longitudinais baseada na teoria simplificada de contato de rolamento de Kalker. Da mesma forma, pôde-se estender o método de aproximação para as forças de contato laterais.

Shen, Hendrick e Elkins constituíram uma extensão da formulação de Vermuelen e Jonhnson para baixas velocidades de rotação a partir dos valores dos coeficientes de Kalker e incluindo na força lateral a parcela de pivotamento, Barbosa (1999). E assim, a expressão para a força lateral é modificada para:

$$
\begin{aligned}
v^{\prime}{ }_{y} & =\frac{-G a b\left[C_{22} v_{y}+(a b)^{\frac{1}{2}} C_{23} v_{s p}\right]}{3 \mu F_{z}} \\
u^{\prime}{ }_{s p} & =\frac{-G a b\left[(a b)^{\frac{1}{2}} C_{32} v_{y}+a b C_{33} v_{s p}\right]}{3 \mu F_{z}}
\end{aligned}
$$

Em 1984, Kalker formulou a teoria completa, que foi utilizada no programa CONTACT. Os escorregamentos lateral, longitudinal e rotacional e os coeficientes de rigidez de contato são utilizados para determinar as forças de contato:

$$
F_{T}=[C]\{u\}
$$


A complexidade do processo aumenta consideravelmente o tempo de processamento para que essas tarefas sejam realizadas junto com o cálculo do comportamento dinâmico do veículo, gerado a partir da solução das equações dinâmicas.

A formulação das forças de contato em função da força vertical foi primeiramente utilizada por Hertz (1991). O objetivo dessa técnica é determinar as forças tangenciais a partir das reações verticais. As propriedades da elipse de contato são calculadas para uma força vertical unitária, relacionando as forças tangenciais proporcionais à força normal $N$ :

$$
\begin{aligned}
& F_{x}=-G a b C_{11} v_{x} N^{\frac{2}{3}} \\
& F_{y}=-G a b\left[C_{22} v_{y} N^{\frac{2}{3}}+(a b)^{\frac{1}{2}} C_{23} v_{s p} N\right]
\end{aligned}
$$

Em sistemas mecânicos, as forças não conservativas podem ser responsáveis pela instabilidade, o que amplia a atenção dada ao fenômeno do escorregamento que não deixa de ser uma força não conservativa.

\section{4 Perfil da Roda e do Trilho}

A função tanto do perfil da roda quanto perfil do trilho fornece os raios de rolamento nos pontos de contato. A dirigibilidade na inscrição de uma curva ou a simples restituição para o centro da via após a aplicação de uma força externa lateral dependem dos perfis de rolamento. Outro fator importante é o desgaste dos perfis. Ao mudar o raio dos pontos de contato e o ângulo da conicidade da roda no contato, as forças tangenciais também mudam. $\mathrm{Na}$ teoria da mecânica de contato, a área de contato se forma com tamanho reduzido, sendo chamada também como ponto de contato. Múltiplos pontos de contato dificultam a determinação das forças tangenciais porque a teoria de Hertz é válida para apenas uma área de contato. Programas como o VOCO, ADAMS, e VAMPIRE consideram mais de um ponto de contato na simulação. O método de Pascal (1991) trata de múltiplos pontos de 
contato através da proposta de um ponto equivalente representativo dos demais pontos de contato e, para esse ponto, calcula-se uma elipse de contato equivalente que permite a determinação das forças tangenciais equivalentes. O maior problema é representar o momento gerado pelos diversos pontos de contato se o centro de rotação instantânea é de difícil determinação.

A roda possui um perfil cônico (figura 8), do friso para o centro, que propicia o autodirecionamento do rodeiro. O friso impede que a roda exceda o limite de deslocamento lateral resultante do movimento de comportamento dinâmico do sistema. Na região do friso aparecem intensas forças tangencias laterais resultantes da forte presença do efeito de pivotamento. Ao se afastar do friso, as forças tangenciais terão predominância da parcela que depende do deslocamento lateral.

Perfis desenvolvidos recentemente propõem um casamento entre as superfícies com o objetivo de evitar o contato múltiplo. A conformidade entre as superfícies de contato aumenta a área de contato, e é percebida pela concordância entre os raios de rolamento. Essas características reduzem a possibilidade de aparecimento de contatos múltiplos.

A determinação precisa dos parâmetros de contato é responsável pela qualidade na modelagem e sua proximidade com o comportamento dinâmico do veículo.

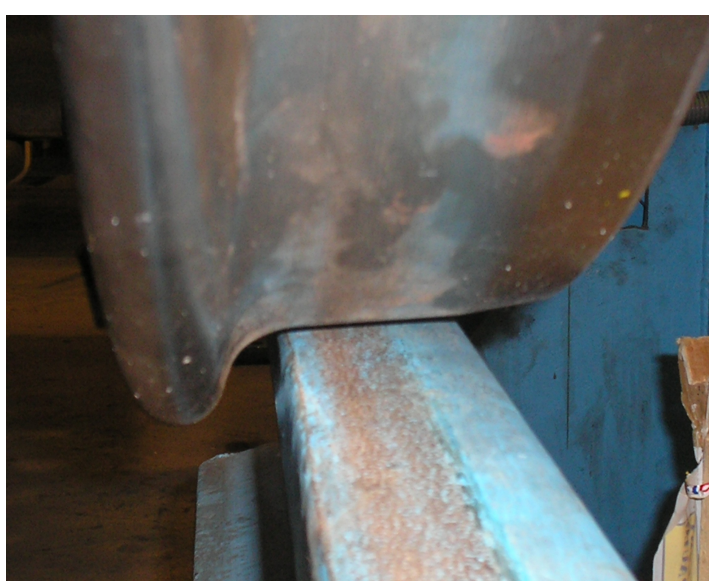

Figura 8: Vista frontal do perfil roda trilho 
Num modelo linear, a conicidade efetiva representa de forma mais adequada o contato roda trilho. Nessa situação, a relação direta entre diferença dos raios de rolamento das rodas e deslocamento lateral determina a inclinação do rodeiro (IWNICKI, 2003):

$$
\phi=\frac{\left(R_{e}-R_{d}\right)}{2 \mathrm{u}_{y}}
$$

Essa representação é válida apenas para região linear em função da curvatura dos perfis de contato variar consideravelmente. A simulação de um modelo linear permite, uma vez fixadas as propriedades de contato, a observação das relações da estabilidade com as velocidades de translação do sistema. As propriedades de contato podem ser alteradas com o objetivo de se verificar sua influência na estabilidade, adotando elevação e abaixamento da inclinação de contato.

\section{5 Escorregamento}

Através do movimento de corpo rígido da roda sobre os trilhos é possível a identificação das velocidades de translação $V_{t}$ e rotação $V_{c}$ do sistema. Publicações de Kalker (1982a), Pascal (1993b), Barbosa (1996), e Barbosa (1999) abordam o cálculo de escorregamentos. Ao desenvolver movimento de rolamento perfeito, sem escorregamento e sem deformação (corpos rígidos), a velocidade circunferencial $V_{c}$ é o resultado do produto da velocidade de rotação pelo raio. A velocidade encontrada na translação é a mesma da velocidade circunferencial. Se existir escorregamento, as velocidades de translação e circunferencial não são mais as mesmas e aparecem forças tangenciais no contato com o objetivo de mudar a velocidade de translação. 


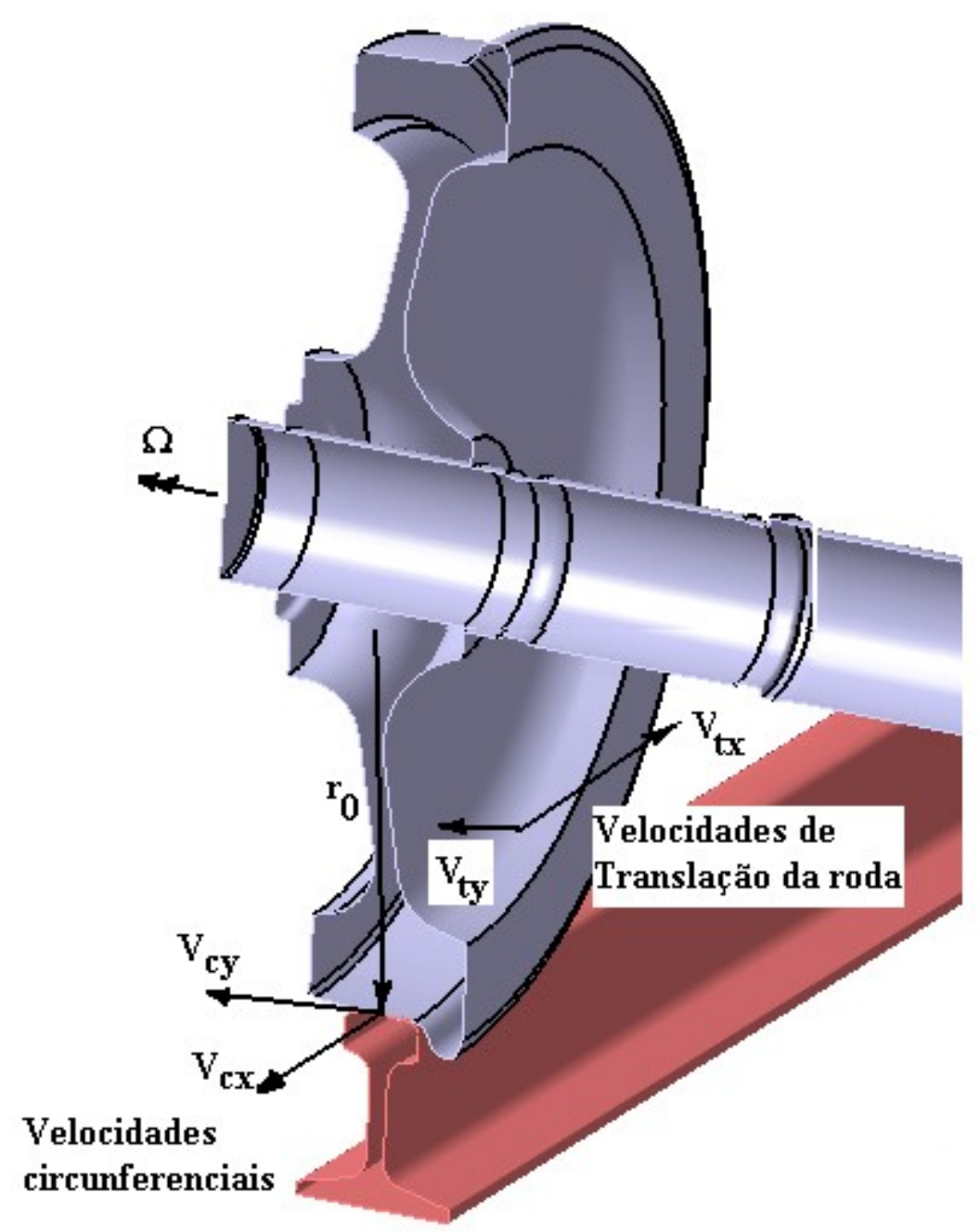

Figura 9: Cinemática de Contato

A dinâmica do sistema torna-se conhecida quando o rodeiro se movimenta com velocidade de translação $V_{t}$ igual a $V_{0}$. A força resultante do sistema é nula e o rodeiro se encontra no centro da via com o contato de rolamento de raio inicial $r_{0}$. A velocidade circunferencial, no contato da roda com o trilho, é $V_{c}$, sendo decomposta nas direções do plano de contato. A velocidade angular do eixo do rodeiro é $\Omega$. Dessa forma, tem-se um corpo sólido rolante sobre os trilhos e mostrado na figura 9. 
A origem do sistema de coordenadas está definido no Centro de Gravidade do rodeiro (CG), o que significa que a semi distância do raio de rolamento do contato ao CG é o braço b. O ângulo de inclinação criado com relação a linha de centro da via é indicado por $\varphi_{z}$.

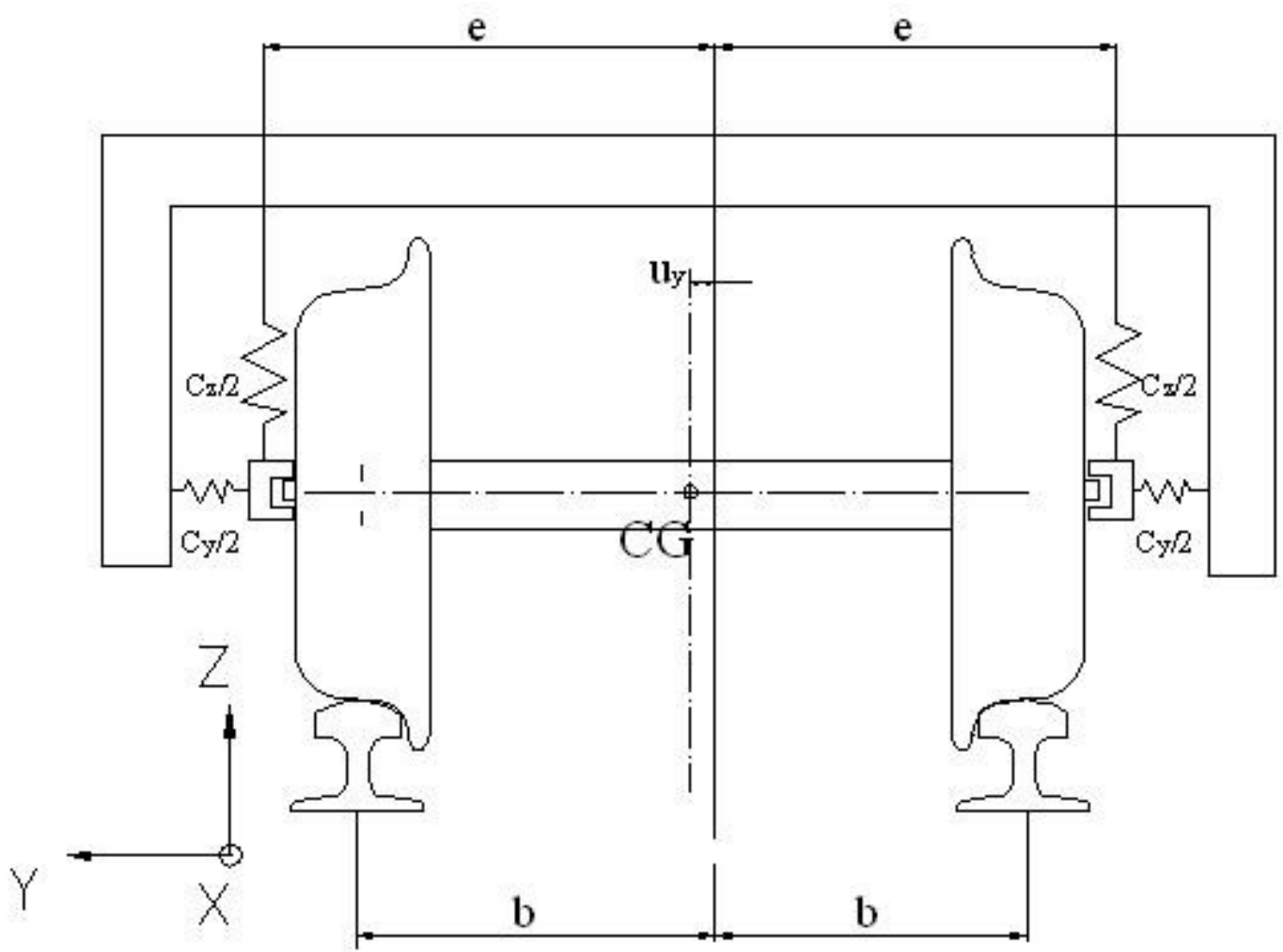

Figura 10: Descrição da geometria envolvida no modelo do rodeiro

O sistema sai do equilíbrio à medida que o rodeiro é acelerado, ou freado, ou na inscrição de uma curva. O mesmo também ocorre em situações que a suspensão, excitada, aplica forças laterais, ou ao receber uma aceleração tangencial (o que resulta em componentes normais).

Ao prosseguir sobre uma linha reta, plana, sem esforços laterais, a distância percorrida em um giro da roda será exatamente a de uma circunferência de raio $s_{1,2}= \pm \sqrt{\lambda}$ Ao se aplicar um torque $\left(T_{\varphi}\right)$ ao eixo de rolamento do rodeiro (figura 17), o sistema gira, se afasta do equilíbrio. Nessa situação, os raios de rolamento 
deixam de ser aqueles da posição de equilíbrio $\left(r_{0}\right)$. Raios de rolamento diferentes (entre as rodas) implicam em forças tangenciais também diferentes. A força tangencial, de cada roda, é responsável pelo binário resultante. Quanto mais o rodeiro continua a se deslocar do centro da via, mais as forças tangenciais crescem com esse deslocamento lateral. Em um determinado ponto, as forças de restituição tornam-se maiores e a resultante vira-se para o sentido do centro da via. $\mathrm{O}$ deslocamento aproxima-se do valor máximo enquanto o ângulo de yaw do rodeiro tende a zero. As forças de contato, ainda presentes como forças de restituição, retornam o rodeiro para a linha de equilíbrio diminuindo sua intensidade. Quando o rodeiro estiver no centro da via, o ângulo de yaw será máximo e a diferença entre as forças longitudinais no contato de cada roda também.

Pode-se encontrar escorregamento na inscrição de uma curva, onde a diferença de raio de giro entre as rodas gera momento de giro e variação na direção. Esse mesmo fenômeno é observado na saída do rodeiro da posição de equilíbrio. Também no movimento longitudinal, ao se aumentar à velocidade circunferencial, no caso de movimento acelerado, a velocidade circunferencial se torna maior que a de translação, gerando esforço tangencial no contato.

Todos esses escorregamentos estão presentes no movimento do rodeiro. Esse esforço tangencial pode ser determinado pela diferença entre as velocidades, normalizado pela velocidade média, que é determinada pela média aritmética das duas velocidades. O escorregamento (creepage) é uma componente escalar e é calculado como:

$$
u=\frac{\left(\vec{V}_{c}-\vec{V}_{t}\right)}{\left|\vec{V}_{0}\right|}
$$

em geral:

$$
V_{0}=\frac{\left(\vec{V}_{c}+\vec{V}_{t}\right)}{2}
$$

E como o escorregamento acontece no sentido do movimento, lateral e de pivotamento do rodeiro, pode-se estender a fórmula anterior a:

$$
v_{x}=\frac{\left(\vec{V}_{c x}-\vec{V}_{t x}\right)}{\left|\vec{V}_{0}\right|} \quad v_{y}=\frac{\left(\vec{V}_{c y}-\vec{V}_{t y}\right)}{\left|\vec{V}_{0}\right|} \quad v_{s p}=\frac{\omega_{z}}{\left|\vec{V}_{0}\right|}
$$


O balanço de pivotamento é responsável por gerar a inclinação do rodeiro no plano xy e sua intensidade depende da conicidade da roda e da velocidade angular do rodeiro.

$$
\omega_{z}=\Omega \operatorname{sen} \delta
$$

Tomando para análise das velocidades do lado esquerdo do rodeiro, tem-se a seguinte composição:

$$
V_{c x}=\Omega r-b \dot{\varphi}_{z}
$$

Considerando que o CG do rodeiro se encontra-se no centro da via, o contato da roda no trilho tem raio de rolamento nominal igual a $r_{0}$. O raio de rolamento, está relacionado com o deslocamento lateral conforme segue abaixo:

$$
r=r_{0}+\lambda u_{y}
$$

Substituindo na velocidade circunferencial longitudinal:

$$
\begin{aligned}
V_{c x}=\Omega\left(r_{0}+\lambda u_{y}\right)-b \dot{\varphi}_{z} \\
V_{c x}=V_{0}+\frac{\left(V_{0} \lambda u_{y}\right)}{r_{0}}-b \dot{\varphi}_{z}
\end{aligned}
$$

A velocidade de translação é contrária à velocidade no contato. $\mathrm{O}$ escorregamento longitudinal pode ser calculado da seguinte forma:

$$
v_{x}=\frac{\left(\lambda u_{y}\right)}{r_{0}}+b \frac{\dot{\varphi}_{z}}{V_{0}}
$$

Como o ângulo de yaw é muito pequeno, tem-se $\operatorname{sen} \varphi_{z} \simeq \varphi_{z} \mathrm{e} \cos \varphi_{z} \simeq 1$. O escorregamento na direção lateral é dado a seguir:

$$
v_{y}=\frac{\dot{u_{y}}}{V_{0}}-\varphi_{z}
$$

A velocidade angular de pivotamento é dada a partir de (17):

$$
\omega_{s p}=\dot{\varphi}_{z}
$$

E, dessa forma, os escorregamentos nos dois contatos das rodas (direito e esquerdo) são apresentados a seguir:

$$
\begin{gathered}
v_{x E}=\frac{-\left(\lambda u_{y}\right)}{r_{0}}-b \frac{\dot{\varphi}_{z}}{V_{0}} \quad v_{x D}=\frac{\left(\lambda u_{y}\right)}{r_{0}}+b \frac{\dot{\varphi}_{z}}{V_{0}} \\
v_{y E}=v_{y D}=\frac{\dot{u}_{y}}{V_{0}}-\varphi_{z}
\end{gathered}
$$


As equações acima são reorganizadas na forma:

$$
\left\{\begin{array}{c}
v_{x} \\
v_{y} \\
u_{s p}
\end{array}\right\}=\frac{1}{V_{0}}\left[\begin{array}{cc}
0 & -b \\
1 & 0 \\
0 & 1
\end{array}\right]\left\{\begin{array}{c}
u_{y} \\
\dot{\varphi}_{z}
\end{array}\right\}+\left[\begin{array}{cc}
\frac{\lambda}{r_{0}} & 0 \\
0 & -1 \\
0 & 0
\end{array}\right\}\left\{\begin{array}{c}
u_{y} \\
\varphi_{z}
\end{array}\right\}
$$

\section{6 Forças no Contato}

O projeto do rodeiro e de qualquer sistema ferroviário (truque, caixa, ou trem urbano - TU) deve garantir que a velocidade crítica se encontre acima da velocidade de rolamento. Isso depende do dimensionamento das forças de contato, a partir do conhecimento do escorregamento, das propriedades de contato, da rigidez de contato e Lei de saturação.

Em função da elasticidade dos materiais em contato, as deformações entre eles dão origem às forças entre os corpos em rolamento. A força na lateral, por exemplo, depende do escorregamento $v_{y}$ e da rigidez $k_{y}$. O mesmo ocorrerá com as forças longitudinais no contato.

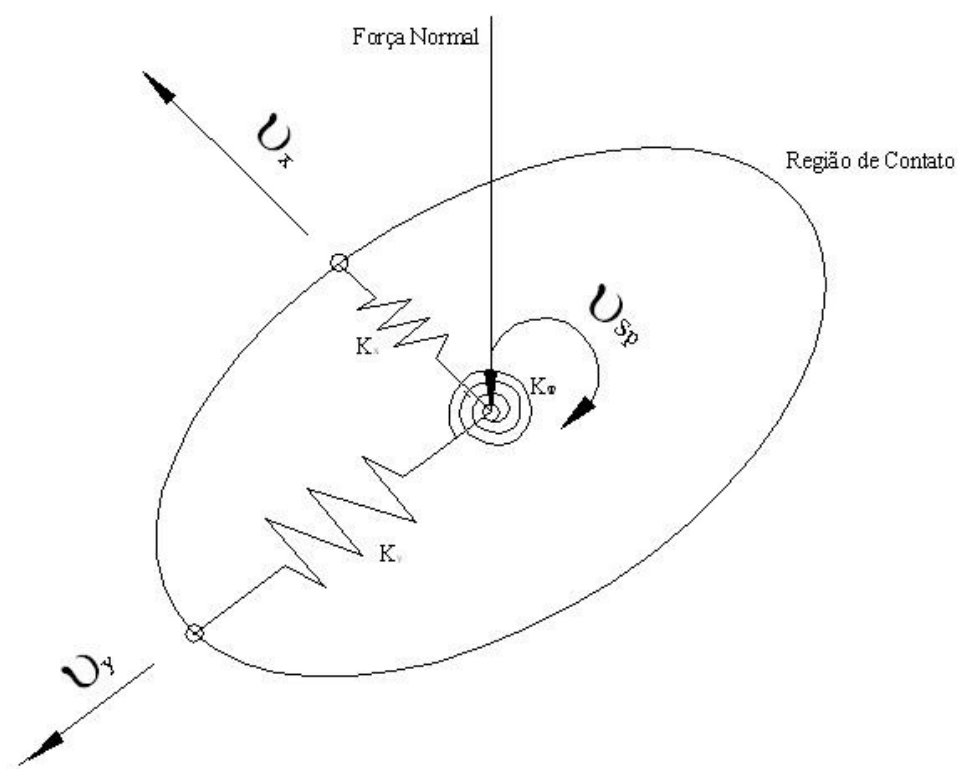

Figura 11: Rijezas e escorregamentos no contato 
A resistência ao escorregamento é representada pela rigidez no contato. Quando o rodeiro passeia lateralmente ou torce com relação ao seu eixo, ele enfrenta uma resistência no contato. $\mathrm{O}$ rodeiro recebe a reação de restituição quando sai da posição de equilíbrio.

A força lateral no contato das duas rodas, dada por $F_{c y}=k_{y} v_{y}$, representa a soma das forças laterais de cada roda $F_{c y}=F_{c y l}+F_{c y 2}$. O mesmo acontece com $F_{c x}$ . A resistência ao ângulo de "yaw" é calculada a partir $M_{c z}=F_{c x} b_{0} \cos \varphi_{z} \simeq F_{c x} b_{0}$.

$\mathrm{O}$ momento de giro do rodeiro, dado por $M_{c}=k_{x} b_{0}^{2} \varphi$, é resultado do binário $F_{c x}=F_{c x l}-F_{c x 2}$. As forças de contato são calculadas através das relações a seguir:

$$
\left\{\begin{array}{l}
F_{c y} \\
F_{c w}
\end{array}\right\}=\left[\begin{array}{cc}
k_{y} & 0 \\
0 & k_{x}
\end{array}\right]\left[\begin{array}{l}
u_{x} \\
v_{s p}
\end{array}\right]
$$

Os escorregamentos são pequenos o bastante para cobrir toda a zona de adesão no contato, conforme a teoria linear. As deformações elásticas compensam toda a diferença de deslocamento devido ao escorregamento entre os corpos rígidos. A relação entre a distribuição de pressões tangenciais na área de contato e a função das diferenças de deslocamento dos corpos pode ser expressa segundo as expressões lineares a seguir (Barbosa, 1999):

$$
\begin{aligned}
& F_{c x}=G a b C_{11} v_{x} \\
& F_{c y}=-G a b\left[C_{22} v_{y}+(a b)^{\frac{1}{2}} C_{23} v_{s p}\right] \\
& M_{c z}=-G a b\left[(a b)^{\frac{1}{2}} C_{23} v_{y}+C_{33} v_{s p}\right]
\end{aligned}
$$

O rearranjo pode ser feito na forma matricial:

$$
\left\{\begin{array}{l}
F_{c x} \\
F_{c y} \\
M_{c z}
\end{array}\right\}=-G a b\left[\begin{array}{ccc}
-C_{11} & 0 & 0 \\
0 & C_{22} & (a b)^{\frac{1}{2}} C_{23} \\
0 & (a b)^{\frac{1}{2}} C_{23} & a b C_{33}
\end{array}\right\}\left\{\begin{array}{c}
v_{x} \\
v_{y} \\
v_{s p}
\end{array}\right\}
$$

E simplificado pela expressão geral:

$$
F_{\tau}=C v_{x, y, s p}
$$


As forças tangenciais de contato, resumidas em (32), serão as forças geradas no contato se as deformações elásticas compensarem toda a diferença de velocidades. Ao se respeitar a Lei de saturação no contato, observada por Charles Coulomb (1736-1806), as forças no plano de contato serão calculadas através de uma função de saturação do contato. Ela depende das condições de superfície tais como: rugosidade, aderência e contaminação. A saturação desta força acontecerá de forma gradual devido à natureza dos escorregamentos estabelecidos entre os corpos rolantes e determinada pela mecânica de contato (Barbosa, 1999).

Segundo a curva de saturação, pode-se concluir que próximo à origem a tangente da curva equivale à rigidez de contato fornecida pela tabela de Kalker. A partir do escorregamento de 0,1 , a tangente ou derivada da curva de saturação diminui em função das deformações internas da elipse de contato. No ponto de maior saturação, quando o escorregamento é próximo de 2, a curva atinge o valor máximo determinado pela lei de Coulomb $\left(F_{\tau}=\mu F_{c z}\right)$.

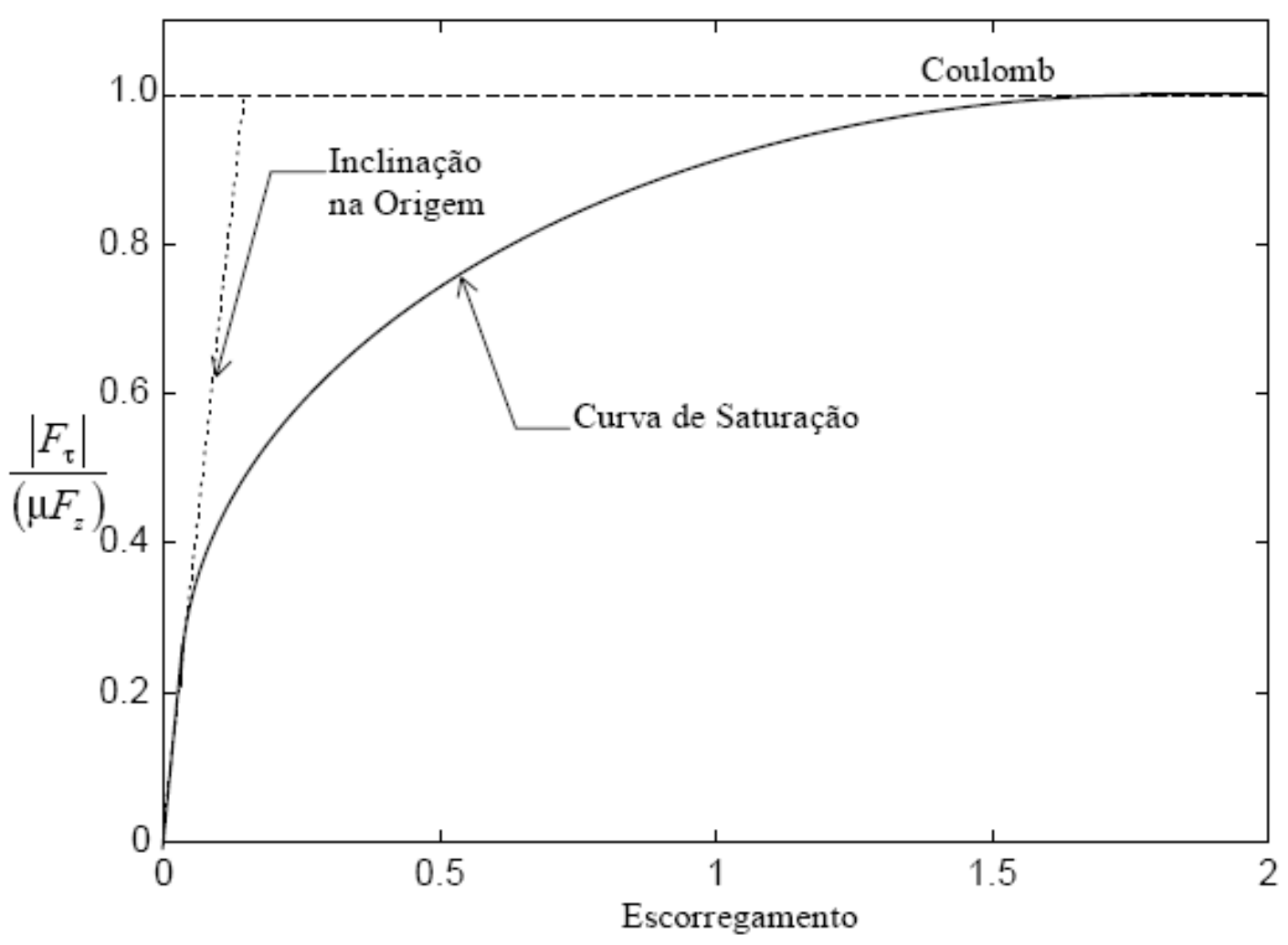

Figura 12: Curva de saturação das forças tangenciais (Barbosa, 1999) 
De acordo com Barbosa (1999) a saturação é determinada por uma função cúbica. Nos casos em que o contato roda trilho se aproxima do friso, ocorre intenso escorregamento por rotação e essas aproximações não são mais válidas. Para esses casos, programas mais elaborados através de algoritmos como FASTSIM são recomendados. De certa forma, cada teoria reserva uma aplicabilidade específica em que seus resultados são mais seguros (Barbosa, 1999):

- Aceleração ou frenagem, com predomínio de escorregamento longitudinal, recomenda-se Shen-Hedrick-Elkins (SHE);

- Dinâmica veicular, sem que a roda encoste o friso no boleto do trilho, podese utilizar a tabela de rigidez de contato, fornecida por SHE ou pelo FASTSIM. Esse tipo de análise é geralmente utilizado para análise de conforto sem inscrição em curvas;

- Dinâmica veicular, com predomínio de rotação no contato, deve-se seguir a utilização da tabela de rigidez de contato (linear) ou FASTSIM (não linear).

Ao se aproximar o contato na região do friso, as curvaturas entre as superfícies se tornam muito diferentes e aparecem mais de um ponto de contato. $\mathrm{O}$ rodeiro se encontra deslocado da posição central da via. Nessa situação, há um predomínio de rotação no contato e a forma do contato deixa de ser elíptica, o que não se adapta a teoria de Hertz. Também, quando as curvaturas dos perfis são muito parecidas, podem aparecer dois pontos de contato. As forças resultantes dos dois contatos deverão ser calculadas a partir da distribuição dos esforços em cada região.

A solução do problema das propriedades de contato depende da dimensão de cada força normal e tangencial para os contatos, e isso contribui para o aumento da complexidade do problema, Kalker (1979a). Para essa abordagem, uma das ferramentas indicadas é o programa CONTACT. Porém, o consumo de tempo de cálculo aumenta, inviabilizando seu uso dentro da simulação.

Com o objetivo de criar uma técnica simplificada para abordar o problema de contato, privilegiando maior velocidade na geração dos resultados numéricos sem prejuízo para a precisão do modelo, Pascal e Sauvage (1990c) se concentraram no esforço de desenvolvimento da técnica do ponto de contato duplo, e em seguida na 
divisão em múltiplos pontos de contato Pascal e Sauvage (1991). Através da deformação elástica encontrada a cada elipse, chega-se à proporção das deformações individuais com relação à deformação total. Essa relação determina a proporção das forças de contato de cada elipse que, dessa forma, serão determinadas individualmente pela teoria de Hertz. Uma vez estudado a força resultante no contato, a área de uma elipse de contato equivalente pode ser determinada e correlacionada com o contato múltiplo. Assim, para essa elipse equivalente, uma vez calculado os escorregamentos, têm-se as mesmas forças tangenciais que aparecem no problema de contato múltiplo.

Em comparação com o CONTACT de Kalker, a metodologia da técnica de múltiplos contatos hertzianos foi considerada válida desde que um número suficiente de elipses de contato fosse considerado (Pascal,1993a).

Perfis conformes, criados pelo desgaste mútuo, ou contatos em regiões próximas do friso, ganharam condições determinação das forças no contato.

\section{7 Descrição da via}

A via é constituída pela guia e pelos dormentes. A guia é a linha por onde o veículo se sustenta interagindo com as forças tangenciais do contato. O eixo de orientação da via é determinado por seis grandezas, as quais três são de rotação e três de translação.

Os desvios na direção de um rodeiro são criados ao passar por um aparelho de mudança de via (AMV), uma curva, uma sobrelevação ou simplesmente uma agulha (kink). A inclinação da via (grade) $\alpha$ muda a altura de rodagem (vide figura 13). O ângulo de agulha $\beta$ gera o desvio lateral. E a sobrelevação $\gamma$ gera diferença de altura entre as rodas do rodeiro. 

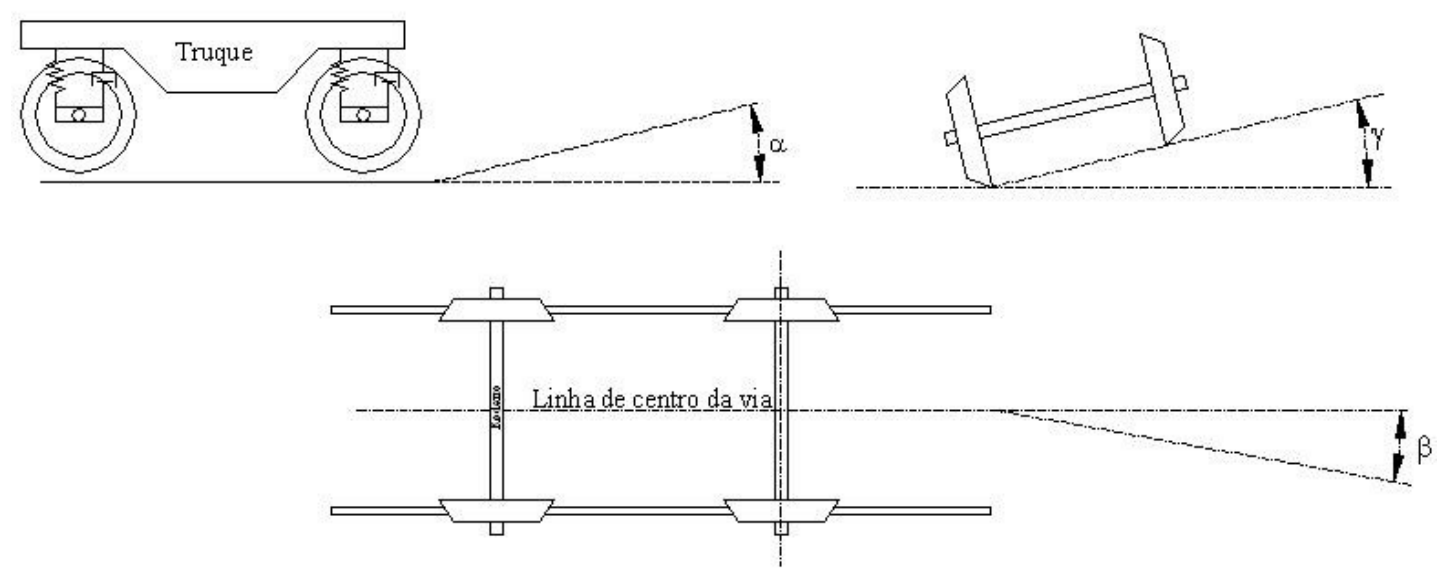

Figura 13: Exemplos de mudança de via

Ao se estabelecer à necessidade de se caracterizar a posição e atitude (ângulos) de uma via, as informações com respeito às mudanças de direção estarão relacionadas com o sistema de referência global adotado no modelo.

As irregularidades da via são classificadas dentro do grupo de irregularidades geométricas, sendo divididas em irregularidades em fase ou defasadas. As irregularidades em fase se caracterizam pela variação no alinhamento lateral ou nivelamento vertical. As irregularidades defasadas se caracterizam pela variação de bitola ou nivelamento cruzado. Para se medir as irregularidades, utiliza-se de equipamentos topográficos e de veículos especiais contendo o sistema de medição apoiado sobre a via (Miniprof). Uma vez determinadas às irregularidades da via, o sistema de manutenção pode intervir ou determinar a data de manutenção da via bem como o local exato que necessita de correção. As irregularidades poderão ser do tipo determinística ou aleatório (Barbosa,1999). As irregularidades determinísticas são aquelas que,em função de sua repetitividade, podem ser analisadas através de técnicas de análise de sinais periódicos (Fourier). 

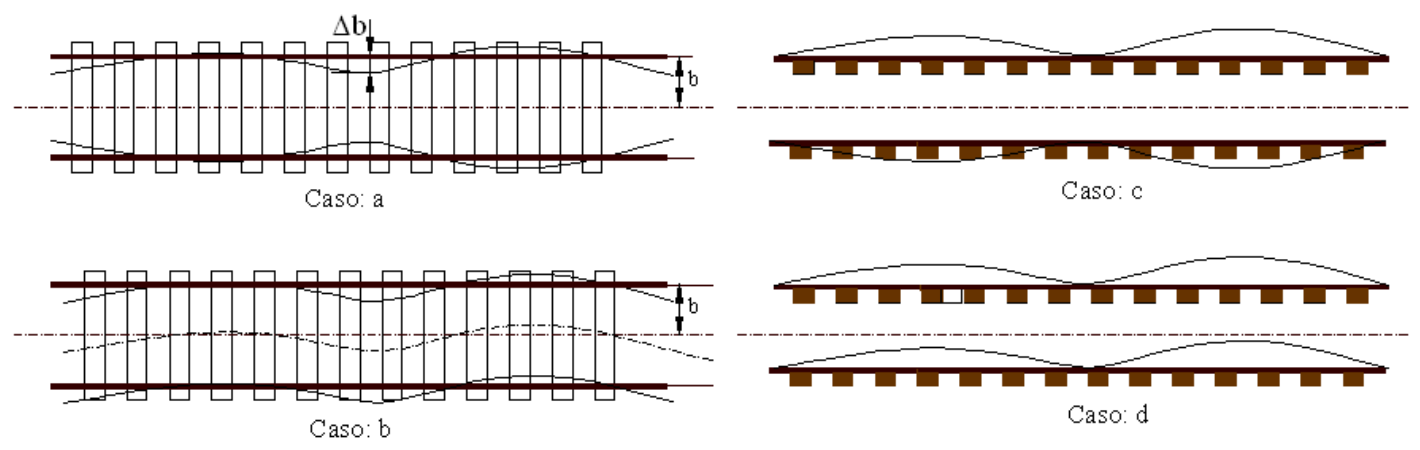

Figura 14: Irregularidades da via

Identifica-se entre os vários comprimentos de onda aqueles que excitam a estrutura do veículo e analisa-se o veículo para essas excitações.

As aleatórias são mais imprevisíveis e difíceis de serem identificadas, pois elas deixam de ser aleatórias se ocorrer ciclos repetitivos, e passam a ser determinísticas.

O veículo trafega sobre a via com liberdade para realizar movimentos laterais excitados por irregularidades na via e inscrição em curvas. Uma vez fora do ponto de equilíbrio, o sistema de autodirecionamento, proporcionado pelas rodas cônicas, restituirá o sistema após negociar a interação dos esforços no contato roda-trilho. A interação roda-trilho gera solicitações que são responsáveis pela qualidade de passeio do veículo. Os escorregamentos e a tensão no contato geram desgaste que pode ser verificado através da visualização dos perfis usados. Quando as solicitações estão acima do esperado em projeto, o nível de agressividade das rodas aumenta, prejudicando o desempenho, conforto e a durabilidade dos perfis.

A curva é o meio projetado para se mudar a direção de um veículo ferroviário. A inscrição em curva é tratada através de análise quase-estática com aplicação de forçamento lateral equivalente às acelerações centrífugas. Os fenômenos transitórios são negligenciados nesse tratamento. O projeto de passeio em curva deve garantir uma aceleração centrífuga da ordem de $1 \mathrm{~m} / \mathrm{s}^{2}$, através da relação entre a velocidade de tráfego do veículo e o raio mínimo de curvas (Barbosa, 1999). Nesse caso, a força centrífuga nas curvas são parcialmente compensadas a partir da super elevação do trilho externo. 
O aparelho de mudança de via ou AMV transfere uma composição ferroviária de uma via a outra através de uma transição abrupta, o que exige do projeto uma preocupação com relação às forças de interação veículo-via. A conexão entre uma curva de raio constante e uma reta pode ser realizada através de uma curva de transição que inicia em uma reta de raio infinito (curvatura zero) e se finaliza na curva com raio idêntico a esta. As formas de curvas de transição disponíveis estão ilustradas na figura 15 .

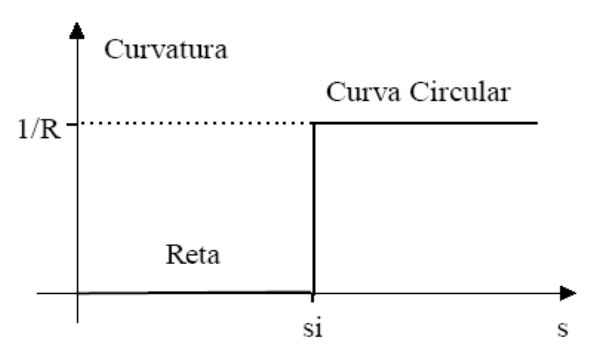

Sem Transição

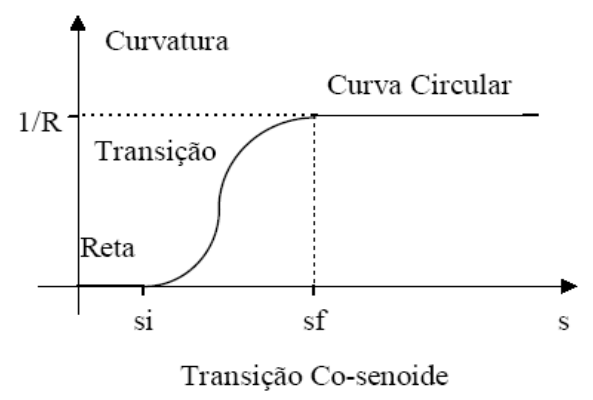

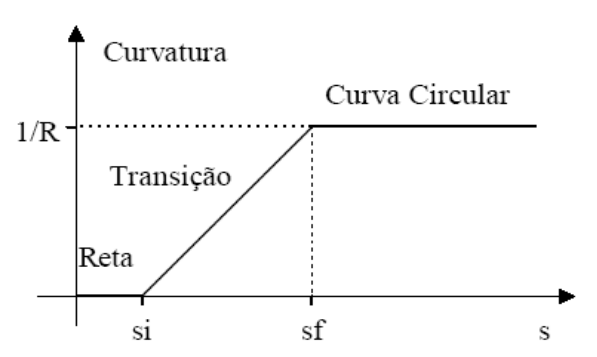

Transição Clotóide

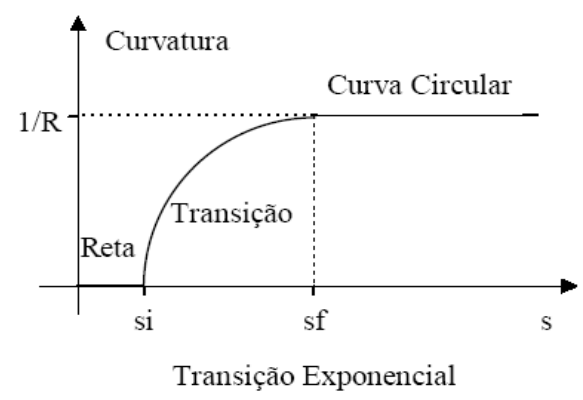

Figura 15: Curva de transição de vias (Barbosa, 1999)

Um projeto otimizado é aquele que gera baixo nível de agressividade e desgaste no par "roda-trilho". A velocidade de tráfego deve se encontrar abaixo da velocidade crítica satisfazendo os requisitos de estabilidade. Para alcançar esses aspectos no projeto, a concepção deve ser feita de modo integrado unindo elementos de massa e rijezas, os quais representam a suspensão primária + massa 1 (truque) e secundária + massa 2 (veículo). A figura 16 mostra um rodeiro e a suspensão primária. 


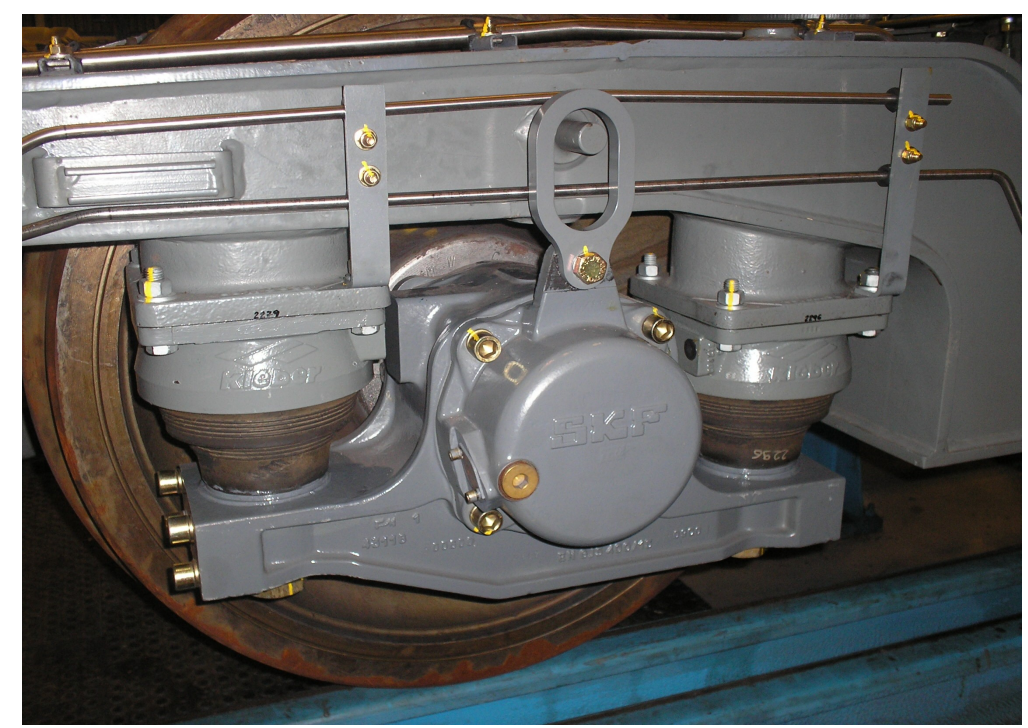

Figura 16: Rodeiro ligado à caixa de rolamento e a suspensão primária

A figura 17 mostra um truque, formado pelo elemento de massa não suspensa (rodeiro) e a suspensão primária (elemento de ligação elástica). Ainda na mesma figura, o esqueleto do truque é conectado ao veículo através da suspensão secundária (bolsa de ar).

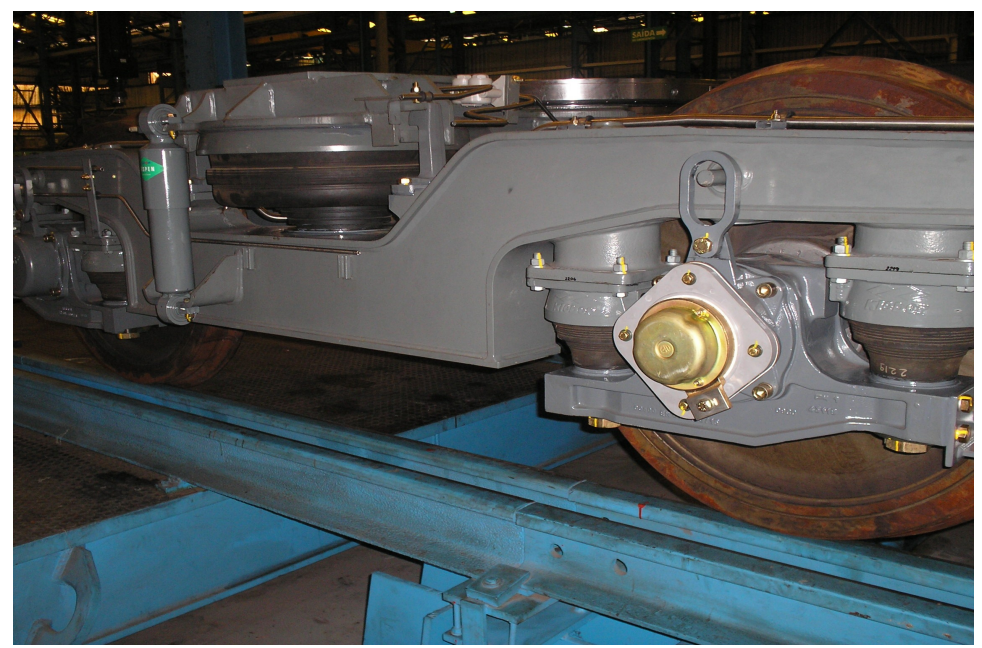

Figura 17: Truque ferroviário

A bitola varia ao longo da via, podendo alterar as propriedades no contato uma vez que as propriedades do contato não consideram essas variações na largura da bitola. A simulação incluindo este parâmetro exige a parametrização das propriedades de contato para cada largura da bitola. 
O desgaste diferenciado do perfil do trilho ao longo da via também dificulta a previsão da resposta dinâmica na simulação, aparecendo com mais periodicidade em regiões com intensas forças no contato e as acelerações transversais, como no aparelho de mudança de via (AMV) e em curvas muito fechadas. A representação dessa situação pode ser feita através da determinação das propriedades de contato para cada um dos perfis (Barbosa, 1999). Uma opção consiste na interpolação linear das propriedades de contato entre os extremos de perfis, o que também carrega a simulação. 


\section{MODELO MATEMÁTICO}

A criação do modelo exige a correta abordagem dos aspectos relevantes de um problema de modelagem. A descrição do modelo físico irá determinar quais aspectos serão relevantes dentre todos os observados. A simplificação, quando necessária, é o passo seguinte, e depende da compreensão do esforço disponível para resolver o problema através da utilização das ferramentas certas para a análise. Algumas vezes, o engenheiro se depara com problemas de difícil solução porque o modelo exige o conhecimento do comportamento de uma série de variáveis não lineares.

As equações constitutivas que irão descrever matematicamente o modelo são geradas. A solução das equações visa determinar o comportamento dinâmico do sistema, seja analítica ou numericamente, mas não determina o fim do processo. Todo resultado teórico deve ser comparado com o sistema real ou outro trabalho de igual valor. Isso serve para a correção e ajuste dos parâmetros das equações constitutivas. A previsão da resposta do sistema é utilizada quando a segurança na aplicação do modelo é estabelecida. Assim, uma vez corrigidos todos os parâmetros, pode-se modificar o sistema físico agora previsível.

O rodeiro tem suas particularidades geométricas. A figura 18 mostra o rodeiro ligado à estrutura de um suporte por meio da suspensão primária. Esse suporte faz o papel do esqueleto do truque. O suporte viaja com a mesma velocidade do rodeiro e não desenvolve velocidade relativa com o eixo referencial.

Conforme os dados fornecidos pelo artigo Dinâmica do rodeiro ferroviário, seguem os valores utilizados na elaboração da análise linear:

- Conicidade da Roda $\lambda=0,10 ;$

- Raio Nominal da Roda (36") $\mathrm{r}_{\mathrm{o}}=0,4572 \mathrm{~m}$;

- Semi Largura Rodeiro (bitola via) $b_{o}=0,7175 \mathrm{~m}$;

- Semidistância da Susp. Primária $\quad \mathrm{e}_{\mathrm{o}}=0,61 \mathrm{~m}$;

- Massa do Rodeiro $\mathrm{m}=1751 \mathrm{~kg}$;

- Momento de Inércia do Rodeiro $\quad \Theta=800 \mathrm{~kg} \mathrm{~m} 2$; 
- Rigidez Long. Susp. Primária

- Rigidez Lat. Susp. Primária

- Rigidez Long. Contato

- Rigidez Lat. Contato

- Rigidez Torcional Susp Primária

$$
\begin{aligned}
& \mathrm{c}_{\mathrm{x}}=4,5687 \times 10^{6} \mathrm{~N} / \mathrm{m} ; \\
& \mathrm{c}_{\mathrm{y}}=1,00 \times 10^{2} \mathrm{~N} / \mathrm{m} ; \\
& \mathrm{k}_{\mathrm{x}}=6,20 \times 10^{6} \mathrm{~N} ; \\
& \mathrm{k}_{\mathrm{y}}=6,50 \times 10^{6} \mathrm{~N} ; \\
& \mathrm{k}_{\mathrm{zz}}=1,70 \times 10^{6} \mathrm{~N} \mathrm{~m} / \mathrm{rad} .
\end{aligned}
$$

Por ser o primeiro elemento a receber os esforços externos do sistema, o rodeiro ganha importância no sistema mecânico ferroviário. Estudá-lo de forma isolada permite a identificação do seu comportamento e compreender a sua estabilidade.

A posição lateral do rodeiro $u_{y}$ determina o raio de rolamento das rodas esquerda e direita $\left(e_{2}\right)$. $\mathrm{O}$ friso das rodas limita o deslocamento lateral máximo desenvolvido. A curva perfeita acontecerá quando o rodeiro inscrevê-la sem que o friso das rodas se encontre com os trilhos (IWNICKI, 2003) . A variação em torno da linha central de equilíbrio (entendida como linha de centro da via) é gerada pelo overshooting do rodeiro e é conhecido como Hunting. Dessa forma, o fenômeno de hunting é limitado pelo friso das rodas e pode ser o responsável por levar o rodeiro ao descarrilamento.

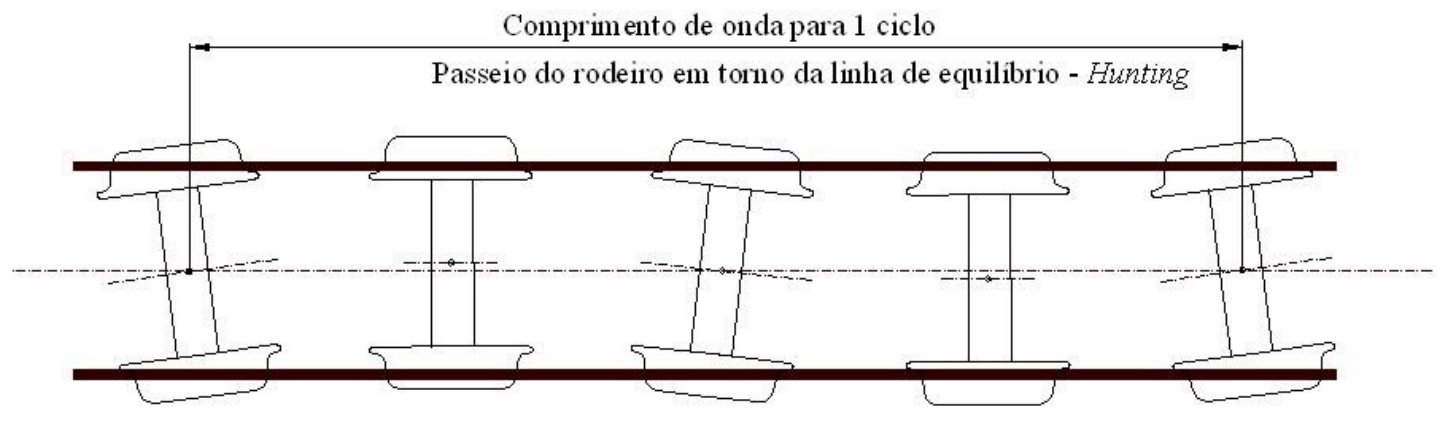

Figura 18: Modo de movimento lateral e angular (Yaw)

Quando se mencionar a velocidade de hunting, tem-se em mente a velocidade crítica de rolamento determinada pelo passeio lateral sobre a qual o rodeiro se tornará instável. 


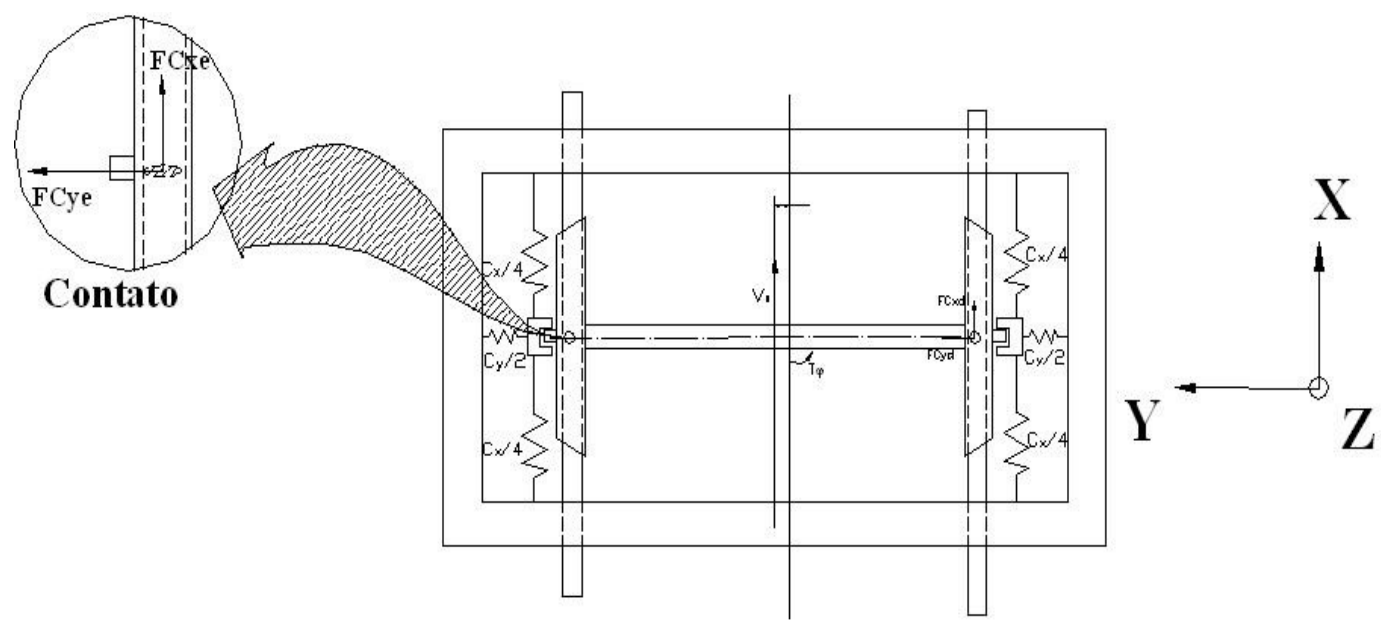

Figura 19: Forças de contato e vista superior do rodeiro simplificado

A orientação do modelo mecânico segue a posição do Centro de Gravidade do rodeiro quando posicionado no centro da via. O sistema pode ser expresso através das coordenadas $u_{y}, u_{x} e \varphi_{z}$ diretamente, sem que a referência tenha sua posição alterada.

Para análise do sistema do rodeiro segue o esboço com as dimensões pertinentes:

As forças nos contatos são apresentadas nas equações abaixo:

$$
\begin{aligned}
& F_{c x}=F_{c x D}+F_{c x E}=2 k_{x} v_{x} \\
& F_{c y}=F_{c y D}+F_{c y E}=k_{y} v_{y} \\
& F_{c w}=F_{c x D}-F_{c x E}=k_{x}\left(v_{x D}-v_{x E}\right)
\end{aligned}
$$

Usando a segunda lei de Newton e para a determinação das equações do movimento do rodeiro em contato com os trilhos tem-se:

$$
\begin{aligned}
& m \ddot{u}_{x}+u_{x} c_{x}+\left(F_{x D}+F_{x E}\right)=0 \\
& m \ddot{u}_{y}+u_{y} c_{y}+\left(F_{y D}+F_{y E}\right)=0 \\
& \Theta \ddot{\varphi}_{z}+\left(e_{0}^{2} c_{x}\right) \varphi_{z}+b_{0}\left(F_{x D}-F_{x E}\right)=0
\end{aligned}
$$

Rearranjando:

$$
\left[\begin{array}{ccc}
m & 0 & 0 \\
0 & m & 0 \\
0 & 0 & \Theta
\end{array}\right]\left\{\begin{array}{c}
\ddot{u}_{x} \\
\ddot{u}_{y} \\
\ddot{\varphi}_{z}
\end{array}\right\}+\left[\begin{array}{ccc}
c_{x} & 0 & 0 \\
0 & c_{y} & 0 \\
0 & 0 & c_{x} e_{0}^{2}
\end{array}\right]\left\{\begin{array}{l}
u_{x} \\
u_{y} \\
\varphi_{z}
\end{array}\right\}=\left\{\begin{array}{c}
-\left(F_{x D}+F_{x E}\right) \\
-\left(F_{y D}+F_{y E}\right) \\
-b\left(F_{x D}-F_{x E}\right)
\end{array}\right\}
$$


Como a análise de interesse se restringe à dinâmica lateral e "hunting":

$$
\left[\begin{array}{cc}
m & 0 \\
0 & \Theta
\end{array}\right]\left\{\begin{array}{c}
\ddot{u}_{y} \\
\ddot{\varphi}_{z}
\end{array}\right\}+\left[\begin{array}{cc}
c_{y} & 0 \\
0 & c_{x} e_{0}^{2}
\end{array}\right]\left\{\begin{array}{c}
u_{y} \\
\varphi_{z}
\end{array}\right\}=\left\{\begin{array}{c}
-\left(F_{y D}+F_{y E}\right) \\
-b_{0}\left(F_{x D}-F_{x E}\right)
\end{array}\right\}
$$

Das equações (37) e (38) tem-se as seguintes equações de movimento:

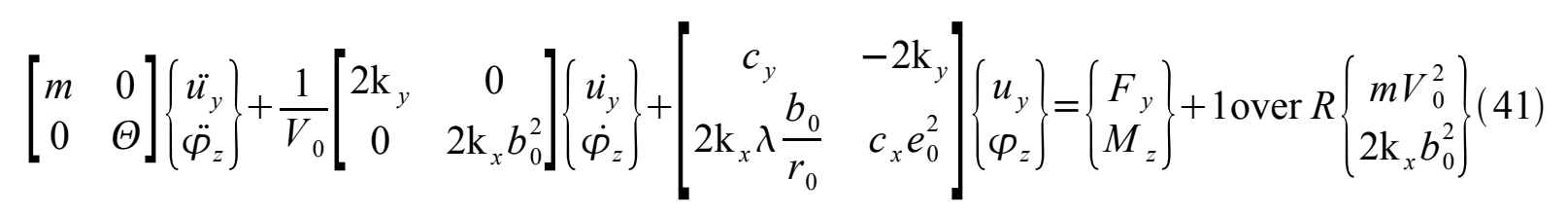

\section{1 Solução das equações de movimento}

Seja a equação de movimento que representa o sistema não amortecido:

$$
[M][\ddot{x}]+[K][x]=[0]
$$

A resposta desse sistema será dada através de uma combinação de senos e cossenos também representada por Euler.

$$
x(t)=\{u\} e^{\lambda t}
$$

E sua segunda derivada:

$$
\ddot{x}(t)=\lambda^{2}[u] e^{\lambda t}
$$

em que $\lambda= \pm i w$ representa um par de raízes de um sistema não amortecido e que portanto não possui parte real. A amplitude modal $[u]$ representa o modo de vibrar do sistema.

$$
x(t)=\{u\} e^{i w t}
$$

Tomando a resposta do sistema (43) e sua segunda derivada (44), inserindo no sistema e cancelando as parcelas comuns (Ogata, 2002) tem-se:

$$
\begin{gathered}
{[M] \ddot{x}(t)+[K] x(t)=[0]} \\
{[M] \lambda^{2}\{u\} e^{\lambda t}+[K]\{u\} e^{\lambda t}=[0]} \\
\left([K]+\lambda^{2}[M]\right)\{u\}=[0]
\end{gathered}
$$

A solução trivial é $[u]=0$. A solução não trivial é apresentada a seguir:

$$
\operatorname{det}\left([K]+\lambda^{2}[M]\right)=[0]
$$


A resultante do determinante gera o polinômio característico $P_{n}(s)$ de ordem n. As enésimas raízes são pares imaginários conjugados da forma $\lambda_{r}= \pm i w_{r}$. A raiz $\mathrm{r}$ está associada ao modo de vibrar r. Os autovetores $\left\{X_{r}\right\}$ representam o modo de vibrar $\mathrm{r}$ descoberto a partir dos autovalores $w_{r}$. Quando se substituir às freqüências naturais na expressão (47), tem-se:

$$
\left([K]-w_{r}^{2}[M]\right)\left\{X_{r}\right\}=[0]
$$

onde $r=1, \ldots ., n$.

Seja os modos distintos $\left\{X_{r}\right\}$ e $\left\{X_{j}\right\}$ obtidos em (47) a partir das freqüências $w_{r}$ e $w_{j}$ na forma:

$$
\begin{aligned}
& {[K]\left\{X_{r}\right\}-w_{r}^{2}[M]\left\{X_{r}\right\}=[0]} \\
& {[K]\left\{X_{j}\right\}-w_{j}^{2}[M]\left\{X_{j}\right\}=[0]}
\end{aligned}
$$

Uma vez multiplicados pelos autovetores transpostos $\left\{X_{r}\right\}^{T} \mathrm{e}\left\{X_{j}\right\}^{T}$ cada um dos membros tem-se:

$$
\begin{aligned}
& \left\{X_{j}\right\}^{T}[K]\left\{X_{r}\right\}-w_{r}^{2}\left\{X_{j}\right\}^{T}[M]\left\{X_{r}\right\}=[0] \\
& \left\{X_{r}\right\}^{T}[K]\left\{X_{j}\right\}-w_{j}^{2}\left\{X_{r}\right\}^{T}[M]\left\{X_{j}\right\}=[0]
\end{aligned}
$$

Para matrizes simétricas $\quad\left\{X_{r}\right\}^{T}[K]\left\{X_{j}\right\}=\left\{X_{j}\right\}^{T}[K]\left\{X_{r}\right\} \mathrm{e}$ $\left\{X_{j}\right\}^{T}[M]\left\{X_{r}\right\}=\left\{X_{r}\right\}^{T}[M]\left\{X_{j}\right\}$, e dessa forma subtraindo as equações (53) de (52):

$$
\left(w_{r}^{2}-w_{j}^{2}\right)\left\{X_{r}\right\}^{T}[M]\left\{X_{j}\right\}=[0]
$$

Assim, para $w_{r} \neq w_{j}$ tem-se:

$$
\begin{aligned}
& \left\{X_{r}\right\}^{T}[K]\left\{X_{j}\right\}=\left\{X_{j}\right\}^{T}[K]\left\{X_{r}\right\} \\
& \left\{X_{j}\right\}^{T}[M]\left\{X_{r}\right\}=\left\{X_{r}\right\}^{T}[M]\left\{X_{j}\right\}
\end{aligned}
$$

E a Rigidez generalizada $[K]_{g e n}$ é calculada como:

$$
[K]_{g e n}=\left\{X_{r}\right\}^{T}[K]\left\{X_{j}\right\}
$$

E a Massa generalizada $[M]_{\text {gen }}$ é calculada como:

$$
[M]_{\text {gen }}=\left\{X_{j}\right\}^{T}[M]\left\{X_{r}\right\}
$$

Substituindo em (52) as matrizes $[M]_{g e n}$ e $[K]_{g e n}$ tem-se:

$$
[K]_{g e n}-w_{r}^{2}[M]_{g e n}=[0]
$$




$$
w_{r}^{2}=\frac{[K]_{g e n}}{[M]_{g e n}}
$$

onde $r=1, \ldots \ldots, n$.

\section{2 . 2 Desacoplamento das Equações}

Para se representar o vetor de deslocamentos através das coordenadas generalizadas:

$$
\{u\}=[R]\{q\}
$$

onde $\{u\}$ é o vetor de deslocamentos correspondente aos n graus de liberdade e $\{q\}$ é o vetor de coordenadas generalizadas. A matriz $[R]$ representa a matriz modal formada com $n$ autovetores:

$$
[R]=[\{X 1\}\{X 2\}\{X 3\} \ldots \ldots .\{X n\}]
$$

De posse da equação (47) tem-se:

$$
[M]\{\ddot{u}\}+[K]\{u\}=[0]
$$

Substituindo (59) e suas derivadas, o sistema passa a ser representado pelas coordenadas generalizadas:

$$
[M][R]\{\ddot{q}\}+[K][R]\{q\}=[0]
$$

Multiplicando pela transposta da matriz modal:

$$
[R]^{T}[M][R]\{\ddot{q}\}+[R]^{T}[K][R]\{q\}=[0]
$$

Através das propriedades de ortogonalidade, $\left[M_{g e n}\right]$ e $\left[K_{g e n}\right]$ são matrizes diagonalizadas, o que desacopla a determinação dos autovalores do sistema:

$$
\left[M_{\text {gen }}\right]\{\ddot{q}\}+\left[K_{\text {gen }}\right]\{q\}=[0]
$$

O sistema de equações desacopladas é apresentado por (63) e permite que sejam obtidas as soluções das equações de forma independente.

\section{3 Sistema com amortecimento}

Seja o sistema de equações diferenciais lineares de um sistema amortecido: 


$$
[M]\{\ddot{x}\}+[C]\{\dot{x}\}+[K]\{x\}=[F]
$$

onde a matriz $\{M\}$ equivale a massa, a matriz $\{C\}$ o amortecimento do sistema, a matriz $\{K\}$ a rigidez, e a matriz $\{F\}$ a força externa.

Para se solucionar o sistema de equações diferenciais de segunda ordem, realiza-se uma transformação do sistema de segunda ordem para o sistema de equações diferenciais simultâneas de primeira ordem, Barbosa (1993).

$$
\left[\begin{array}{ll}
{[C]} & {[K]} \\
{[K]} & {[0]}
\end{array}\right]\left[\begin{array}{l}
\dot{u} \\
u
\end{array}\right]-\left[\begin{array}{cc}
-[M] & {[0]} \\
{[0]} & {[K]}
\end{array}\right]\left[\begin{array}{l}
\ddot{u} \\
\dot{u}
\end{array}\right]=\left[\begin{array}{c}
F \\
0
\end{array}\right]
$$

A representação em espaços de estado na forma $[D]\{u\}-[C]\{\dot{u}\}=\{F\}$ (65b) gera um sistema contínuo de $2 \mathrm{n}$ graus de liberdade com as matrizes de estado sendo:

$$
[D]=\left[\begin{array}{ll}
{[C]} & {[K]} \\
{[K]} & {[0]}
\end{array}\right] \quad[C]=\left[\begin{array}{cc}
-[M] & {[0]} \\
{[0]} & {[K]}
\end{array}\right]\{F\}=\left[\begin{array}{c}
F \\
0
\end{array}\right]
$$

Os vetores de estado agrupam de forma vetorial os graus de liberdade e suas derivadas:

$$
\left[\begin{array}{l}
\dot{u} \\
u
\end{array}\right]=[u] \quad\left[\begin{array}{l}
\ddot{u} \\
\dot{u}
\end{array}\right]=\left[\begin{array}{l}
\dot{u} \\
u
\end{array}\right]=[\dot{u}]
$$

Para a solução do sistema de equações diferenciais homogêneas:

$$
\{F\}=\left[\begin{array}{l}
F \\
0
\end{array}\right]=\left[\begin{array}{l}
0 \\
0
\end{array}\right]
$$

E a reposta do sistema é dada por Euler:

$$
x(t)=\{u\} e^{\lambda t}
$$

E leva-se ao seguinte problema de autovalor, do qual a solução não trivial é o conjunto de 2 n raízes:

$$
\left([D]-\lambda^{2}[C]\right)\{u\}=[0]
$$

Para uma solução linear, a reposta é dada pela superposição ponderada de cada modo de vibrar, Ogata (2002):

$$
\{u\}=\left\{r_{1}\right\}\left\{q_{1}\right\}+\left\{r_{2}\right\}\left\{q_{2}\right\}+\left\{r_{3}\right\}\left\{q_{3}\right\}+\ldots \ldots \ldots \ldots+\left\{r_{n}\right\}\left\{q_{n}\right\}
$$

E essa equação equivale à equação (59):

$$
\{u\}=\{R\}\{q\}
$$


Em que $\{u\}$ é a matriz de coordenadas locais e $\{q\}$ a matriz de coordenadas generalizadas. A matriz modal (60) é dada como:

$$
[R]=[\{r 1\}\{r 2\}\{r 3\} \ldots \ldots .\{r n\}]=\left[\left\{\begin{array}{c}
\lambda u_{1} \\
u_{1}
\end{array}\right\}\left\{\begin{array}{c}
\lambda u_{2} \\
u_{2}
\end{array}\right\}\left\{\begin{array}{c}
\lambda u_{3} \\
u_{3}
\end{array}\right\} \ldots \ldots .\left\{\begin{array}{c}
\lambda u_{2 \mathrm{n}} \\
u_{2 \mathrm{n}}
\end{array}\right\}\right]
$$

Substuindo (65b) pela representação das coordenadas generalizadas e multiplicando pela transposta $[R]^{T}$ :

$$
\begin{gathered}
{[D]\{R\}\{q\}-[C]\{R\}\{q\}=\{F\}} \\
\{R\}^{T}[D]\{R\}\{q\}-\{R\}^{T}[C]\{R\}\{\dot{q}\}=\{R\}^{T}\{F\}
\end{gathered}
$$

As matrizes de estado $[D]$ e $[C]$ são simétricas, sendo iguais a transposta das mesmas, Barbosa (1993):

$$
\begin{aligned}
& {[D]=[D]^{T}} \\
& {[C]=[C]^{T}}
\end{aligned}
$$

De posse da propriedade ortogonal de (71), as matrizes resultantes são diagonalizadas:

$$
\{d\}\{q\}-\{c\}\{\dot{q}\}=\{h\}
$$

onde $\{R\}^{T}\{F\}=\{h\}$.

$\mathrm{O}$ resultado das matrizes acima gera um conjunto de $2 n$ equações desacopladas para cada grau de liberdade. Pode-se escrever como:

$$
\left\{d_{j}\right\}\left\{q_{j}\right\}-\left\{c_{j}\right\}\left\{\dot{q}_{j}\right\}=\left\{h_{j}\right\}
$$

em que $j=1, \ldots ., 2 n$.

\section{4 Ortogonalidade}

A ortogonalidade do sistema pode ser verificada ao se considerar os autovalores $\mathrm{r}$ e $\mathrm{j}$ correspondentes aos autovetores $\left\{u_{r}\right\}$ e $\left\{u_{j}\right\}$ e aos modos de vibrar $\mathrm{r}$ e j:

$$
\begin{aligned}
& {[D]\left\{u_{r}\right\}-\lambda_{r}[C]\left\{u_{r}\right\}=[0]} \\
& {[D]\left\{u_{j}\right\}-\lambda_{j}[C]\left\{u_{j}\right\}=[0]}
\end{aligned}
$$


Os autovetores $\quad\left\{u_{r}\right\}^{T}$ e $\left\{u_{j}\right\}^{T}$ multiplicam as equações (76) e (75) respectivamente:

$$
\begin{aligned}
& \left\{u_{j}\right\}^{T}[D]\left\{u_{r}\right\}-\lambda_{r}\left\{u_{j}\right\}^{T}[C]\left\{u_{r}\right\}=[0] \\
& \left\{u_{r}\right\}^{T}[D]\left\{u_{j}\right\}-\lambda_{j}\left\{u_{r}\right\}^{T}[C]\left\{u_{j}\right\}=[0]
\end{aligned}
$$

As matrizes $[D]$ e $[C]$ são simétricas e o pressuposto de (52) e (53) também é válido:

$$
\begin{aligned}
& \left\{u_{j}\right\}^{T}[D]\left\{u_{r}\right\}=\left\{u_{r}\right\}^{T}[D]\left\{u_{j}\right\} \\
& \left\{u_{r}\right\}^{T}[C]\left\{u_{j}\right\}=\left\{u_{j}\right\}^{T}[C]\left\{u_{r}\right\}
\end{aligned}
$$

A subtração de (75) e (76) fornece a seguinte equação:

$$
\left(\lambda_{j}-\lambda_{r}\right)\left\{u_{j}\right\}^{T}[C]\left\{u_{r}\right\}=[0]
$$

Como $\left(\lambda_{j}-\lambda_{r}\right) \neq 0$, implica que obrigatoriamente:

$$
\left\{u_{j}\right\}^{T}[C]\left\{u_{r}\right\}=[0]
$$

Considerando os modos $j=r=i$ iguais, define-se uma condição de normalização dos autovetores:

$$
\left\{u_{i}\right\}^{T}[C]\left\{u_{i}\right\}=1
$$

em que $i=1, \ldots ., 2 n$.

Realizando a mesma operação para todos os modos:

$$
\begin{gathered}
\left\{u_{1}\right\}^{T}[C]\left\{u_{1}\right\}=1 \\
\vdots \\
\left\{u_{i}\right\}^{T}[C]\left\{u_{i}\right\}=1 \\
\vdots \\
\left\{u_{2 \mathrm{n}}\right\}^{T}[C]\left\{u_{2 \mathrm{n}}\right\}=1
\end{gathered}
$$

Reunindo:

$$
\{R\}^{T}[C]\{R\}=[I]
$$

Para se obter a normalização dos autovetores, calcula-se a matriz $\left\{u_{i}\right\}^{T}[C]\left\{u_{i}\right\}=\left\{a_{j}\right\}$ :

$$
\left\{u_{i}\right\}^{T}[C]\left\{u_{i}\right\}=\left\{a_{j}\right\}
$$

Sendo o vetor normalizado encontrado como: 


$$
\left\{u_{i}\right\}_{N}=\frac{\left\{u_{i}\right\}}{\left\{a_{j}\right\}^{\frac{1}{2}}}
$$

Substuindo (83) em (77) tem-se:

$$
\left\{u_{j}\right\}^{T}[D]\left\{u_{r}\right\}=[0]
$$

Fazendo uso da equação (76) para o caso de $j=r=i$, e de posse de (84):

$$
\left\{u_{i}\right\}^{T}[D]\left\{u_{i}\right\}-\lambda_{i}=0
$$

Assim:

$$
\left\{u_{i}\right\}^{T}[D]\left\{u_{i}\right\}=\lambda_{i}
$$

Aplicando para todos os modos:

$$
\{R\}^{T}[D]\{R\}=[\lambda]
$$

onde $[\lambda]$ representa a matriz dos autovalores diagonalizada.

\subsection{Matriz fundamental}

Seja o sistema de equações diferenciais lineares de um sistema amortecido apresentado em (64) para um forçamento nulo:

$$
[M]\{\ddot{x}\}+[C]\{\dot{x}\}+[K]\{x\}=[0]
$$

A equação (64) é chamada de equação diferencial linear homogênea. A solução desse sistema é expressa por uma combinação linear de senos e cossenos ou através da forma de Euler:

$$
x(t)=\{u\} e^{\lambda t}=\left\{\begin{array}{l}
u_{1} \\
u_{2}
\end{array}\right\} e^{\lambda t}
$$

A solução de (91), conforme Dorf (2001), é dada como:

$$
\begin{aligned}
& \lambda^{2}[M]+\lambda[C]+[k]=[0] \\
& \operatorname{det}\left(\lambda^{2}[M]+\lambda[C]+[k]\right)=[0]
\end{aligned}
$$

Os $\lambda_{r}$ encontrados formam os polinômios característicos cujas raízes são as freqüências do sistema. Os autovetores $\{u\}$ são expressos inserindo-se os autovalores em (93). Para o sistema amortecido de 2 graus de liberdade (GL), o polinômio 
característico gera raízes aos pares conjugados do tipo $\lambda_{1}=-\lambda_{3}$ e $\lambda_{2}=-\lambda_{4}$, o que cria $2 \mathrm{n}$ autovetores distintos e complexos conjugados. A solução será dada para cada um dos modos como segue:

$$
\begin{aligned}
& \{u\}=\sum_{j=1}^{4}\left\{u_{j}\right\}\left\{q_{j}\right\} e^{\lambda_{j} t} \\
& \{\dot{u}\}=\sum_{j=1}^{4} \lambda\left\{u_{j}\right\}\left\{q_{j}\right\} e^{\lambda_{j} t}
\end{aligned}
$$

Agrupando na forma matricial:

$$
\left.\left[\begin{array}{l}
\dot{u} \\
u
\end{array}\right]=\left[\begin{array}{cccc}
\lambda u_{1} & \lambda u_{2} & \lambda u_{3} & \lambda u_{4} \\
u_{1} & u_{2} & u_{3} & u_{4}
\end{array}\right]\left[\begin{array}{cccc}
e^{\lambda_{1} t} & 0 & 0 & 0 \\
0 & e^{\lambda_{2} t} & 0 & 0 \\
0 & 0 & e^{\lambda_{3} t} & 0 \\
0 & 0 & 0 & e^{\lambda_{4} t}
\end{array}\right] \mid \begin{array}{l}
q_{1} \\
q_{2} \\
q_{3} \\
q_{4}
\end{array}\right]
$$

E na forma reduzida:

$$
\left[\begin{array}{l}
\dot{u} \\
u
\end{array}\right]=[R]\left[e^{\lambda_{j} t}\right][q]
$$

Para o tempo inicial $t_{0}=0$, implica que $e^{\lambda_{j} 0}=e^{0}=1$ e para as condições iniciais:

$$
\left[\begin{array}{l}
\dot{u}_{0} \\
u_{0}
\end{array}\right]=[R][q] \Rightarrow[q]=[R]^{-1}\left[\begin{array}{l}
u_{0} \\
u_{0}
\end{array}\right]
$$

A matriz fundamental para sistemas amortecidos será expressa através da substituição de (99) em (98). A matriz fundamental correlaciona o estado do sistema em um tempo qualquer com o estado inicial do mesmo sistema.

$$
\left[\begin{array}{l}
\dot{u} \\
u
\end{array}\right]=\underbrace{[R]\left[e^{\lambda_{j} t}\right][R]^{-1}}_{[\Phi]}\left[\begin{array}{l}
u_{0} \\
u_{0}
\end{array}\right]
$$

Reduzindo:

$$
\left[\begin{array}{l}
\dot{u} \\
u
\end{array}\right]=[\Phi]\left[\begin{array}{l}
\dot{u}_{0} \\
u_{0}
\end{array}\right]
$$

Sendo a matriz fundamental apresentada como:

$$
[\Phi]=[R]\left[e^{\lambda_{j} t}\right][R]^{-1}
$$

\section{6 Integral de convolução}


O sistema mecânico apresentado por (65) será excitado por força externa variável no domínio do tempo.

$$
[M]\{\ddot{x}\}+[C]\{\dot{x}\}+[K]\{x\}=[F]
$$

A transformação das equações diferenciais de segunda ordem para o sistema de primeira ordem é visto no detalhe na seção 1.4, equação (65b):

$$
[D]\{x\}-[C]\{\dot{x}\}=\{F\}
$$

De (65a) tem-se:

$$
\left[\begin{array}{ll}
{[C]} & {[K]} \\
{[K]} & {[0]}
\end{array}\right]\left[\begin{array}{l}
\dot{x} \\
x
\end{array}\right]-\left[\begin{array}{cc}
-[M] & {[0]} \\
{[0]} & {[K]}
\end{array}\right]\left[\begin{array}{l}
\ddot{x} \\
\dot{x}
\end{array}\right]=\left[\begin{array}{l}
F_{1} \\
F_{2}
\end{array}\right]
$$

Para a solução do sistema de equações diferenciais não homogêneas:

$$
\{F\}=\left[\begin{array}{l}
F_{1} \\
F_{2}
\end{array}\right]=\left[\begin{array}{l}
F \\
0
\end{array}\right]
$$

de (65b), tem-se:

$$
\begin{aligned}
& {[C]\{\dot{x}\}=[D]\{x\}-\{F\}} \\
& \{\dot{x}\}=[C]^{-1}[D]\{x\}-[C]^{-1}\{F\}
\end{aligned}
$$

reduzindo tem-se:

$$
\{\dot{x}\}=[A]\{x\}+[B]\{F\}
$$

onde tanto a matriz $[A]$ quanto $[B]$ são fornecidas como segue:

$$
[A]=[C]^{-1}[D]
$$

A matriz $[A]$ é a matriz dinâmica do sistema e $[B]$ a matriz de combinação de forçamento externo:

$$
[B]=\left[\begin{array}{cc}
-[M] & {[0]} \\
{[0]} & {[K]}
\end{array}\right]
$$

Para o caso de forçamento dado por $[F]$, segue:

$$
[B]\{F\}=[C]^{-1}\{F\}=\left[\begin{array}{cc}
-[M] & {[0]} \\
{[0]} & {[K]}
\end{array}\right]\left[\begin{array}{l}
F \\
0
\end{array}\right]=\{-[M] \quad 0\}\left[\begin{array}{c}
F \\
0
\end{array}\right]
$$

A expressão (105) descreverá o comportamento do sistema contínuo no domínio do tempo. Para a solução do sistema a partir da entrada de um forçamento externo variável e fornecido através de uma função discreta no domínio do tempo, a 
integral de convolução será utilizada. A expressão para o cálculo da resposta do sistema é dada a seguir:

$$
\{x\}_{t}=[\Phi]_{\left(t-t_{0}\right)}\{x\}_{t_{0}}+\int_{t_{0}}^{t}[\Phi]_{(t-\tau)}[B]\{F\}_{\tau} d \tau
$$

Através de parâmetros constantes ao longo do tempo, conforme Ogata (2002), é possível mostrar:

$$
\begin{gathered}
{\left[\begin{array}{c}
\dot{x} \\
x
\end{array}\right]=[\Phi]_{t-t_{0}}\left[\begin{array}{c}
\dot{x}_{0} \\
x_{0}
\end{array}\right]} \\
{[\Phi]_{t-t_{0}}=e^{[A]_{t-t_{0}}}}
\end{gathered}
$$

O sistema é contínuo porém o mesmo sofre uma excitação externa $\{F\}$ discretizada. A força externa discretizada é inserida no sistema ao longo do domínio do tempo da seguinte forma:

$$
f(t)=f(n T)=f(n) \quad \text { para } \quad n T \leq t<(n+1) T
$$

em que $n=1,2,3 \ldots$. A diferença entre uma força contínua e uma força discreta está no intervalo de tempo entre dois valores de entrada da força discreta $f(n T)$. A força contínua informa ao sistema o ocorrido entre os intervalos de tempo e dentro dos mesmos. A força discreta informa ao sistema apenas entre os intervalos de tempo.

Assim, o comportamento do sistema submetido a força externa constante entre os intervalos de tempo $t_{k}=k T$ e $t_{k+1}=(k+1) T$ é dado conforme Ogata, 2002.

$$
\{x\}_{t k+1}=[\Phi]_{(T)}\{x\}_{t k}+\int_{t k}^{t k+1} e^{[A](t k+1-\tau)}[B] d \tau
$$

O interesse é no comportamento do sistema nos instantes discretos $T=t_{k+1}-t_{k}$ onde $t_{k}=k T$.

$$
\begin{gathered}
x_{(t k+1)}=[\Phi]_{(T)} x_{t k}+H_{(t k)} F_{(t k)} \\
H_{(t k+1)}=\int_{t k}^{t k+1} e^{[A](t k+1-\tau)}[B] d \tau
\end{gathered}
$$

Fazendo $f=k+1-\tau$ e calculando a integral:

$$
H_{(T)}=\int_{0}^{T} e^{[A] f}[B] d f=[A]^{-1}\left(e^{[A]_{T}}-[I]\right)[B]
$$


pois $I=\int_{0}^{t} e^{K x} d x=\frac{1}{K}\left(e^{K x}-1\right)$.

Sendo que $[I]$ é uma matriz identidade, $[A]$ a matriz dinâmica, e $[B]$ a matriz de combinação de forçamento externo. Dessa forma, equação final para cálculo da resposta do sistema a uma excitação discreta:

$$
\{x\}_{t_{k}+1}=[\Phi]_{T}\{x\}_{t_{k}}+[A]^{-1}\left([\Phi]_{T}-[I]\right)[B]\{F\}_{t_{k}}
$$

Um sistema contínuo terá uma solução desenvolvida por uma abordagem contínua, que não poder ser aplicada com o uso de integradores numéricos. Esses integradores fornecem a solução do sistema através da utilização de intervalos de dados discretos. A entrada e a saída são discretizadas.

A mesma equação para a solução contínua possui representação no tempo discreto, dentro do período $\mathrm{T}=t-t_{0}$.

\section{7 Métodos de integração numérica}

A seguir é apresentado o método Runge Kutta de primeira, segunda e quarta ordem.

\subsubsection{Primeira ordem}

Considera-se o problema de valor inicial:

$$
y^{\prime}=f(x, y), y\left(x_{0}\right)=y_{0}
$$

Existem métodos de Runge-Kutta de várias ordens. Esses métodos são obtidos por meio de expansão da série de Taylor, Zill (2003):

$$
y\left(x_{n+1}\right)=y\left(x_{n}+h\right)=y\left(x_{n}\right)+h y^{\prime}\left(x_{n}\right)+h^{2 \mathrm{over}} 2 ! y^{(k)}\left(x_{n}\right)+\ldots . .+\frac{h^{(k+1)}}{(k+1) !} y^{(k+1)}(c)
$$


para $\quad c$ algum número entre os valores $x_{n}$ e $x_{(n+1)}$. Fazendo $k=1$ e considerando $\frac{h^{2}}{2 !} y^{\prime \prime}(c) \simeq 0$ tem-se:

$$
y_{n+1}=y_{n}+h y_{n}^{\prime}=y_{n}+h f\left(x_{n}, y_{n}\right)
$$

A expansão de série de Taylor de ordem 1 é o método de Euler, que por sua vez equivale também ao método de Runge-Kutta de primeira ordem. O erro de truncamento local, ou erro de cada passo $y\left(x_{n}\right)$, é dado como, Zill (2003):

$$
y^{\prime \prime}(c) \frac{h^{2}}{2 !} \Rightarrow O\left(h^{2}\right)
$$

O erro de truncamento global, conhecido como erro total em $y\left(x_{n+1}\right)$ calculado a partir do acumulo de erros em cada um dos passo anteriores, é dado como:

$$
y^{\prime}(c) h \Rightarrow O\left(h^{1}\right)
$$

\subsubsection{Segunda ordem}

Chamando $k_{1}=h f\left(x_{n}, y_{n}\right) \quad$ e $k_{2}=h f\left(x_{n}+\alpha h, y_{n}+\beta k_{1}\right)$ e expandindo a série de Taylor até a ordem 2, tem-se método de Runge-Kutta de segunda ordem quando se encontra valores para $a, b, \alpha, \beta$ de tal modo que a equação (117) coincida com o polinômio de Taylor de grau 2, Zill (2003):

$$
y_{n+1}=y_{n}+a k_{1}+b k_{2}
$$

Para isso, tem-se que $a+b=1, \quad b \alpha=\frac{1}{2}$ e $b \beta=\frac{1}{2}$. O erro de truncamento local é dado como:

$$
y^{(3)}(c) \frac{h^{3}}{3 !} \Rightarrow O\left(h^{3}\right)
$$

E o global:

$$
y^{\prime \prime}(c) \frac{h^{2}}{2 !} \Rightarrow O\left(h^{2}\right)
$$




\subsubsection{Quarta ordem}

O método de Runge-Kutta de quarta ordem depende que se encontre os valores das constantes apropriadas de tal forma que a fórmula coincida com um polinômio de grau quatro:

$$
y_{n+1}=y_{n}+a k_{1}+b k_{2}+c k_{3}+d k_{4}
$$

onde:

$$
\begin{gathered}
k_{1}=h f\left(x_{n}, y_{n}\right) \\
k_{2}=h f\left(x_{n}+\alpha_{1} h, y_{n}+\beta_{1} k_{1}\right) \\
k_{3}=h f\left(x_{n}+\alpha_{2} h, y_{n}+\beta_{2} k_{1}+\beta_{3} k_{2}\right) \\
k_{4}=h f\left(x_{n}+\alpha_{3} h, y_{n}+\beta_{4} k_{1}+\beta_{5} k_{2}+\beta_{6} k 3\right)
\end{gathered}
$$

O conjunto de valores mais comumente usado é apresentado a seguir (Zill, 2003):

$$
y_{n+1}=y_{n}+\frac{1}{6}\left(k_{1}+2 k_{2}+2 k_{3}+k_{4}\right)
$$

Substituindo em (5):

$$
\begin{aligned}
& k_{1}=h f\left(x_{n}, y_{n}\right) \\
& k_{2}=h f\left(x_{n}+\frac{1}{2} h, y_{n}+\frac{1}{2} k_{1}\right) \\
& k_{3}=h f\left(x_{n}+\frac{1}{2} h, y_{n}+\frac{1}{2} k_{2}\right) \\
& k_{4}=h f\left(x_{n}+h, y_{n}+k 3\right)
\end{aligned}
$$

O erro de truncamento local é dado como:

$$
y^{(5)}(c) \frac{h^{5}}{5 !} \Rightarrow O\left(h^{5}\right)
$$

E o global:

$$
y^{(4)}(c) \frac{h^{4}}{4 !} \Rightarrow O\left(h^{4}\right)
$$




\section{2 . 8 Propriedade do Sistema}

O sistema do rodeiro sobre trilhos, quando definido segundo as propriedades de contato lineares, possui comportamento muito bem definido. É possível identificar como a resposta do sistema se altera com o crescimento da velocidade.

Percebe-se que para velocidades muito baixas (gráfico da figura 20) a parcela imaginária é muito pequena no primeiro modo indicando comportamento próximo de um sistema criticamente amortecido $(\xi \simeq 1)$. O aumento da velocidade permite que a parcela imaginária cresça, o que indica que o movimento oscilatório do transiente da resposta também cresça. Para o primeiro modo, seção superior da figura 20, o sistema se comporta como um sistema sub amortecido. Esse fenômeno é observado até a velocidade de $20 \mathrm{~m} / \mathrm{s}$. Após essa velocidade, o módulo da parcela real entra em declínio gradual enquanto a parcela imaginária continua aumentando, ou seja, os pares complexos conjugados continuam se afastando. Algo muito interessante é que para a parcela real diminuir enquanto a parcela imaginária aumenta, faz-se necessário que o aumento da parcela real não acompanhe a queda do fator de amortecimento.
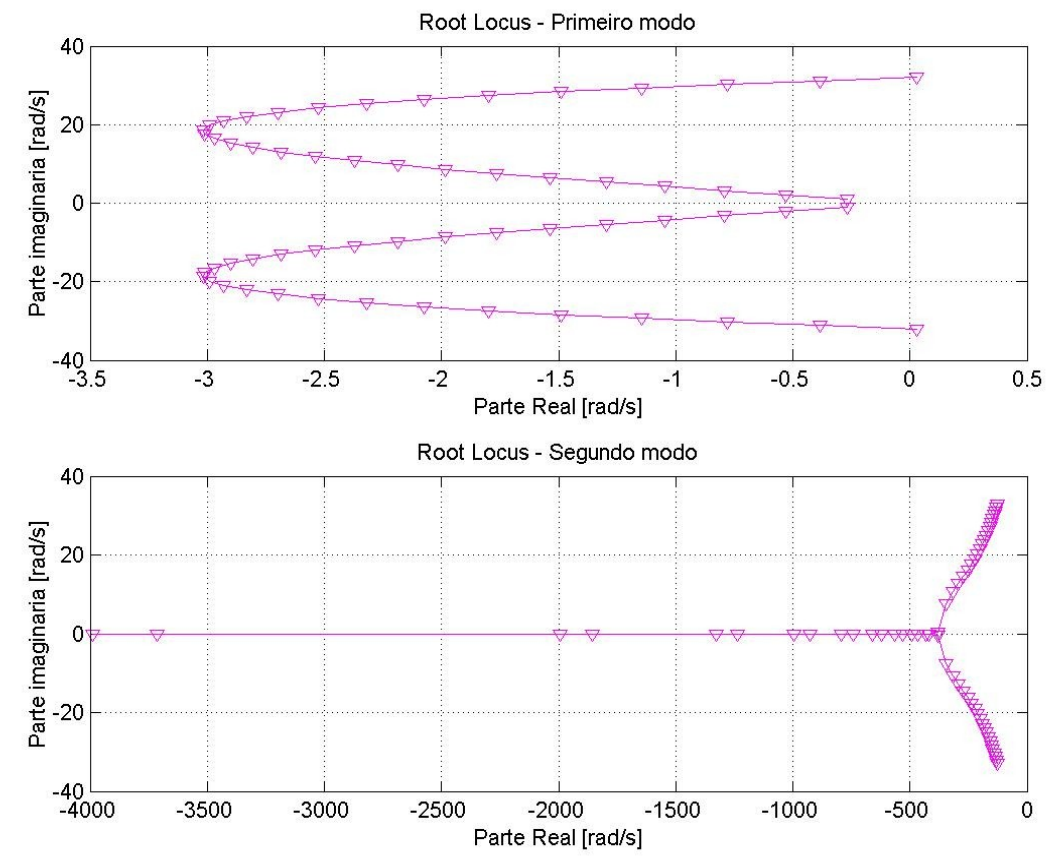

Figura 20: Gráfico lugar das raizes do primeiro (gráfico superior) e segundo modos 
Após os $60 \mathrm{~m} / \mathrm{s}$, o sistema torna-se instável pois as raízes já se encontram do lado direito do eixo real.

O segundo modo possui um comportamento mais previsível à medida que as mudanças que o atingem são apenas em um sentido. As raízes para velocidades baixas se encontram levemente sobre amortecidas ( $\xi>1$ ). Em 18m/s, o sistema migra para sub amortecido. A partir dessa velocidade, as raízes se tornam complexas conjugadas e a resposta passa a ser oscilatória com crescimento do transiente até a velocidade máxima de registro $(60 \mathrm{~m} / \mathrm{s})$.
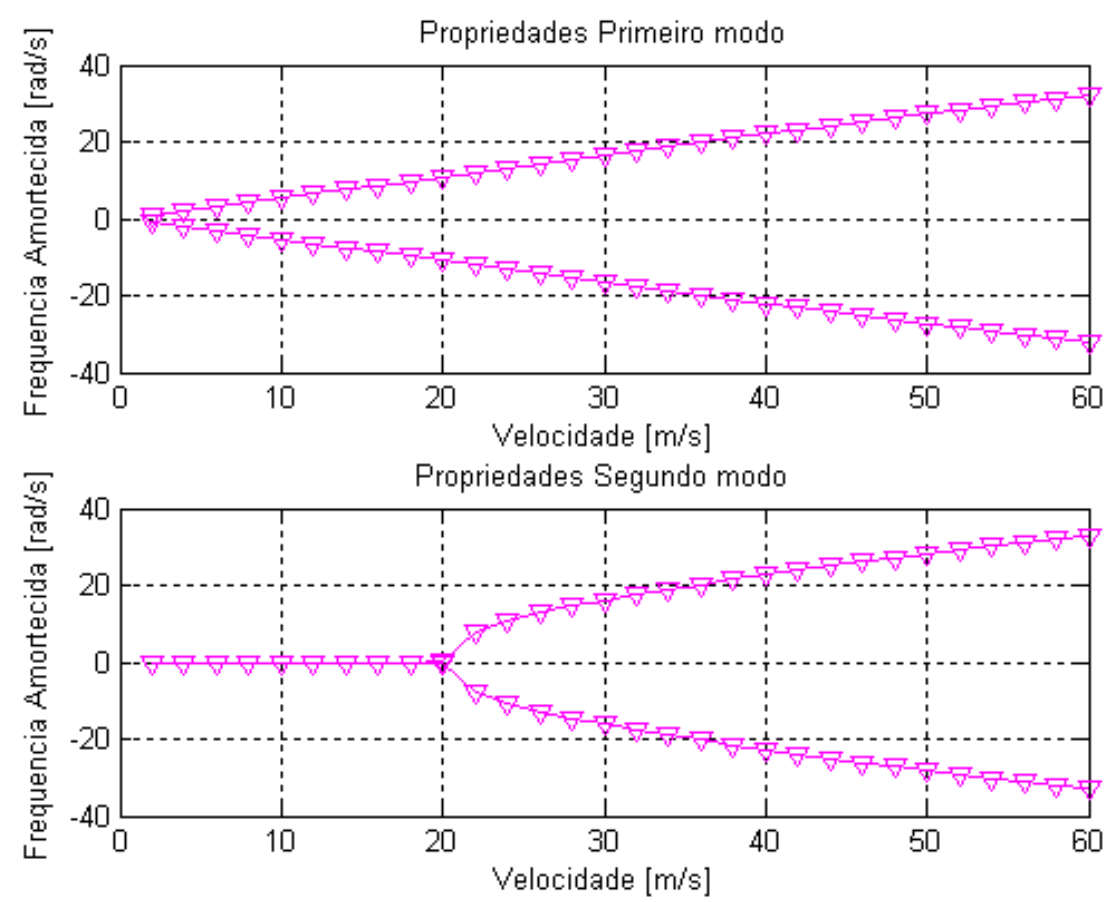

Figura 21: Freqüencia amortecida do primeiro e segundo modos

A figura 21 reforça o que fora dito anteriormente ao mostrar o módulo das raízes da freqüência amortecida, onde o módulo da parcela imaginária é quase nulo em $2 \mathrm{~m} / \mathrm{s}$ no primeiro modo. No segundo modo, o módulo da freqüência natural amortecida se mantém quase nula até $18 \mathrm{~m} / \mathrm{s}$, indicando que $\xi^{2}-1 \simeq 0$. A partir dos $18 \mathrm{~m} / \mathrm{s}$, as raízes se separam brusca mente e o comportamento do sistema é alterado. 

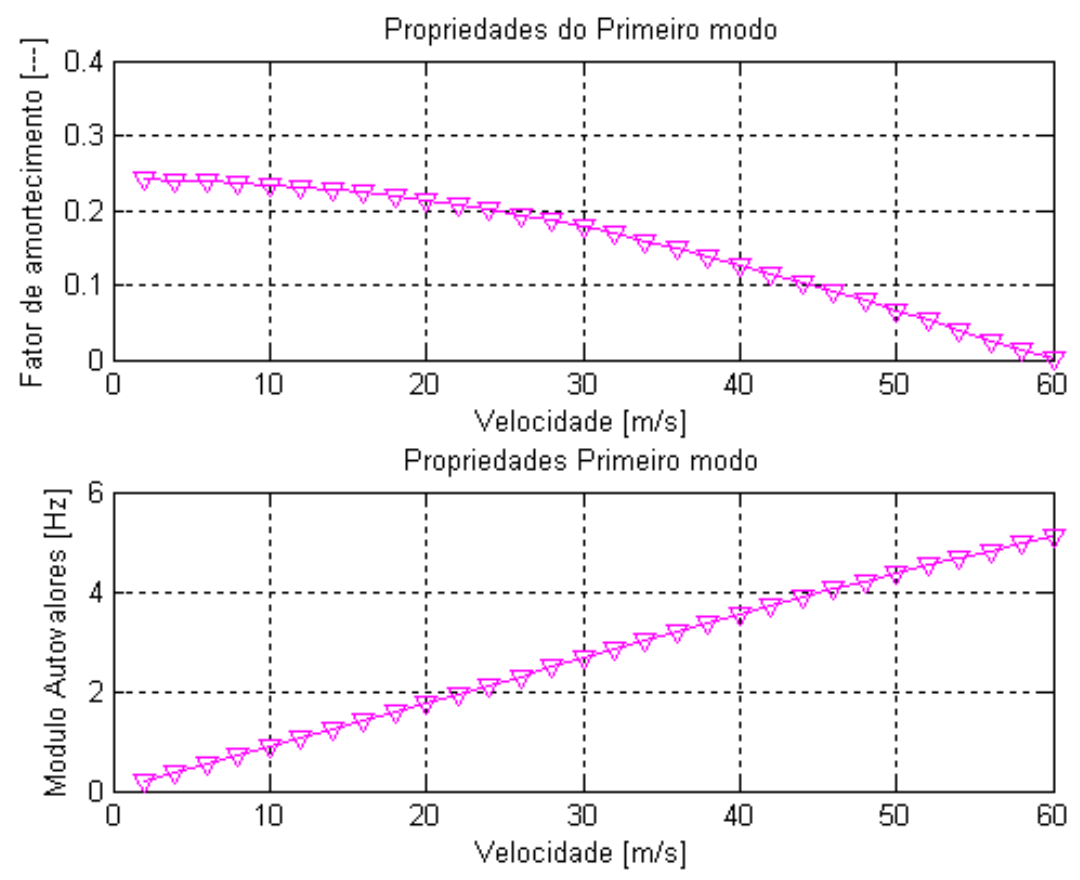

Figura 22: Fator de amortecimento (gráfico superior) e módulo da freqüência do primeiro modo

O fator de amortecimento do primeiro modo está inversamente acoplado à velocidade estabelecida do sistema (figura 22). O fator de amortecimento do segundo modo é próximo de 1 até $20 \mathrm{~m} / \mathrm{s}$. Em $60 \mathrm{~m} / \mathrm{s}$ ele está em 0.968 . À medida que a velocidade cresce, ambos os fatores de amortecimento caem. Porém ainda no primeiro modo, partir de $60 \mathrm{~m} / \mathrm{s}$ ele torna-se negativo. O módulo da freqüência do sistema tende a crescer com a elevação da velocidade no primeiro modo. 

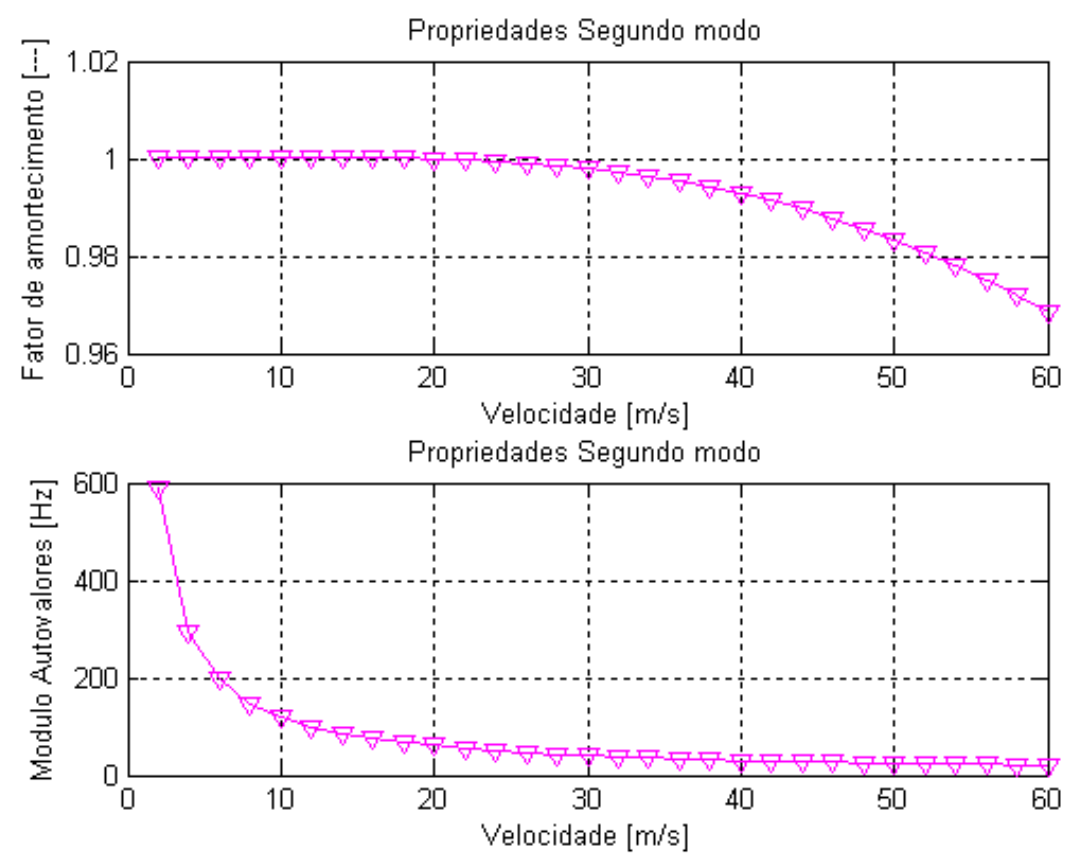

Figura 23: Fator de amortecimento (gráfico superior) e módulo da freqüencia do segundo modo

O módulo da freqüência do segundo modo (gráfico inferior da figura 23) tem um comportamento diferente do primeiro. Ele decai exponencialmente do valor inicial de $600 \mathrm{~Hz}$,para velocidade de $2 \mathrm{~m} / \mathrm{s}, 70 \mathrm{~Hz}$ para a velocidade de $20 \mathrm{~m} / \mathrm{s}$. Desse instante em diante, o sistema encontra um valor de equilíbrio em torno de $35 \mathrm{~Hz}$ na velocidade de $60 \mathrm{~m} / \mathrm{s}$.

\section{9 Sensibilidade do sistema}

A equação (41) foi parametrizada em função da velocidade de rodagem para determinação da estabilidade do sistema. Como o sistema foi linearizado em torno de um ponto de contato, a influência do contato nos autovalores (vide ANEXO B) não pode ser registrada, o que não exclui sua importância, principalmente na região de proximidade com o friso da roda. Como mostrado pelas equações (39) a (41), a rijezas de contato $k_{x}, k_{y}$ são fortemente dependentes da elipse de contato e esta, por sua vez, estará relacionada à posição lateral do contato sobre o boleto do trilho. A 
conicidade do plano de contato também está presente na matriz de rigidez $[\mathrm{K}]$. A variação desse parâmetro também interfere na matriz de autovalores do sistema.

Com o objetivo de verificar a influência da conicidade ao longo do crescimento da velocidade na matriz de autovalores, variou-se a conicidade de $0.1 \mathrm{a}$ 1.0 , como pode ser visto na figura 24 .
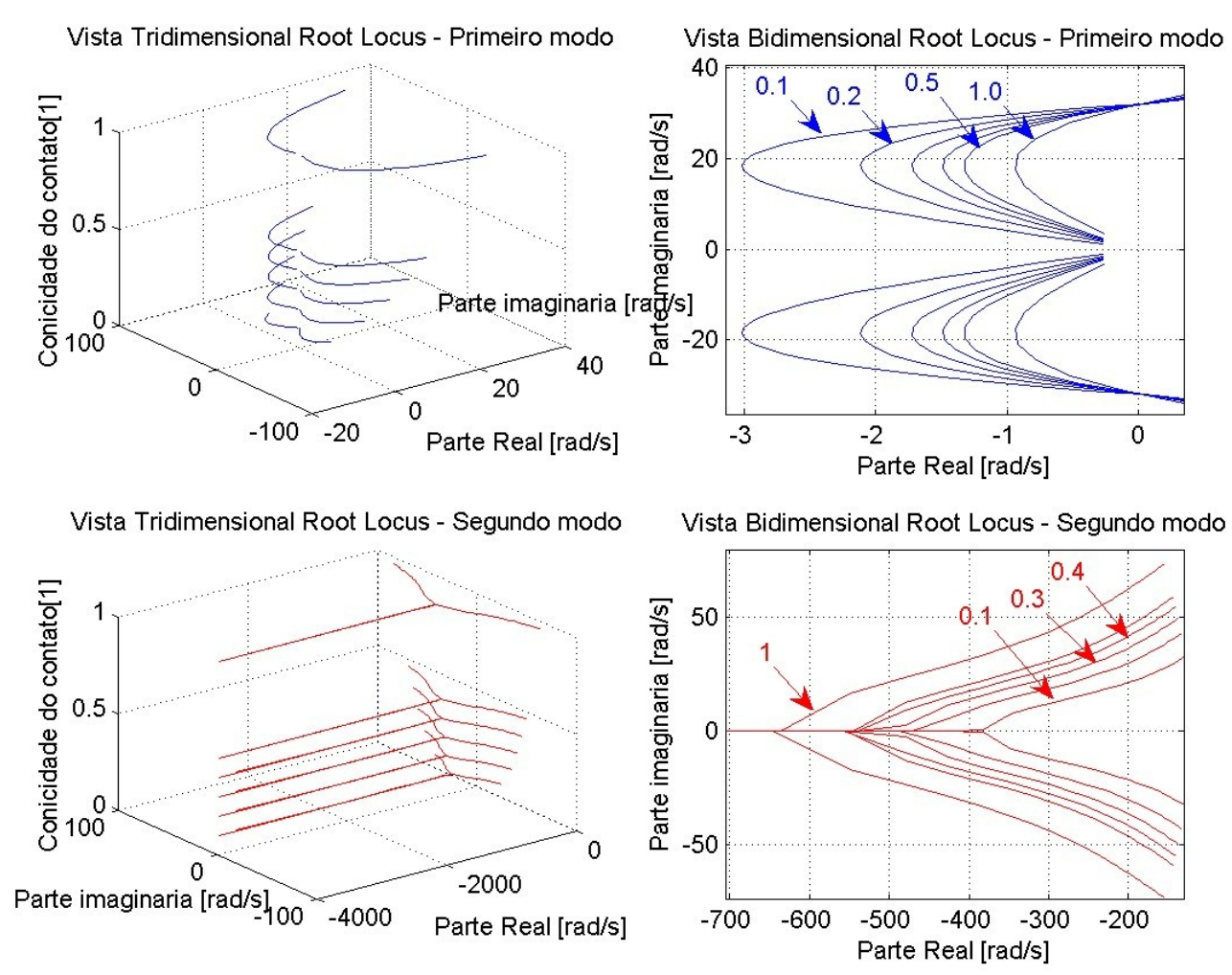

Figura 24: Comportamento dos autovalores do primeiro (em azul) e segundo (em vermelho) modos para conicidade crescente

A conicidade da roda $\lambda$, quando cresce, é responsável por um passeio menor da curva de autovalores do primeiro modo (curva em azul) no eixo real. A variação da parcela imaginária permanece constante. O segundo modo torna-se sub amortecido para freqüências maiores à medida que se aumenta a conicidade. 

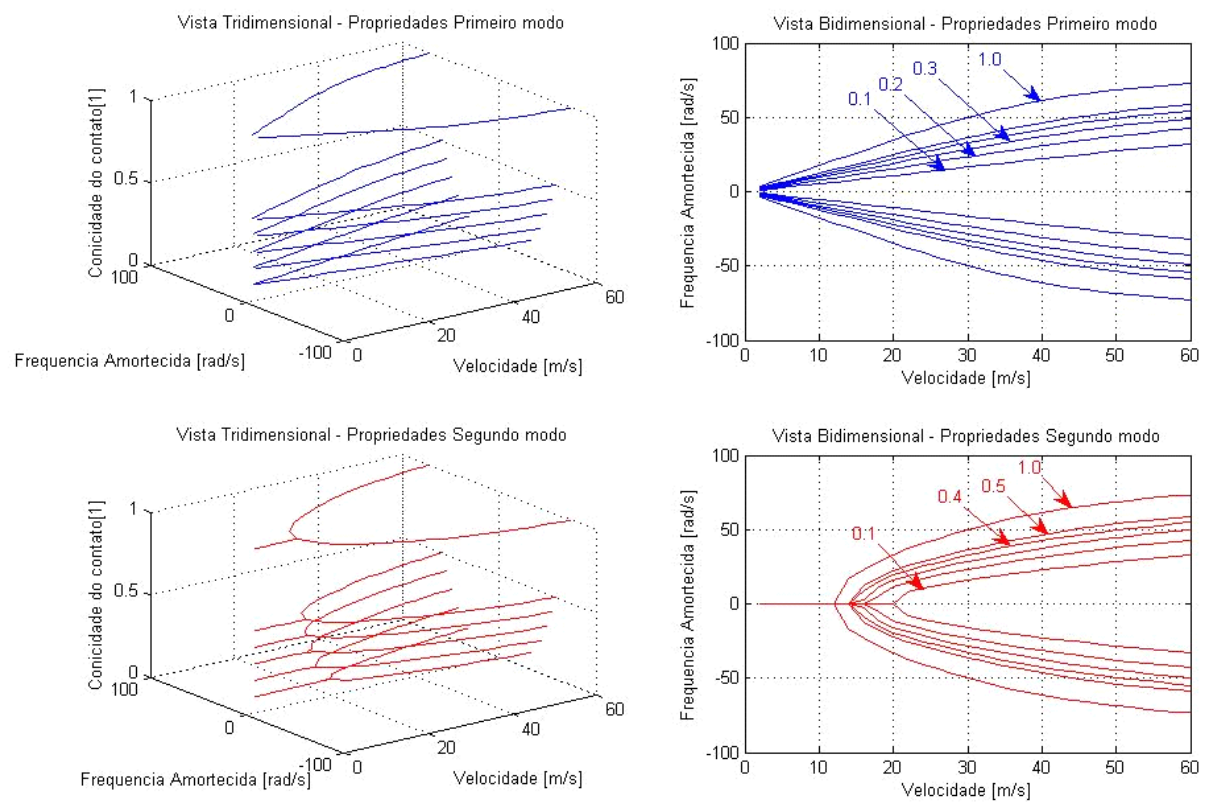

Figura 25: Comportamento da freqüencia amortecida do primeiro (em azul) e segundo (em vermelho) modos para conicidade crescente

A conicidade igual a 1 gera um gradiente mais acentuado para velocidades entre $2 \mathrm{~m} / \mathrm{s}$ e $30 \mathrm{~m} / \mathrm{s}$ do que para velocidades entre 40 e $60 \mathrm{~m} / \mathrm{s}$. De qualquer forma, a curva do comportamento da freqüência amortecida ao longo das crescentes velocidades para o primeiro modo (gráficos bi e tri-dimensionais da metade superior) deixa de ser linearmente crescente para se comportar de duas formas diferentes.

O segundo modo, metade inferior da figura 25, torna-se sub amortecido para velocidades menores, à medida que cresce a conicidade da roda. 

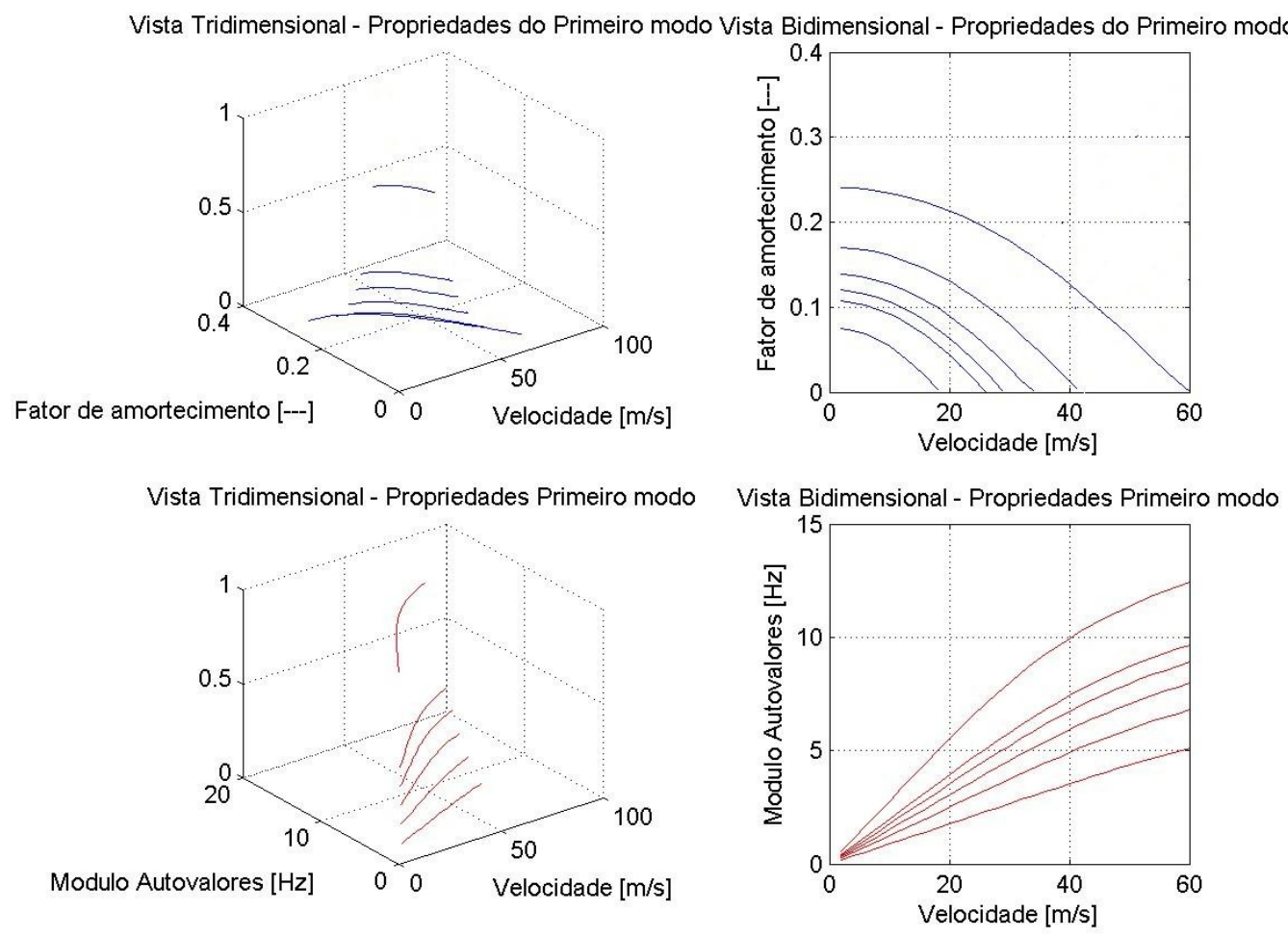

Figura 26: Comportamento do fator de amortecimento (em azul) e módulos de autovalores (em vermelho) do primeiro modo

O fator de amortecimento, conforme figura 26 , é de 0.25 para a velocidade de $2 \mathrm{~m} / \mathrm{s}$ ( $\lambda$ igual a 0.1$)$ e diminui consideravelmente para $0.08(\lambda=1.0)$, gráficos da metade superior. $\mathrm{O}$ amortecimento também se torna negativo em velocidades inferiores a $60 \mathrm{~m} / \mathrm{s}$ quando a conicidade cresce.

O módulo dos autovalores, metade inferior da figura 26, reflete um aumento à medida que a conicidade cresce. 

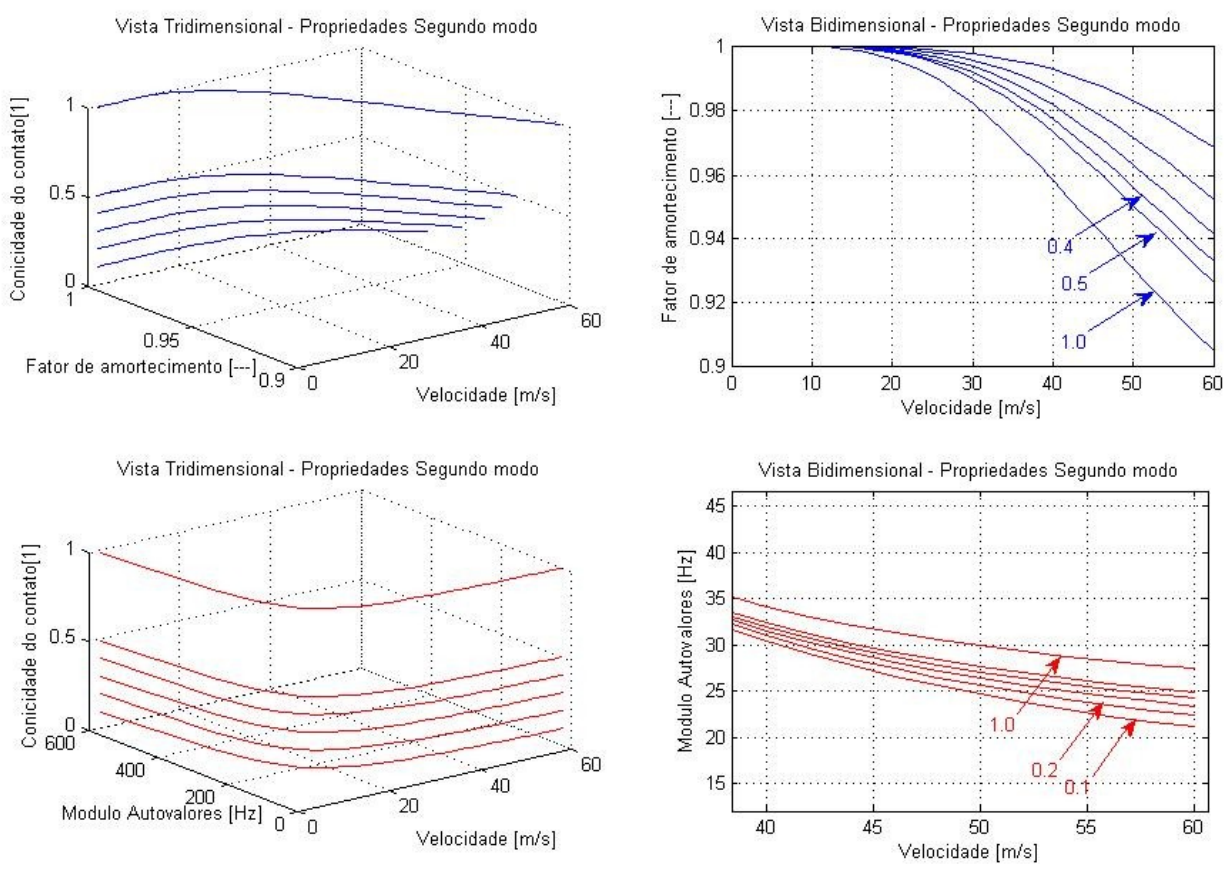

Figura 27: Comportamento do fator de amortecimento (em azul) e módulos de autovalores (em vermelho) do segundo modo

O amortecimento do segundo modo, representado pela figura 27 (curva azul), é menor que 1 para velocidades acima de $20 \mathrm{~m} / \mathrm{s}$, quando a conicidade é 0.1 . À medida que a conicidade aumenta, a curva do fator de amortecimento deixa de ser igual a 1 para velocidades menores. Essa característica é a responsável pelos autovalores se tornarem sub amortecidos, como foi mencionado na análise dos autovalores do segundo modo (figura 27).

Dessa forma, pode-se concluir que quando a conicidade aumenta:

- Freqüência aumenta;

- Velocidade crítica cai;

- Fator de amortecimento diminui. 


\subsection{Rodeiro sobre AMV}

Uma forma de analisar as solicitações externas a que se submete o rodeiro é através da análise do rodeiro atravessando um aparelho de mudança de via (AMV). Esta é a situação onde se encontra maior adversidade para inscrição do rodeiro e local de elevada incidência de acidentes (Barbosa, 1996).

A passagem pelo aparelho de mudança de via (AMV) pode ser descrita em quatro etapas. A etapa 1 (vide figura 28), o rodeiro desloca-se sem mudança de direção. Em seguida, o rodeiro sofre uma mudança brusca no ângulo de kick ou agulha, o que desloca o rodeiro lateralmente. Nessa parte do trecho, o rodeiro se move $15 \mathrm{~m}$. Na terceira etapa, o rodeiro se desloca $2 \mathrm{~m}$ pela curva de transição, descrita como uma curva de raio infinito que gradualmente se torna em uma curva de raio de $300 \mathrm{~m}$. A esse tipo de curva de raio variável dá-se o nome de Clotóide, vide figura 15. Em seguida, na etapa 4, o rodeiro percorre 40m em curva de raio constante e igual a $300 \mathrm{~m}$.

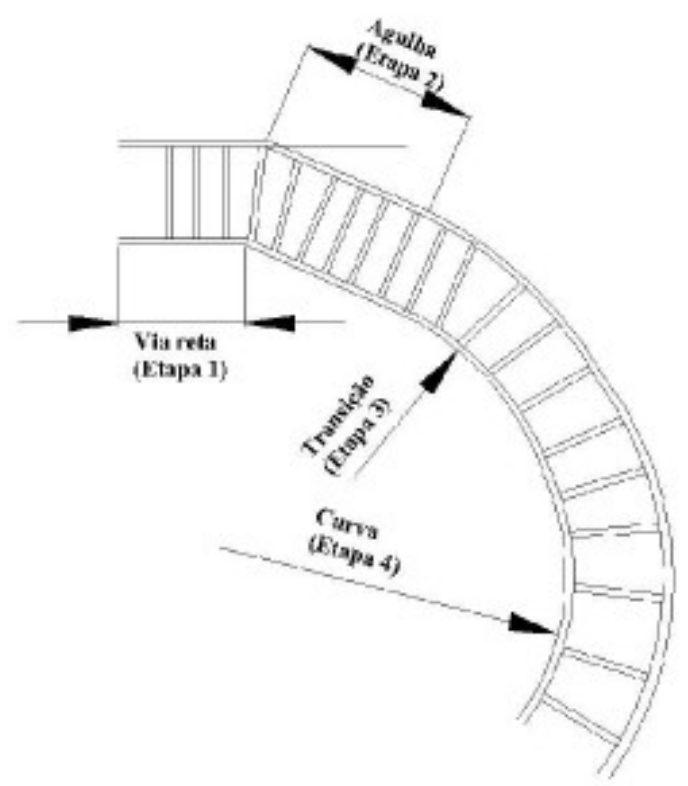

Figura 28: Descrição do $A M V$

O cálculo do raio de transição na curva de transição, dependente do avanço do rodeiro, é apresentado a seguir: 


$$
\frac{1}{R}=\frac{1}{R_{0}} \frac{s}{s_{0}}
$$

onde R é o raio final da curva e $s_{0}$ é a posição na curva de transição. A solução numérica através da integração em passo fixo do modelo linear do rodeiro permite a entrada equivalente à passagem pelo AMV.

A entrada da agulha do AMV é criada através de uma simplificação que simula um trecho reto de grande curvatura representado através do pulso de curvatura de valor $R=\frac{V_{0} \Delta t}{\alpha}$. O incremento do tempo utilizado é $\Delta t=0.01 \mathrm{~s}$.

A simulação do rodeiro, ao atravessar o AMV, é apresentado pela figura 31. A resposta do sistema é calculada através do comportamento do ângulo de yaw e do deslocamento lateral do rodeiro uma vez que a mesma origem do sistema de coordenadas está posicionada no centro da via e viaja na mesma velocidade $V_{0}=20 \mathrm{~m} / \mathrm{s}$.

A inscrição no Aparelho de Mudança de Via (AMV) passa pelo ângulo da agulha que gera uma mudança repentina do ângulo de ataque do rodeiro. Em seguida, o rodeiro passeia lateralmente cerca de $27.5 \mathrm{~mm}$ e gira um ângulo de yaw de $18.5 \mathrm{mrad}$ até entrar na curva de transição. Logo após a curva de transição, o rodeiro sofre um deslocamento de $11.0 \mathrm{~mm}$ e estabiliza em $16.0 \mathrm{~mm}$. Considerando que a partir de $6.2 \mathrm{~mm}$ a roda de perfil UIC60 se aproxima do contato com o friso, ao se deslocar $11.0 \mathrm{~mm}$ a roda certamente terá um comportamento não linear no contato com forte presença do componente gerado pelo escorregamento de pivotamento. Dessa forma, esse estudo demonstra a intensidade dos esforços gerados na passagem pelo aparelho de mudança de via, além de identificar os pontos onde ocorrerão os deslocamentos e ângulos máximos. 


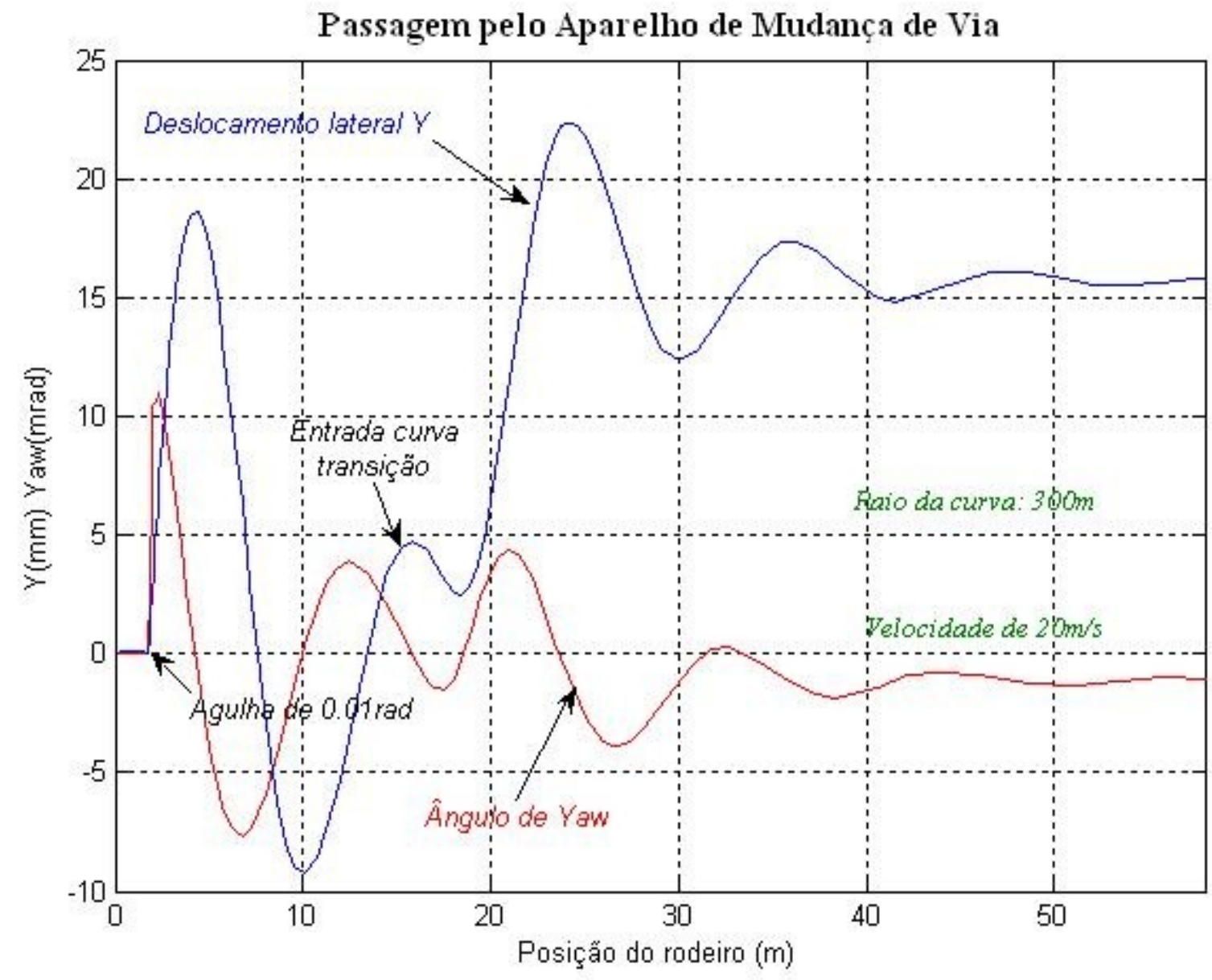

Figura 29: Resultado da simulação numérica do rodeiro 


\subsection{Conclusões}

A simulação do rodeiro atravessando um aparelho de mudança de via permite observar os locais de altos deslocamentos. Percebem-se as inversões de movimentos no comportamento dinâmico do rodeiro quando ele atravessa a curva de transição e em seguida a curva de raio $300 \mathrm{~m}$. As amplitudes do passeio lateral e angular alcançam valores elevados e em seguida o modelo se estabiliza numa posição de equilíbrio dinâmico em torno de $16.0 \mathrm{~mm}$ e $1.5 \mathrm{mrad}$. Os resultados estão dentro do esperado e concordam com Barbosa (1996).

O modelo, embora linear, mostra o comportamento do rodeiro na interação com o aparelho de transição de vias criando subsídio para a concepção de projetos de rodeiro que venham a precisar atravessar esses tipos de vias e fornecendo base para o entendimento das características do sistema dinâmico, necessárias para a implementação do modelo tridimensional não linear. 


\section{MODELO NÃO LINEAR}

$\mathrm{Na}$ elaboração do modelo matemático, a representação do comportamento dinâmico depende do conhecimento das forças de contato. No escorregamento entre superfícies de contato em que não existe variação no raio de rolamento, a velocidade relativa entre as partículas não é a mesma. Como o contato roda-trilho possui curvatura variável, o escorregamento também se torna variável.

Devido às deformações elásticas locais, ao rolar um corpo sobre o outro, os pontos de cada superfície que se tocam, continuam lado a lado durante a passagem pela zona de contato até o limite em que as contrações tangenciais (dependentes da pressão normal e do coeficiente de atrito) superem o valor máximo.

As diferenças de velocidade geram as deformações locais entre as partes em contato. Ao se deslocar lateralmente, as velocidades longitudinal e lateral tangenciais no rodeiro mudam. Além dos escorregamentos longitudinal e lateral, a diferença de inclinação entre o plano de contato e o eixo do rodeiro cria uma componente de rotação neste plano. Esse componente de rotação é conhecido como escorregamento de pivotamento. Porém, como há componente de escorregamento neste plano, determina-se o centro instantâneo de rotação angular, com o qual chega-se aos escorregamentos gerados pelas velocidades tangenciais. A combinação dos efeitos no contato será responsável pelas forças tangenciais que governam o comportamento do rodeiro.

\section{1 Disposição espacial da geometria do modelo}

Em programas de simulação com multicorpos, a localização do ponto de contato determina as diferenças de velocidade entre os corpos. A figura 30 apresenta a descrição da geometria do modelo. 


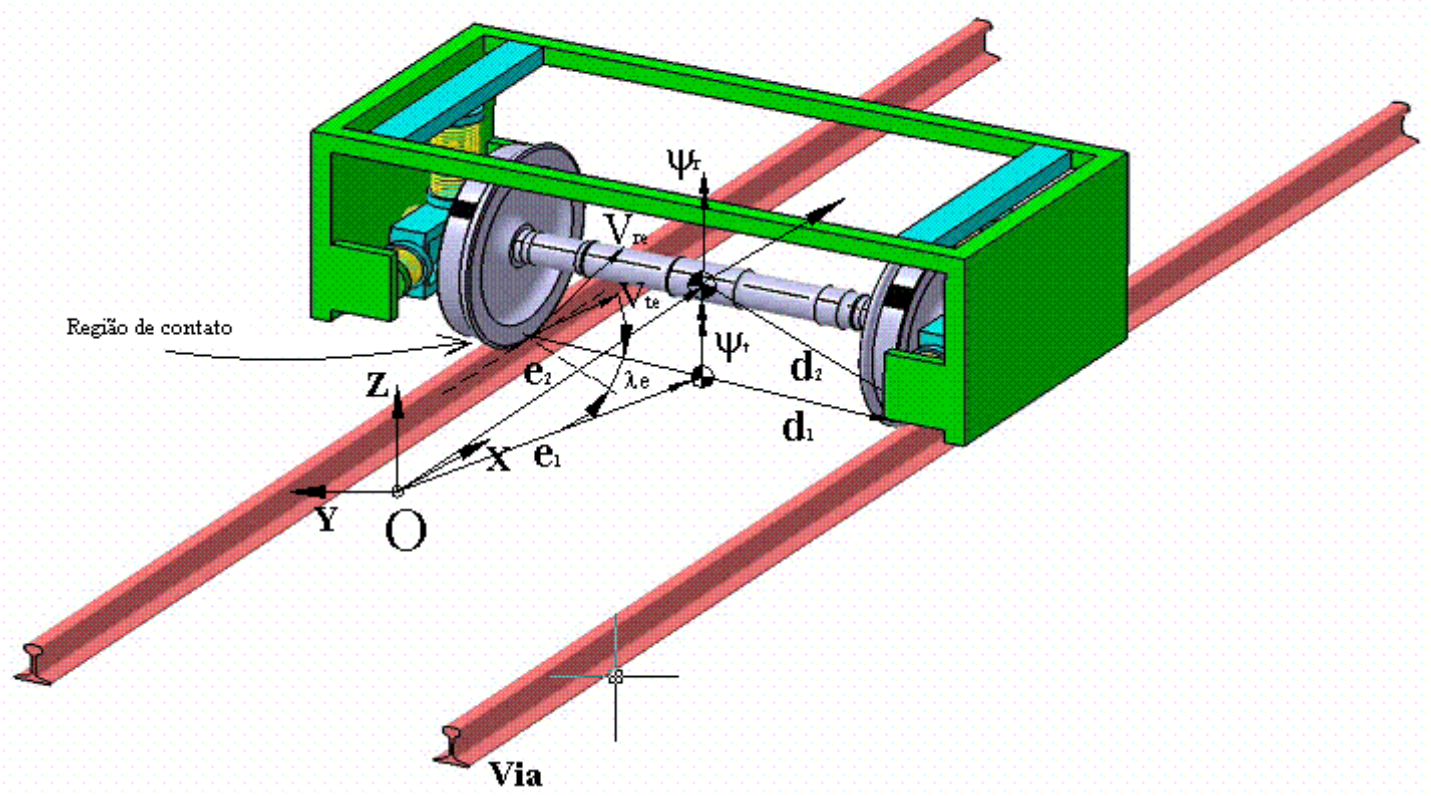

Figura 30: Identificação das referências Global e Local e região de contato roda trilho

Os movimentos de corpo rígido do rodeiro são representados por seu deslocamento lateral e angular com relação ao trilho. Em programas de multicorpos, o escorregamento pode ser obtido diretamente através da diferença entre as velocidades de cada ponto de contato normalizada pela velocidade de translação. $\mathrm{O}$ posicionamento do ponto de contato no espaço é determinado pelos vetores $e_{1}$ e $e_{2}$ no lado esquerdo da roda e trilho e $d_{1} e d_{2}$ para o ponto do contato direito.

Definido as velocidades $V r_{1,2}$ como as velocidades da superfície da roda esquerda e direita $(1,2)$ e $V t_{1,2}$ como as velocidades dos trilhos, tem-se que os escorregamentos no plano de contato são determinados como:

$$
\vec{T}=\frac{\vec{V} r-\overrightarrow{V t}}{\left|V_{0}\right|}
$$

E em função da inclinação do plano de contato tem-se o escorregamento por pivotamento gerado através da diferença de velocidades angulares entre a roda e o trilho e pela projeção de rotação do rodeiro $\Omega$ sobre o plano de contato definido por $\lambda$ :

$$
\vec{\Omega}_{p}=\left(\Psi_{r}-\Psi_{t}\right)+(\Omega \operatorname{sen} \delta)
$$




\section{2 Geometria de contato}

As propriedades de contato são determinadas a partir da identificação da posição geométrica do rodeiro em relação à via. Isso é feito deslocando lateralmente $\mathrm{o}$ rodeiro e calculando à medida que o mesmo se desloca suas propriedades geométricas.

O primeiro passo será dado com o conhecimento do perfil de cada roda e suas distâncias do rodeiro, do perfil do trilho de cada lado, inclinação do trilho e a distância das faces internas dos boletos. Uma outra opção é a determinação das dimensões através da geração normalizada seguindo as instruções de normas especializadas (UIC, AAR, etc). Uma vez discretizados os pontos que representam a geometria dos perfis, podem-se calcular as funções que melhor os representam no espaço, através de "splines" cúbicas.

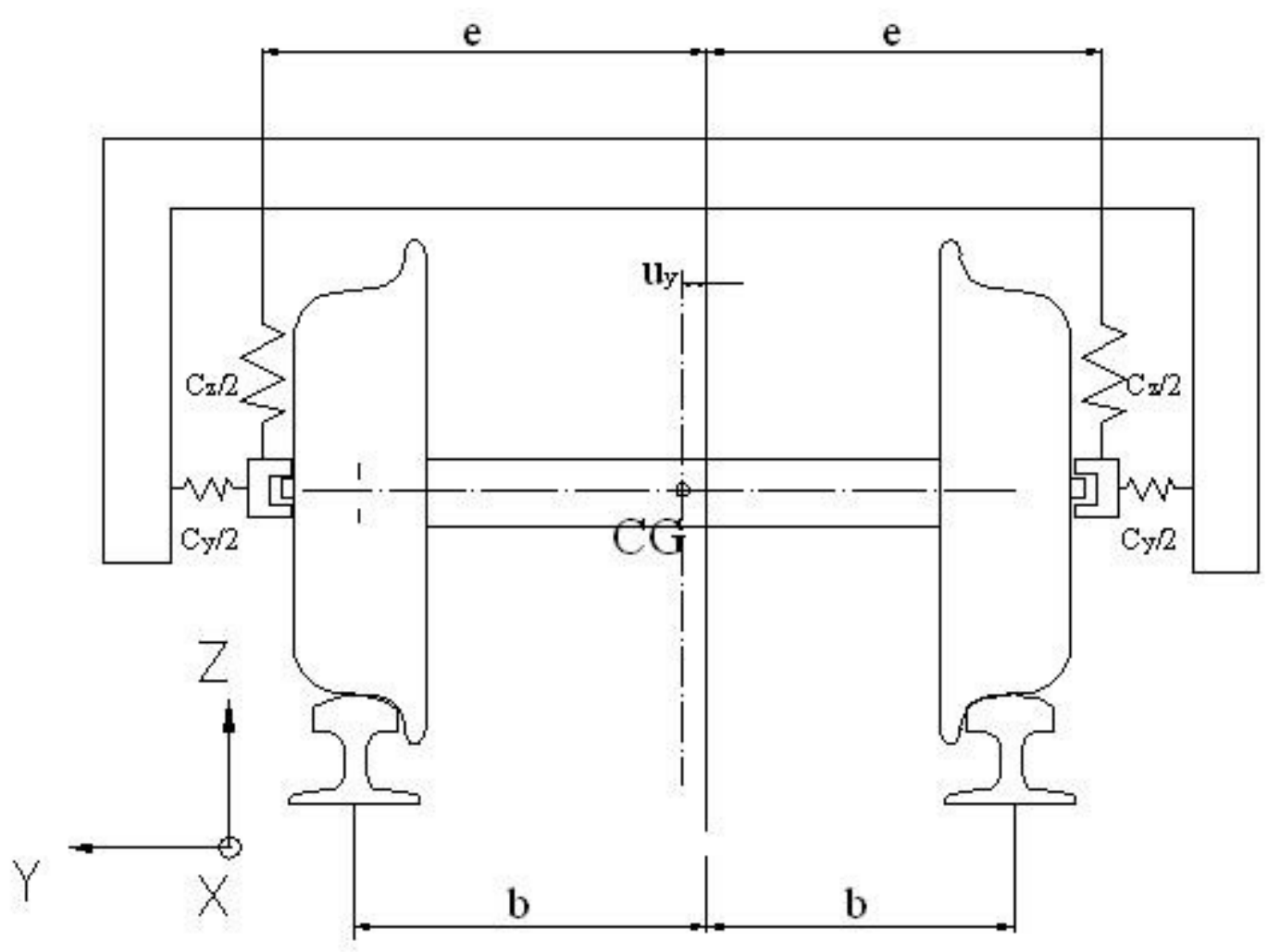

Figura 31: Disposição do rodeiro na via 
Na figura 31, apresenta-se a disposição do rodeiro na via. Com base no sistema de coordenadas YOZ, posicionado no centro da via, a posição lateral do rodeiro é dada pelo afastamento lateral $u_{y}$. Essa mesma apresentação também é A determinação da posição angular do rodeiro $\phi$ capresentada por Barbosa, 1999. om relação a via é feita através da determinação da distância mínima entre roda e trilho de cada lado.

$$
\begin{aligned}
D_{E, D(\min )} & =\operatorname{Pr}_{E, D}\left(f\left(\operatorname{Pr}_{E, D}, \phi\right)\right)-P t_{E, D} \\
\phi & =\tan ^{-1}\left(\frac{D_{E, D(\text { min })}}{b}\right)
\end{aligned}
$$

Através do afastamento $u_{y}$ e de uma estimativa inicial $\phi_{0}$, determina-se as distâncias mínimas entre os perfis e a localização dos pontos de contato. Esses valores são então usados para se calcular através da equação 128 o valor de $\phi$. Se o cálculo de $\phi$ está dentro da margem de erro $\varepsilon$ esperado, calcula-se os pontos de contato, caso contrário, o valor calculado é usado no lugar do valor estimado inicialmente. Essa lógica pode ser melhor apresentada pelo diagrama da figura 32. 


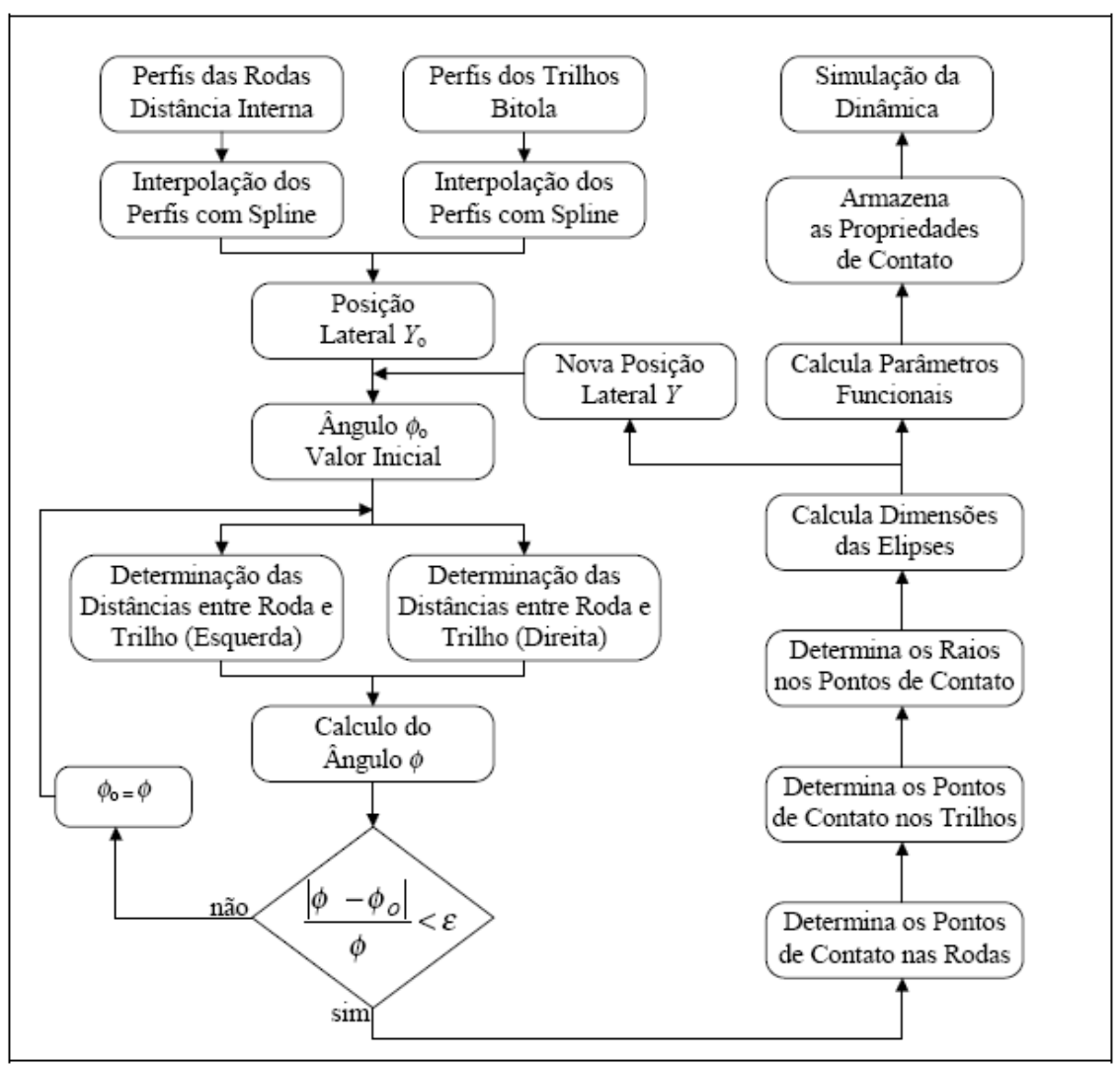

Figura 32: Representação lógica para cálculo das propriedades de contato (Barbosa, 1999)

Após a determinação dos pontos de contato, calcula-se os raios de contato $r_{t(D, E)}$ e $r_{r(D, E)}$ do trilho e da roda levando-se em consideração as splines dos perfis. Conforme mencionado na seção 2.1, Hertz mostrou que o contato gera uma região elíptica. A solução geral pode ser encontrada e consultada em diversas referências (Kalker, 1979a, Barbosa,1999).

\subsubsection{Análise da deformação elástica no contato}

A análise da deformação elástica no contato é realizada com base na deformação desenvolvida no contato roda-trilho. 


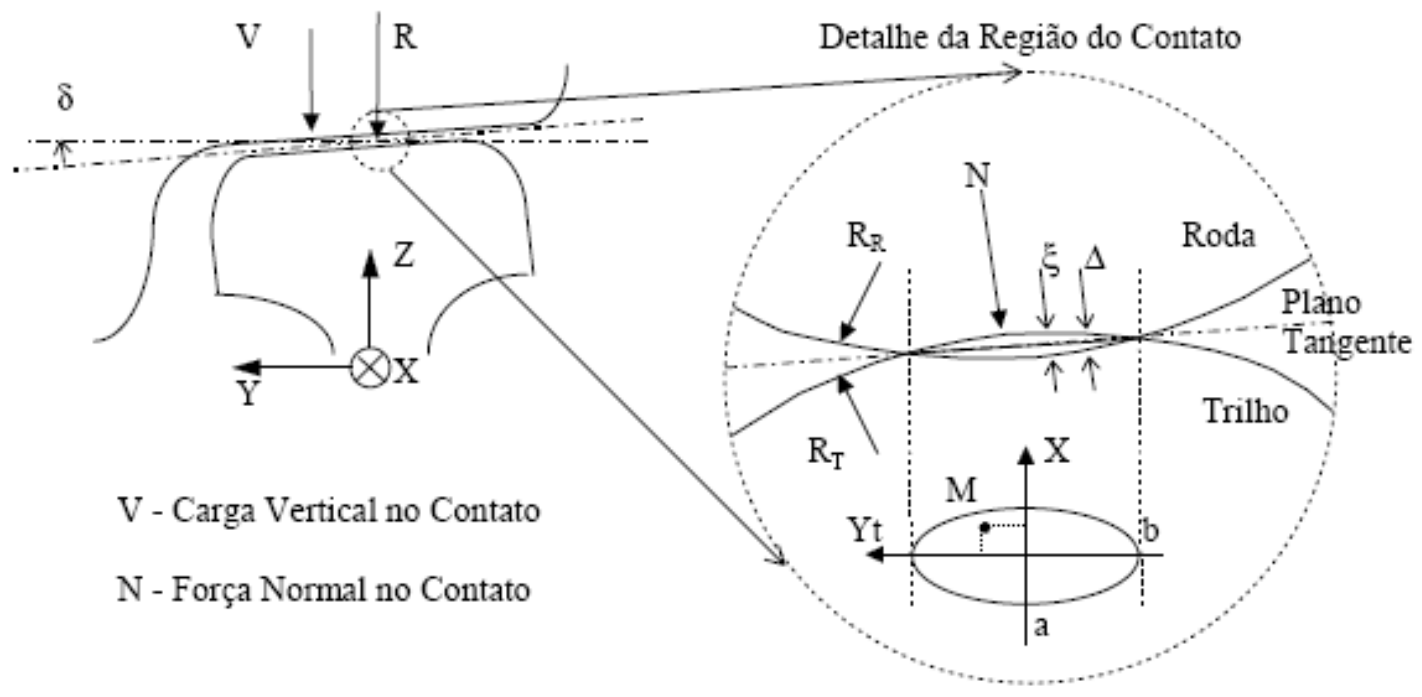

Figura 33: Detalhes das deformações nas regiões de contato (Barbosa, 1999)

A distância $\Delta$ é calculada conforme a expressão quadrática de Taylor:

$$
\Delta=A u_{x}^{2}+b u_{y}^{2}-\xi
$$

sendo $A=\frac{\cos \delta}{2 \mathrm{R}}$ e $B=\frac{1}{2 R_{r}}+\frac{1}{2 R_{t}}$.

Para valores entre $0^{\circ}$ e $90^{\circ}, \Theta$ pode ser calculado como segue:

$$
\Theta=A \cos \left(\frac{|A-B|}{|A+B|}\right)
$$

$a=n C N^{\frac{1}{3}}, b=m C N^{\frac{1}{3}}$ e $\xi=r|A+B| C^{2} N^{\frac{2}{3}}$. Nessas condições os valores de a e b são calculados para $\frac{A}{B} \geq 1$. Para o caso $\frac{A}{B} \leq 1$, inverte-se as posições entre $\mathrm{n}$ e $\mathrm{m}$. Os valores de m, n, r são calculados em função de integrais elípticas.

$$
C=\left[\frac{3}{2} \frac{1-v^{2}}{G|A+B|}\right]^{\frac{1}{3}}
$$

O cálculo do componente normal do contato é dado por $N=\frac{V}{\cos \delta} \cdot$ E a distribuição das pressões normais na região da elipse de contato:

$$
P=\frac{3 N}{2 \pi a b} \sqrt{1-\left(\frac{u_{x}}{a}\right)^{2}-\left(\frac{u_{y}}{b}\right)^{2}}
$$


Essa solução considera as deformações na região nos pontos de contato. Foram desenvolvidos métodos para o cálculo de propriedades considerando a deformação elástica entre os corpos. Essa técnica possui muita utilidade em casos em que se consideram múltiplos pontos de contato.

As propriedades de contato são calculadas previamente, antecedendo a simulação. O ângulo de inclinação $\phi$ do rodeiro, o ângulo do plano de contato $\lambda \mathrm{e}$ os raios de rolamento (perfis das rodas) também serão indispensáveis durante os cálculos da simulação. Ao gerar as propriedades de contato antes da simulação, se ganha em tempo e centralizam-se as atenções para a solução das equações diferenciais criadas na modelagem. As propriedades de contato são reunidas a seguir para os perfis UIC60 (trilho) e S1002 (roda) e inclinação de 1/40.

Essas propriedades foram geradas para a análise do modelo não linear do rodeiro que será discutido no item posterior.

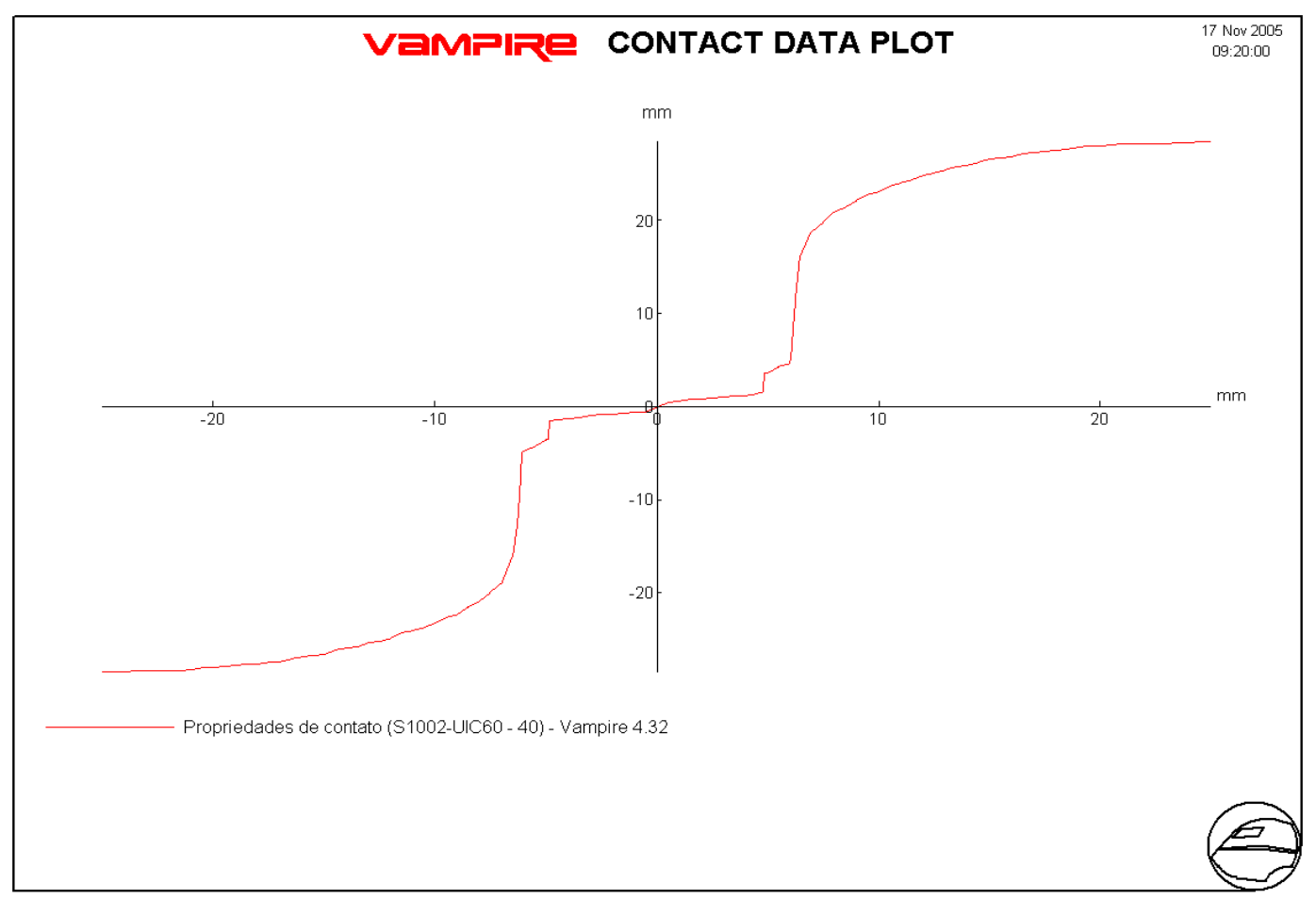

Figura 34: Diferença entre os raios de rolamento 


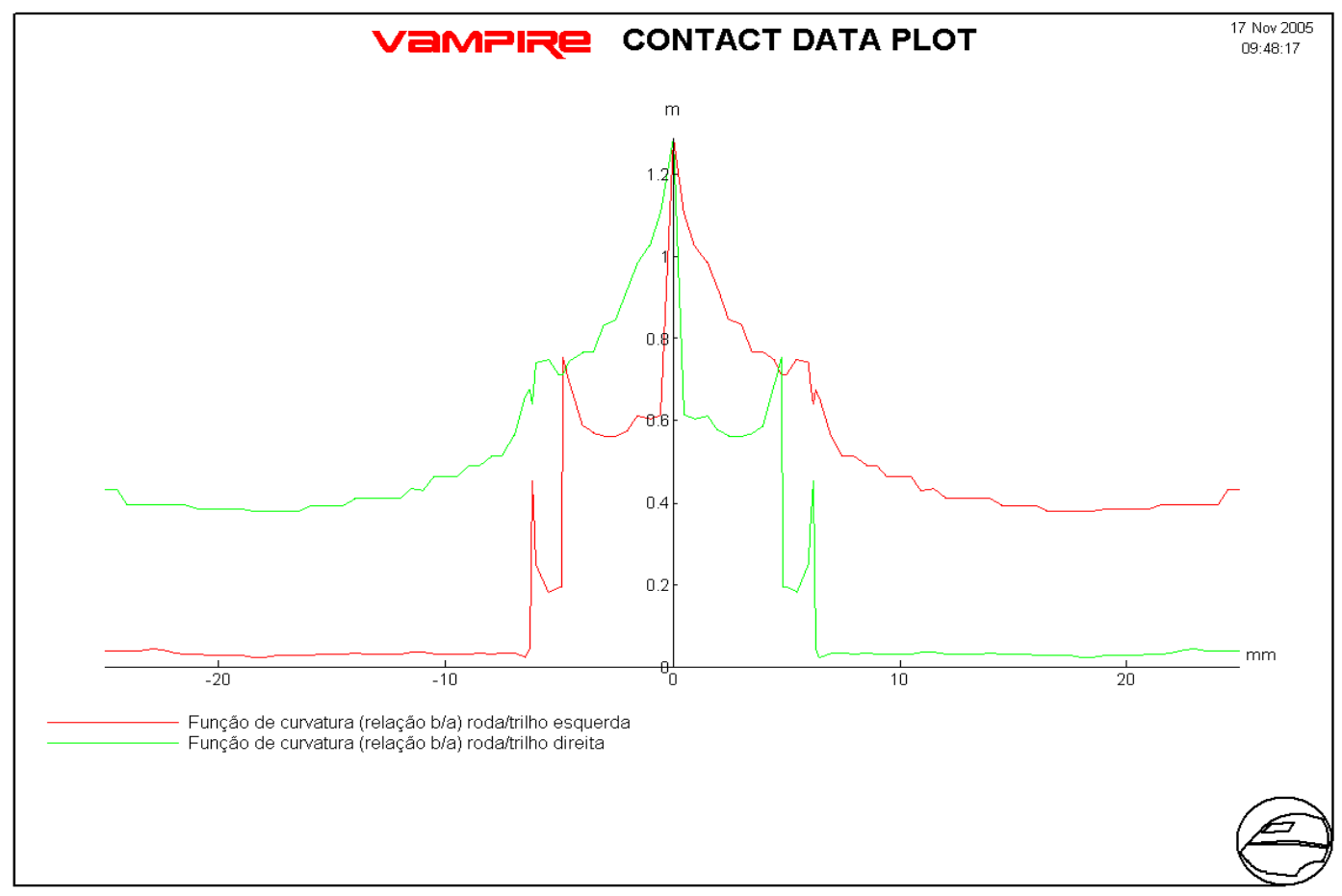

Figura 35: Relação entre as dimensões da elipse de contato

O gráfico nas figuras 34 e 35 mostram que as propriedades do par de rolamento são bastante não lineares e muito dependentes do formato dos perfis. Ao se aproximar da região de interface entre o friso e o boleto do trilho a diferença dos raios de rolamento apresenta descontinuidade visível. O mesmo pode ser observado nas proporções da elipse de contato(figura 35), próximo da região de posicionamento centralizado. A partir de $7 \mathrm{~mm}$, as proporções se mantém relativamente constantes.

\section{3 Teoria da mecânica de contato}

Em condições de grandes escorregamentos solução não linear a força tangencial no contato torna-se limitada à Lei de Coulomb. A teoria da saturação do contato é responsável por determinar o limite da força tangencial em função do escorregamento que aparece entre as duas superfícies.

Barbosa(1999) propõe como uma boa abordagem à utilização da rotina FASTSIM, desenvolvida por Kalker(1982a), para cálculo das forças tangenciais de contato de rolamento entre corpos rígidos, com escorregamentos tangenciais e 
rotacionais. Baseada na distribuição parabólica de pressão normal numa área elíptica, dependente do cálculo da relação a/b, a rotina do FASTSIM é bastante utilizada no área ferroviária. A rotina considera que na zona de contato, a lei de atrito de Coulomb é aplicada junto com a hipótese de proporcionalidade para os deslocamentos elásticos e deformações tangenciais.

O problema tangencial pode ser entendido através da abordagem de que o escorregamento de corpo rígido acontece ao mesmo tempo em que o deslocamento elástico relativo $\mathrm{U}$ entre as superfícies de contato.

$$
\vec{W}=V_{x}\left(\vec{T}+\vec{\Omega}_{p} \times O M-\frac{\partial}{\partial x} \vec{U}\right)
$$

Para a região de contato, o movimento permanece dentro da região de contato. Decompondo nas devidas direções:

$$
\begin{gathered}
\frac{W_{x}}{V_{x}}=v_{x}-u_{y} \phi-\frac{\partial U_{x}}{\partial x} \\
\frac{W_{y}}{V_{x}}=v_{y}-u_{x} \phi-\frac{\partial U_{y}}{\partial x}
\end{gathered}
$$

Utilizando os coeficientes $\left(L_{i}\right)$ de proporcionalidade, também conhecidos como flexibilidade do contato, pode-se obter uma relação entre os deslocamentos elásticos $U_{x, y}$ e as deformações geradas pelas forças tangenciais (Barbosa, 1999). Essa resolução, proposta inicialmente por Kalker(1967) é baseada na teoria da elasticidade.

$$
\begin{aligned}
& \frac{W_{x}}{L V_{x}}=\frac{v_{x}}{L_{1}}-u_{y} \frac{\phi}{L_{3}}-\frac{\partial t_{x}}{\partial x} \\
& \frac{W_{y}}{L V_{x}}=\frac{v_{y}}{L_{2}}-u_{x} \frac{\phi}{L_{3}}-\frac{\partial t_{y}}{\partial x}
\end{aligned}
$$

As deformações tangenciais são representadas por $t_{x, y}$.Os valores de $\left(L_{i}\right)$ podem ser obtidos da teoria linear simplificada (Kalker, 1991 apud Barbosa, 1999) junto com os coeficientes de rigidez de contato $C_{i j}$ tabelados em diversas publicações (Kalker, 1979a; 1990c; 1991, Barbosa, 1999).

$$
L_{1}=\frac{8 \mathrm{a}}{3 G C_{11}} \quad L_{2}=\frac{8 \mathrm{a}}{3 G C_{22}} \quad L_{3}=\frac{\pi a}{4 G C_{23}} \sqrt{\frac{a}{b}}
$$


O mesmo sistema pode ser apresentado resumidamente como:

$$
\vec{W}\left(u_{x}, u_{y}\right)=\vec{s}\left(u_{x}, u_{y}\right)-\frac{\partial}{\partial x} \vec{t}\left(u_{x}, u_{y}\right)
$$

A integração de primeira ordem é feita sobre a elipse de contato discretizada em espaços retangulares. Aplica-se sobre cada elemento uma pressão normal $P\left(u_{x}, u_{y}\right)$ igualmente distribuída.

Discretização da Malha para Cálculo da Forças Tangenciais $\mathrm{T}_{\mathrm{x}}, \mathrm{T}_{\mathrm{y}}-\left(\mathrm{m}_{\mathrm{x}}=5 ; \mathrm{m}_{\mathrm{y}}=6\right)$

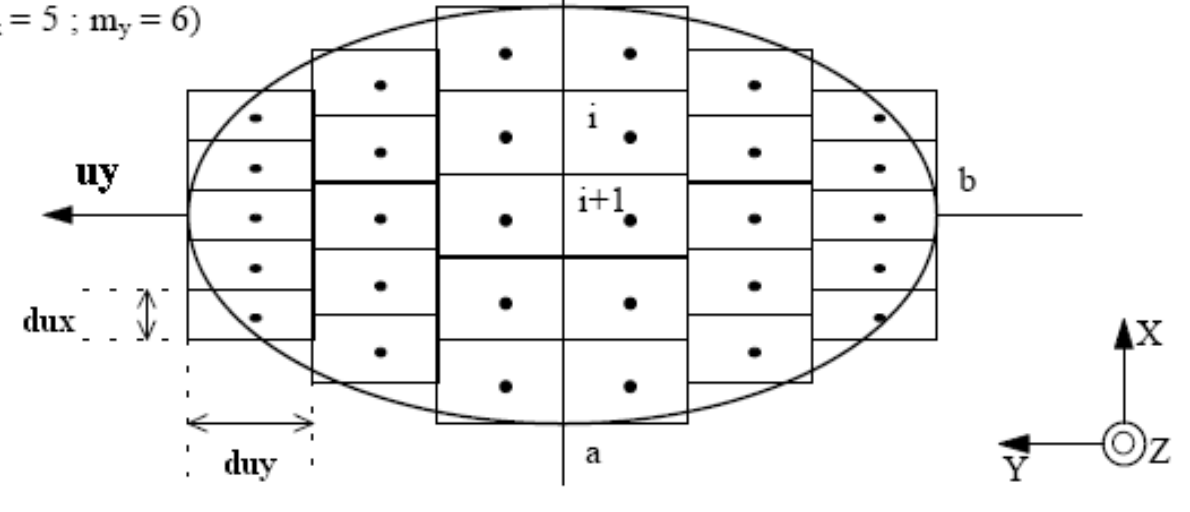

Figura 36: Discretização da elipse de contato (Barbosa, 1999)

$$
P_{\left(u_{x}, u_{y}\right)}=\frac{3 N}{2 \pi a b} \sqrt{1-\left(\frac{u_{x}}{a}\right)^{2}-\left(\frac{u_{y}}{b}\right)^{2}}
$$

A força tangencial no contato depende da soma dos esforços em cada retângulo discretizado na elipse de contato. É encontrado em Barbosa(1999) um exemplo do cálculo das tensões tangenciais em uma situação típica de contato: 


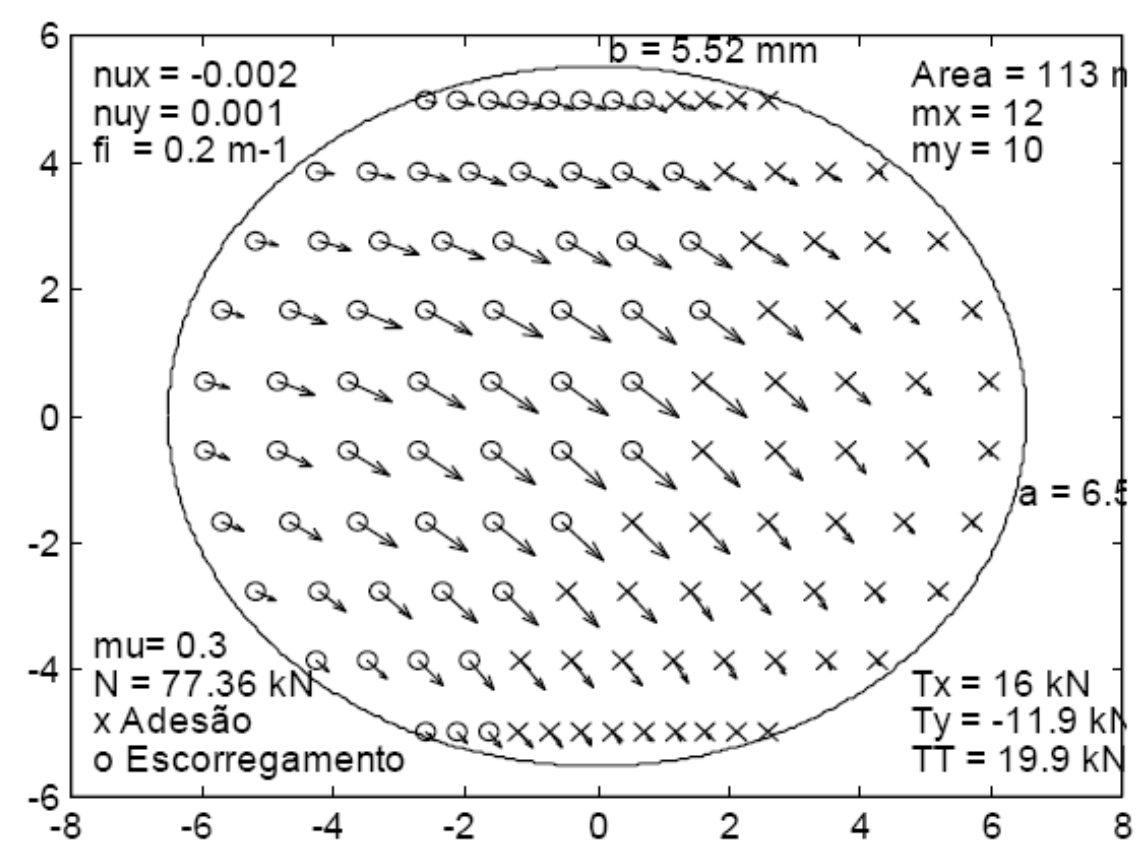

Figura 37: Distribuição de tensões tangenciais (Barbosa, 1999)

Onde: $n u x=v_{x} \quad, \quad n u y=v_{y} \quad, f i=\phi \quad m u=\mu \quad, \quad T x=F_{x}, T y=F_{y}$.

Para maiores esclarecimentos, consulte a lista de símbolos. A área de adesão é representada por "x" e a área de escorregamento como "o". Se o esforço de cada retângulo for somado, o esforço resultante no conjunto de retângulos será responsável pela força tangencial naquele instante. Nesse exemplo, o escorregamento está presente na metade à esquerda da elipse e a adesão prevalece na metade direita.

As forças tangenciais são a conseqüência imediata ao aparecimento da diferença entre a velocidade de rotação e a velocidade de translação em função da variação dos deslocamentos relativos entre os corpos. Sendo assim, as forças tangenciais, desenvolvidas na zona de contato, são proporcionais ao escorregamento presente entre as duas superfícies e podem ser apresentadas como $F_{x, y, z}=f\left(u_{x, y, z}\right)$. Os valores do escorregamento são determinados com o conhecimento das velocidades relativas e de translação.

Barbosa(1999) realizou ensaios para verificar a rigidez de contato e eles se aproximam dos valores tabelados de Kalker, com variações em torno de 3\%. Com o auxílio da rotina do FASTSIM, comparou-se à curva de saturação teórica com os 
resultados dos ensaios e a concordância também é boa. O algoritmo FASTSIM é a aplicação da teoria de contato de rolamento e baseia-se na teoria da distribuição elíptica de Hertz, na lei de saturação de Coulomb e na hipótese de proporcionalidade entre as deformações elásticas das superfícies de contato. Assim, Barbosa(1999) confirmou que essa rotina apresenta boa representatividade do fenômeno físico.

\section{4 Elaboração do modelo}

A elaboração de um modelo requer o conhecimento dos passos que devem ser seguidos para a obtenção de resultados seguros e de boa representatividade física. E está relacionado a um bom conhecimento do sistema real a ser modelado. Dispondo de exemplos de resultados em modelagem e do comportamento médio esperado do modelo, a adequada representatividade do modelo é alcançada com a adequada descrição matemática fundamentada para obtenção das equações diferenciais. A estabilidade do processo de integração numérica é alcançada através de pacotes de simulação reconhecidamente validados na área de dinâmica ferroviária. Conforme se aumenta o grau de complexidade do modelo, o processo numérico torna-se imprescindível para a garantia da solução. A profundidade em que se busca abordar o estudo dinâmico do modelo também é importante porque define as limitações que são aceitas para o modelo e o tempo de processamento que se desprenderá na obtenção da solução. Um modelo em que a solução linear é aceitável terá um tempo de processamento muito menor. Porém suas limitações são maiores e devem ser mencionadas. Por fim, a interpretação dos resultados determina se o projeto atende as exigências esperadas ou se o mesmo precisa de algumas modificações.

A comprovação da representatividade do modelo acontece ou pela comparação com resultados experimentais ou com resultados de outras fontes confiáveis. No caso de um rodeiro submetido a uma força lateral externa, proposta de estudo da IAVSD. Essa proposta define as características do modelo e apresenta os resultados alcançados com o modelo proposto. $\mathrm{O}$ engenheiro de projeto assume a responsabilidade em alcançar resultados similares e identificar as coerências com o 
resultado do "benchmarck". O programa de multicorpos utilizado nessa análise é o VAMPIRE (Vehicle Assembling Multibody Package). É um programa que é resultado da união de uma série de pacotes para a simulação na área ferroviária. Neste estudo é utilizado um programa para a geração das propriedades de contato (baseado na rotina FASTSIM), um editor para a criação do modelo no espaço e geração das equações de movimento, recursos numéricos avançados para a realização da integração das equações algébrico/diferenciais e um pacote para a visualização dos resultados.

Os parâmetros usados foram especificados no "benchmark\#1" e os detalhes de modelagem foram elaborados a premissa de fidelidade máxima com o caso proposto. A avaliação das forças de contato roda-trilho acontece ao se aplicar forças laterais no rodeiro para valores diferentes de coeficiente de atrito. Também são analisadas as relações L/V no descarrilamento.

\section{5 Proposta do benchmark\#1}

O modelo do benchmark\#1 é composto de dois corpos rígidos, a via e o rodeiro. A via se encontra ligada ao referencial inercial através de um junta que permite movimentos em $\mathrm{x}, \mathrm{y}, \mathrm{e} w_{z}$. À medida que o rodeiro atravessa um ponto na via, sua posição geométrica no espaço é registrada. O rodeiro liga-se a via através de uma junta do mesmo tipo que à da via com o referencial e nestas ligações aparecem às forças de contato roda-trilho. A suspensão primária é representada através de molas na direção longitudinal e lateral $\left(C_{x}\right.$ e $\left.C_{y}\right)$. O rodeiro tem liberdade de passeio em torno da linha central da via, movimento que é válido para o modelo. Os graus de liberdade são os deslocamentos longitudinal e lateral $\left(u_{x} e u_{y}\right)$ e as aberturas angulares na direção de "yaw" e rotação do eixo do rodeiro $\left(\begin{array}{llll}\varphi_{z} & e & w_{z}\end{array}\right)$. 


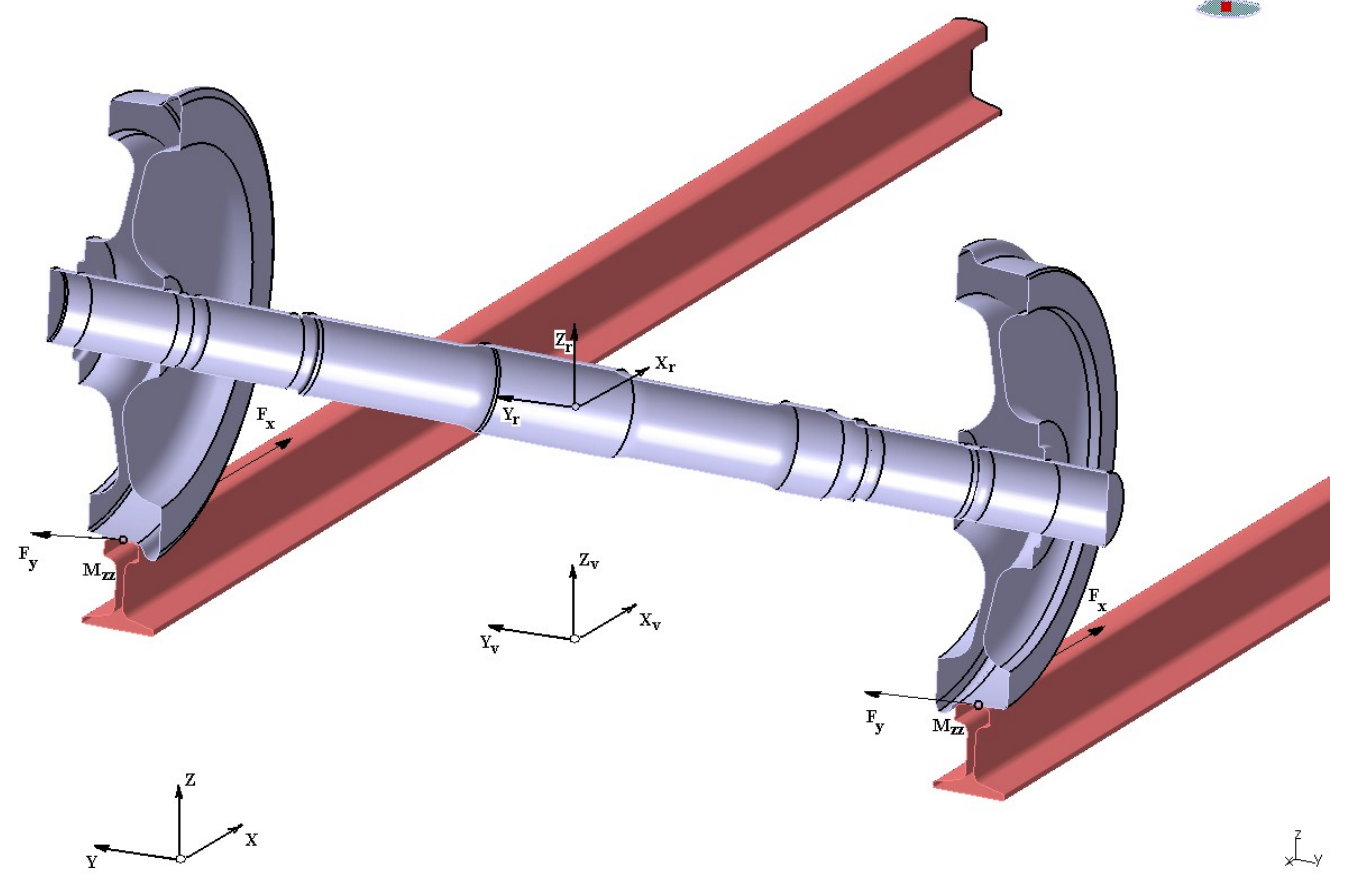

Figura 38: Forças no contato e referências global e local (via)

A orientação do rodeiro e da via são feitos pelos eixos $X_{R}, Y_{R} e Z_{R}$ e $X_{V}, Y_{V} e Z_{V}$. A referência da via viaja na mesma velocidade do rodeiro fazendo com que seu movimento seja medido em função de sua posição. Por sua vez, a referência da via é o eixo inercial $X, Y e Z$. Os movimentos dos corpos rígidos do rodeiro em relação à via permitem o cálculo dos escorregamentos que serão usados para a definição dos valores das forças tangenciais. O diagrama a seguir apresenta os passos envolvidos na determinação das forças de contato.

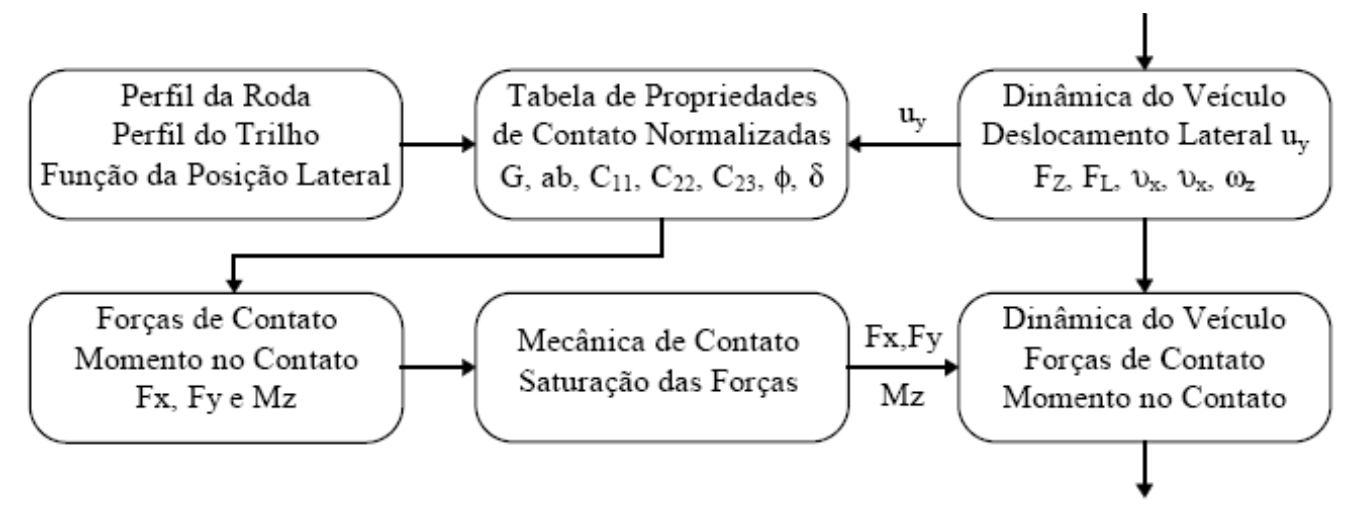

Figura 39: Rotina seguida no cálculo das forças de contato (Barbosa, 1999) 
As propriedades de contato são calculadas através do programa VAMPIRE considerando os perfis, definidos pela UIC, do trilho (UIC60) e da roda (S1002) inclinados uma razão 1/40. A bitola utilizada é de $1.435 \mathrm{~m}$ e o raio da roda é de $0.45 \mathrm{~m}$. Na tabela 1,são apresentados os dados fornecidos no "benchmarck\#1". O perfil da roda é cônico em sua região central até alcançar uma das extremidades onde está o friso. No passeio da região central até a mudança rápida de curvatura (friso), o rodeiro adquire uma rotação no eixo longitudinal $(\phi)$ e elevação do centro de massa $\left(u_{z}\right)$ que aparece em função da diferença de altura dos pontos de contato das rodas. O centro instantâneo de rotação serve de base para, através da rotação do eixo longitudinal, calcular as velocidades de contato $\left(V_{c}\right)$ de ambas as rodas.

A velocidades nos pontos de contato fazem parte das expressões para o cálculo da velocidade vertical e angular do Centro de massa do rodeiro.

$$
\dot{u}_{z}=\frac{\partial u_{z}}{\partial u_{y}} \frac{\partial u_{y}}{\partial t}=\frac{\partial u_{z}}{\partial u_{y}} \dot{u}_{y} \quad \dot{\phi}=\frac{\partial \phi}{\partial u_{y}} \frac{\partial u_{y}}{\partial t}=\frac{\partial \phi}{\partial u_{y}} \dot{u}_{y}
$$

Das velocidades, decorre o cálculo das acelerações:

$$
\ddot{u}_{z}=\frac{\partial u_{z}}{\partial u_{y}} \ddot{u}_{y}+\frac{\partial^{2} u_{z}}{\partial u_{y}{ }^{2}} \dot{u}_{y}{ }^{2} \quad \ddot{\phi}=\frac{\partial \phi}{\partial u_{y}} \ddot{u}_{y}+\frac{\partial^{2} \phi}{\partial u_{y}{ }^{2} u_{y}{ }^{2}}
$$

As expressões das acelerações e das velocidades determinam o movimento prescrito para os cinco graus de liberdade da seção da via, e contemplam o posicionamento geométrico nos eixos x, y, e rotação de "yaw" $\varphi_{z}$.

A proposta do Benchmark for Multibody Simulation Software da IAVSD (Pascal, 1993d) consiste na simulação temporal do comportamento dinâmico do rodeiro ferroviário para avaliação da técnica de multicorpos através do VOCO. Os dados de entrada do modelo são fornecidos na tabela a seguir: 
Tabela 1: Dados de entrada do modelo do benchmarck\#1

\begin{tabular}{l|l}
\hline Item & Dados de entrada \\
\hline Massa do Rodeiro & $1887 \mathrm{~kg}$ \\
Carga Vertical & $154715 \mathrm{~N}$ \\
Carga Vertical+ Peso do rodeiro & $173226 \mathrm{~N}$ \\
Rigidez Torcional $\left(\mathrm{K}_{\varphi}\right)$ & $81,6 \times 10^{6} \mathrm{mN} / \mathrm{rad}$ \\
Raio de Rolamento Central & $0,45 \mathrm{~m}$ \\
Bitola da Via & $1,435 \mathrm{~m}(14 \mathrm{~mm}$ abaixo do topo) \\
Perfil da Roda & $\mathrm{S}-1002$ \\
Perfil do Trilho & $\mathrm{UIC}-60-$ inclinação $1 / 40^{\circ}$ \\
Velocidade de Tráfego & $30 \mathrm{~m} / \mathrm{s}$ (constante) \\
\hline
\end{tabular}

As verificações previstas no benchmark são realizadas conforme as seguintes sugestões:

- Determinar na posição de equilíbrio atingida pelo modelo através da aplicação de uma força externa de $20 \mathrm{kN}$ as forças no contato, reações verticais e deslocamentos lateral e abertura do ângulo de yaw para diversos coeficientes de atrito da via;

- Observação do comportamento das forças de contato através da aplicação da força lateral variável (taxa de $50 \mathrm{kN} / \mathrm{s}$ ) até o descarrilamento;

- Determinação das relações $\mathrm{L} / \mathrm{V}$, máxima força de contato lateral e máxima força transversal nos trilhos para os diversos coeficientes de atrito da via.

Um resumo do modelo em análise é apresentado na figura 40: 


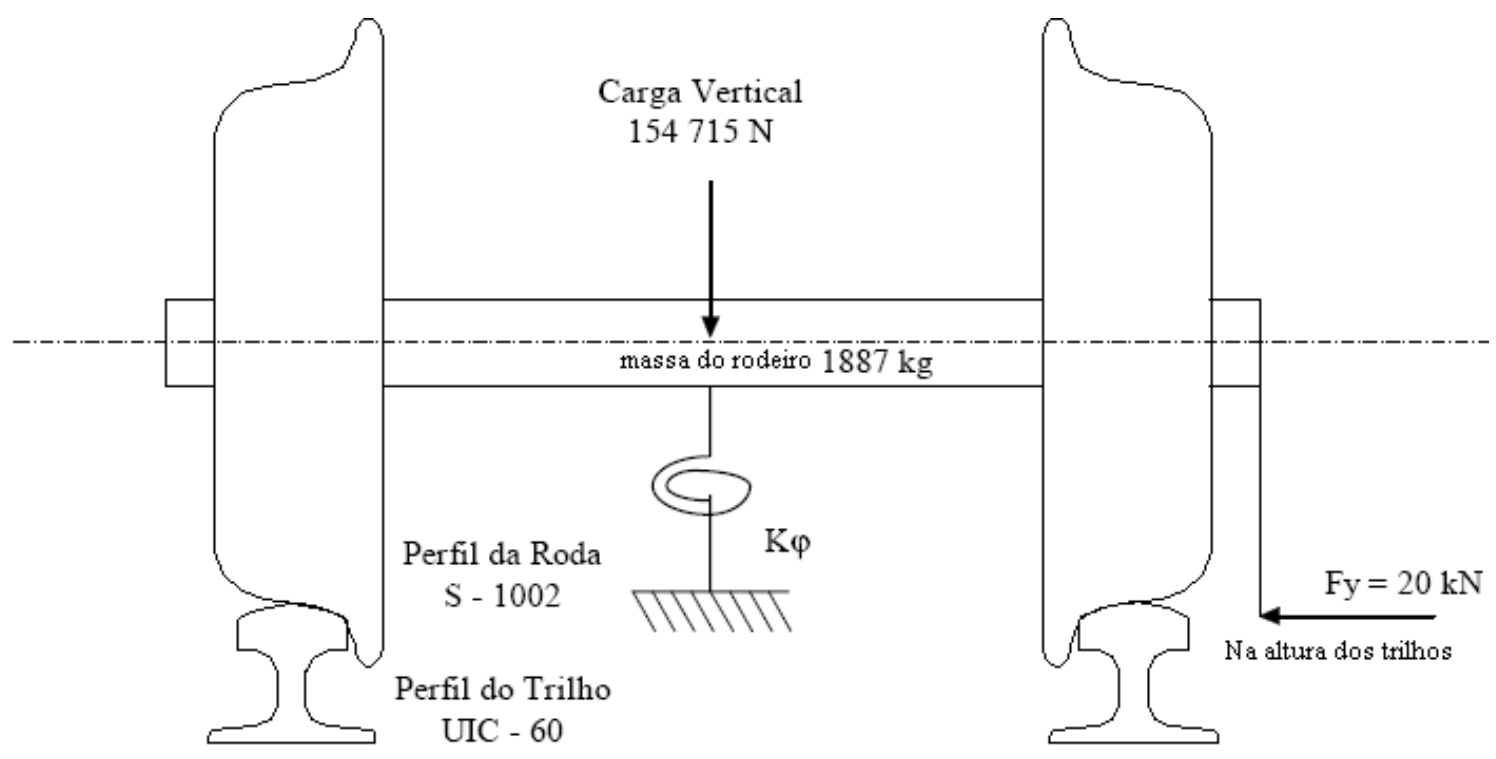

Figura 40: Ilustração do modelo proposto pela IAVSD

\section{6 Modelo da via}

O percurso entre duas localidades é estabelecido por uma via que é responsável pela guiagem do veículo. A trajetória segue as condições de construção as quais também são influenciadas pela topografia do terreno. Dessa forma, as irregularidades são estabelecidas nas direções lateral, vertical e de torção provocando acelerações no veículo ferroviário.

Em uma simulação, o conhecimento da atitude da via, ou seja, sua orientação e posição, fazem-se necessário para a realização da simulação, o que justifica sua descrição ao longo de toda sua extensão. O modelo de via utilizado move-se na mesma velocidade do $\mathrm{CG}$ do rodeiro e estabelecem em cada instante a posição, velocidades e acelerações linear e angular no espaço, que são imprescindíveis para o cálculo dos escorregamentos no contato e determinação das forças de contato. 
A via possui rijezas vertical, lateral e torcional, conforme segue na figura 41:

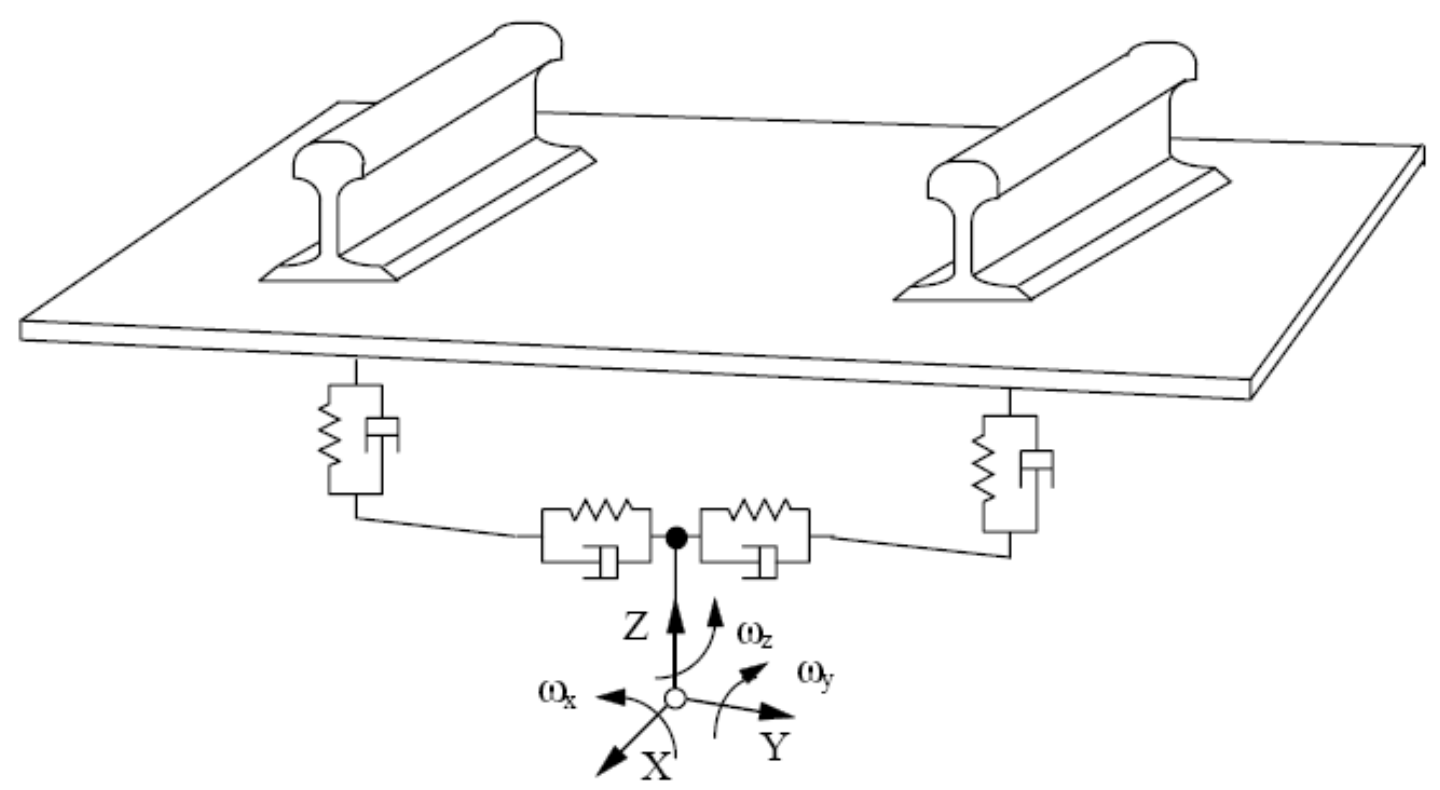

Figura 41: Disposição da via (Barbosa, 1999)

A trajetória da via é descrita através do triedro de Frenet e da geometria diferencial. Considerando um ponto qualquer P que percorre a curva $s$ no espaço tridimensional Euclidiano é localizado pelo vetor $r(t)$. O triedro de Frenet identifica as propriedades da curva, através dos versores $\mathrm{T}$ (tangente a curva), $\mathrm{N}$ (normal a T) e B (binormal a $\mathrm{T}$ e N). O plano Osculador é gerado pelos versores $\mathrm{T}$ e N. O plano Binormal é resultado dos versores N e B(figura 40). Por fim, o plano Retificante é gerado pelos versores T e B. A variação da direção de $\gamma$ é gerado pelo campo de vetores de curvatura $T^{\prime}$. A função de curvatura de $\gamma$ para um dado $s$ no espaço tridimensional é encontrado pelo valor real da função $\kappa$ como $\kappa_{(s)}=\left\|T^{\prime}{ }_{(s)}\right\|$. A torção é determinada pela função $\mathrm{B}^{\prime}=-\tau N$. Dessa forma, o triedro de Frenet é capaz de representar a curva dada por $\kappa_{(s)}$ para uma posição $\mathrm{P}(\mathrm{t})$ em s. O centro instantâneo de rotação da trajetória da via está na direção $N_{(s)}$ com raio $\kappa_{(s)}^{-1}$. 


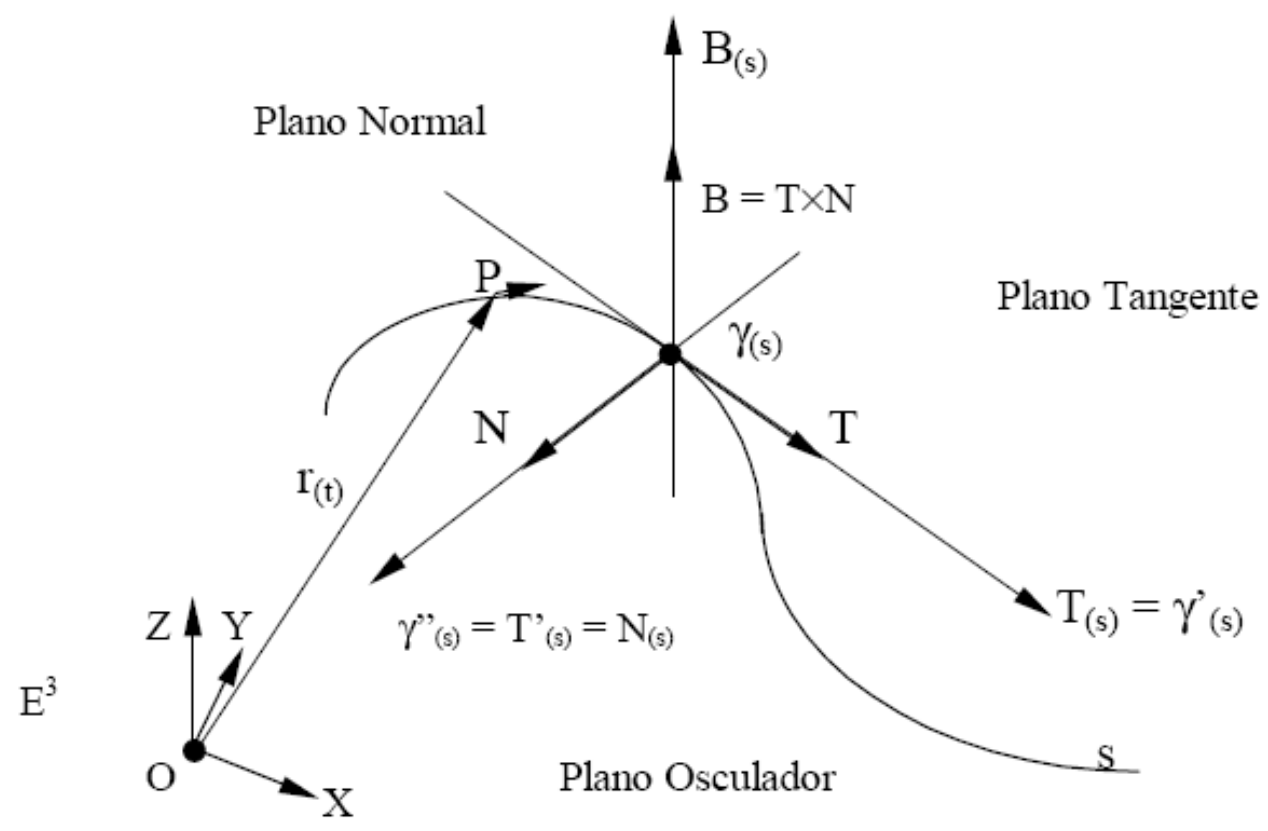

Figura 42: Localização de uma trajetória (Barbosa, 1999)

Em uma função de velocidade variável $v$, tem-se a seguinte forma matricial:

$$
\left\{\begin{array}{l}
T^{\prime} \\
N^{\prime} \\
B^{\prime}
\end{array}\right\}=\mathcal{v}\left[\begin{array}{ccc}
0 & \kappa & 0 \\
-\kappa & 0 & \tau \\
0 & -\tau & 0
\end{array}\right]
$$

Numa curva no plano XY com torção nula $(\tau=0)$, a velocidade do ponto $\gamma$ é determinada como $\gamma^{\prime}=\nu T$ e a aceleração conforme abaixo (Barbosa, 1999):

$$
\gamma^{\prime \prime}=\frac{d v}{d t}+v T^{\prime}=\frac{d v}{d t} T+\kappa v^{2} N
$$

\section{7 Simulação}

O modelo não linear tem como objetivo representar o sistema real da melhor forma possível. Apenas o fenômeno real poderá ser usado como referência na avaliação de uma modelagem. A avaliação da representação do modelo faz-se necessária e é realizada através de uma série de medidas experimentais, afim de 
construir uma linha de tendência para os resultados depois de tratados estatisticamente. As inúmeras variáveis que devem ser medidas para fundamentar o modelo, o esforço de experimentação (instrumentação, coleta, análise, comparação) é muito grande. Porém, simplificações na realização das medições geram risco de produzir informações incompletas, levando a conclusões erradas ou sem significado. Em um processo de medição, a aleatoriedade dos sistemas reais em ensaios tem representação limitada e específica. Gera uma elevada quantidade de informação a um custo relativamente alto para a abrangência da aplicação.

Em função dessas limitações, a proposição de um benchmark, um indicativo numérico de uma simulação de parâmetros conhecidos, fornece as informações necessárias, dando a oportunidade de se gerar um modelo e comparar seus resultados com ganho de experiência e maturidade em modelagem.

\section{8 Descrição do programa de multicorpos}

A AEA Technology Rail tem atuado durante anos no campo de dinâmica ferroviária e interação roda-trilho. Métodos lineares e não lineares de previsão do comportamento ferroviário têm sido desenvolvidos, ao mesmo tempo em que validados cuidadosamente através de ferramentas de ensaios e equipamentos sofisticados. Todas as ferramentas de previsão do comportamento dinâmico foram integradas em um pacote de pré e pós-processamento e chamado VAMPIRE com o objetivo principal de resolver problemas reais em dinâmica ferroviária rapidamente e a um custo baixo. VAMPIRE utiliza o método de modelagem de multicorpos permitindo ao usuário a montagem do modelo matemático.

Os pré-processadores estão inclusos como ferramenta para a checagem do modelo do veículo, apresentação dos perfis da roda e do trilho e criação das propriedades de contato.

A interação roda-trilho é um fenômeno extremamente não linear e as equações de movimento resultantes da integração necessitam de muita atenção. Somado a isso, as equações de movimento do rodeiro ferroviário possuem raízes de 
alta freqüência e muito amortecidas que podem levar o método de integração a instabilidade numérica. Ao se aumentar à complexidade do modelo utilizando um veículo completo com suspensões não lineares, os métodos numéricos são levados ao extremo e a presença de instabilidade na solução aumenta.

O método de integração atualmente usado pelo VAMPIRE foi desenvolvido para análise de pantógrafos. Trata-se do método de Euler, muito conhecido na literatura. Desde os primeiros anos de uso do método do Pantógrafo, novos métodos de integração têm sido criados e divulgados pela comunidade científica: Método ADAMS BASHFORTH, Método de dois passos Gear, Método Park Stiffly Stable e Método Newmark Beta.

Conforme estudos da AEA Technology, existem duas áreas onde aparecem instabilidade na integração das equações de movimento. Estudos aplicando força lateral em um rodeiro identificaram instabilidade quando o contato roda-trilho acontece no friso e quando o rodeiro se desloca em movimento de "roll" sobre o boleto do trilho.

A vantagem do método de integração é o uso do passo de tempo para solução da equação diferencial. Dados os deslocamentos, velocidades e acelerações o procedimento de integração calcula os valores de deslocamento, velocidade e aceleração no passo de tempo seguinte.

Conforme Clark (1992), o Método do Pantógrafo foi utilizado para a solução de equações diferenciais do modelo de um rodeiro sobre um trilho rígido, apresentando resultados bastante satisfatórios. Diversos casos foram simulados: em via reta e curva, irregularidades discretizadas para uma mudança de ângulo de via (kink), bem como uma curva de raio pequeno.

A integração numérica da obra de Clark utiliza passo fixo. Para passos de tempo de $0.002 \mathrm{~s}$, foi utilizado o Método do pantógrafo, apresentando-se mais estável em análise de um rodeiro em trilhos retos. Para passos menores que 0.005 , todos se encontraram estáveis. Para a análise do mesmo modelo com uma mudança de ângulo de via, o método do Pantógrafo e ADAMS BASHFORTH. são levemente instáveis (Marginally unstable), enquanto que os demais são totalmente instáveis. Para valores menores que 0.0001, todos são estáveis. Entretanto, Pascal (1993d) utiliza de um 
código baseado na utilização de passo variado, VOCO, obtendo também resultados estáveis. Em sua obra, Barbosa (1999) utiliza ADAMS Rail, cujo código, de passo variado, também apresenta soluções numéricas muito estáveis.

O diagrama do bloco de integração é apresentado na figura 43:

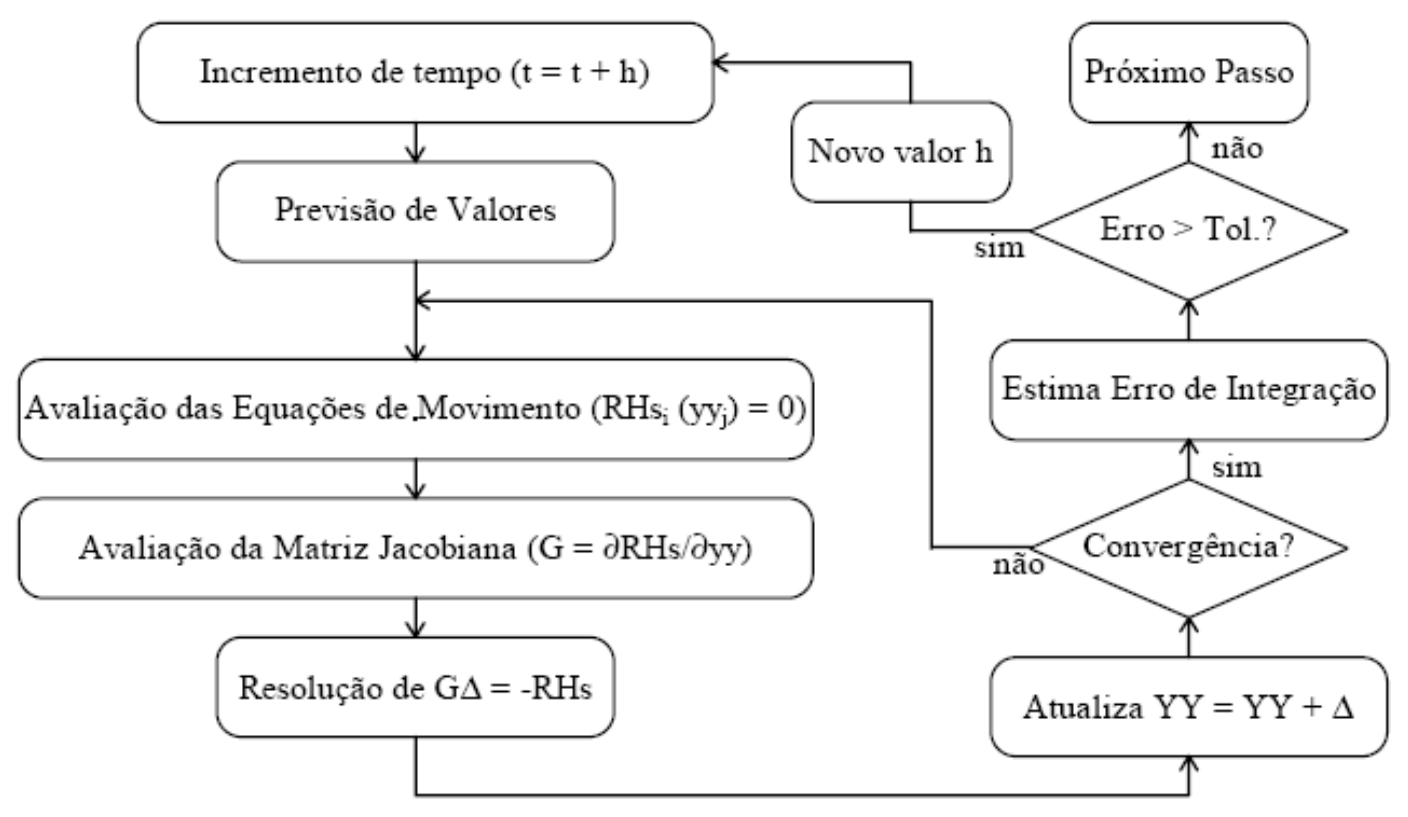

Figura 43: Diagrama do bloco do integrador(Barbosa, 1999)

O método do Pantógrafo é um simples truncamento da série de Taylor:

$$
\begin{aligned}
& u_{y_{t+d t}}=u_{y_{t}}+u_{y_{t}} d t \\
& u_{y_{t+d t}}=u_{y_{t}}+u_{y_{t+d t}} d t
\end{aligned}
$$

\section{9 Resultados}

A primeira análise se caracteriza na aplicação de uma força lateral crescente até $20 \mathrm{kN}$, mantendo-se constante ao atingir esse patamar. Nessa situação são medidas as posições de deslocamento lateral do rodeiro e abertura do ângulo de yaw entre outras informações que são apresentadas na tabela 2. 
Tabela 2: Resultados para força lateral de $20 \mathrm{kN}$

\begin{tabular}{|c|c|c|c|c|c|c|c|c|}
\hline $\begin{array}{l}\text { Coeficient } \\
\text { e de } \\
\text { Adesão }\end{array}$ & $\begin{array}{c}\text { Deslocament } \\
\text { o Lateral } \\
\text { [mml }\end{array}$ & Yaw [mrad] & Reação Vertical [kN] & Carga Normal [kN] & Tan Delta $[\mathrm{H}$ & $\begin{array}{c}\text { Força Fx } \\
{[\mathrm{kN}]}\end{array}$ & $\begin{array}{c}\text { Força Fy } \\
{[\mathrm{kN}]}\end{array}$ & Força de Contato [kN] \\
\hline Direita & & & 88.81 & -91.19 & & 0.84 & -20.72 & 0.08 \\
\hline 0.01 & 4.99 & 0.02 & & & 0.2302 & & & \\
\hline \multirow[t]{2}{*}{ Esquerda } & & & 84.42 & -84.42 & & -0.84 & 0.72 & 0.00 \\
\hline & & & 88.81 & -91.04 & & 8.20 & -20.03 & 1.01 \\
\hline \multirow[t]{3}{*}{0.10} & 4.99 & 0.15 & & & 0.2328 & & & \\
\hline & & & 84.41 & -84.41 & & -8.25 & 0.03 & -0.69 \\
\hline & & & 88.88 & -90.77 & & 15.61 & -18.84 & 4.07 \\
\hline \multirow[t]{3}{*}{0.20} & 5.00 & 0.29 & & & 0.2538 & & & \\
\hline & & & 84.34 & -84.33 & & -15.71 & -1.16 & -1.86 \\
\hline & & & 88.97 & -90.42 & & 21.71 & -17.75 & 7.35 \\
\hline \multirow[t]{3}{*}{0.30} & 5.01 & 0.40 & & & 0.2780 & & & \\
\hline & & & 84.26 & -84.24 & & -21.86 & -2.13 & -2.94 \\
\hline & & & 89.01 & -90.06 & & 26.12 & -16.75 & 9.62 \\
\hline \multirow[t]{3}{*}{0.40} & 5.02 & 0.48 & & & 0.2923 & & & \\
\hline & & & 84.21 & -84.18 & & -26.31 & -3.25 & -3.93 \\
\hline & & & 88.97 & -89.26 & & 36.81 & -13.82 & 11.82 \\
\hline \multirow[t]{2}{*}{1.00} & 5.02 & 0.67 & & & 0.2859 & & & \\
\hline & & & 84.25 & -84.20 & & -37.08 & -6.18 & -6.81 \\
\hline
\end{tabular}

Conforme se pode observar, as simulações atendem aos diversos coeficientes de atrito. $O$ ângulo de inclinação do rodeiro se eleva ao se aumentar o coeficiente de atrito (de $1.2^{\circ}$ a $38.5^{\circ}$ ). O ângulo do plano de contato das superfícies está entre $13.3 \mathrm{e}$ 16.4 graus. Ao se aumentar o coeficiente de atrito, o ângulo do plano de contato diminui. Em função da abertura do ângulo de yaw, é esperado um binário das forças longitudinais em cada contato da roda. Isso pode ser visto na coluna de forças $F_{x}$. A contribuição da força da roda de lado oposto àquela que recebe a aplicação da força lateral é muito pequena quando o coeficiente de atrito é pequeno. Subindo os valores do coeficiente de atrito, a contribuição da roda oposta (força $F_{y}$ ) alcança $44.7 \%$ para $\mu=1$. Ao se aplicar uma força lateral de $20 \mathrm{kN}$, o contato entre as superfícies não alcança a região do friso e, de certa forma, não se espera grandes mudanças nas elipses de contato e por conseqüência, nas forças tangencias.

A tabela 3 compara com outros pacotes de simulação numérica publicados por outros autores os resultados obtidos para a simulação do comportamento do rodeiro, mesma proposta de benchmark, na condição de equilíbrio quase-estático, com aplicação de uma força lateral de $20 \mathrm{kN}$ para um coeficiente de atrito roda-trilho de 0.3 . 
Tabela 3: Resultados da tabela 1 para 0.3 de atrito

\begin{tabular}{|c|c|c|c|c|c|c|c|c|}
\hline $\begin{array}{c}\text { Coeficiente } \\
\text { de Atrito } \\
\mu=0.3\end{array}$ & $\begin{array}{c}\text { Desloc. } \\
\text { Lateral } \\
\text { [mm] }\end{array}$ & \begin{tabular}{|c} 
Yaw \\
[mrad]
\end{tabular} & $\begin{array}{c}\text { Reação } \\
\text { Vertical } \\
\text { [kN] }\end{array}$ & $\begin{array}{c}\text { Carga } \\
\text { Normal } \\
{[\mathrm{kN}]} \\
\end{array}$ & $\begin{array}{c}\text { Tan } \\
\text { Delta } \\
{[-]} \\
\end{array}$ & $\begin{array}{c}\text { Forca } \\
\text { Fx } \\
{[\mathrm{kN}]}\end{array}$ & \begin{tabular}{|c|} 
Força \\
Fy \\
{$[\mathrm{kN}]$} \\
\end{tabular} & $\begin{array}{c}\text { Força } \\
\text { Creep } \\
{[\mathrm{kN}]}\end{array}$ \\
\hline $\begin{array}{l}\text { Direita } \\
\text { voco } \\
\text { Esquerda }\end{array}$ & 5.426 & -0.423 & $\begin{array}{l}84.79 \\
88.44\end{array}$ & $\begin{array}{l}84.80 \\
89.35\end{array}$ & 0.32 & $\begin{array}{r}-23.00 \\
23.00\end{array}$ & $\begin{array}{l}-3.17 \\
-16.83\end{array}$ & $\begin{array}{l}-3.17 \\
10.50\end{array}$ \\
\hline $\begin{array}{c}\text { Direita } \\
\text { Sinmack } \\
\text { Esq. }\end{array}$ & 4.88 & -0.422 & $\begin{array}{l}\mathrm{n} / \mathrm{d} \\
\mathrm{n} / \mathrm{d}\end{array}$ & $\begin{array}{l}84.11 \\
90.32\end{array}$ & $\mathrm{n} / \mathrm{d}$ & $\begin{array}{r}-23.20 \\
23.20\end{array}$ & $\begin{array}{l}n / d \\
n / d\end{array}$ & $\begin{array}{l}-3.30 \\
11.4\end{array}$ \\
\hline $\begin{array}{r}\text { Direita } \\
\text { RyVehSim } \\
\text { Esq. }\end{array}$ & 4.930 & -0.427 & $\begin{array}{l}\mathrm{n} / \mathrm{d} \\
\mathrm{n} / \mathrm{d}\end{array}$ & $\begin{array}{l}84.14 \\
90.21\end{array}$ & $\mathrm{n} / \mathrm{d}$ & $\begin{array}{r}-23.61 \\
23.40\end{array}$ & $\begin{array}{l}n / d \\
n / d\end{array}$ & $\begin{array}{l}-3.34 \\
9.65\end{array}$ \\
\hline $\begin{array}{r}\text { Direita } \\
\text { Robotran } \\
\text { Esq. }\end{array}$ & 5.193 & -0.421 & $\begin{array}{l}\mathrm{n} / \mathrm{d} \\
\mathrm{n} / \mathrm{d}\end{array}$ & $\begin{array}{l}84.11 \\
90.32 \\
\end{array}$ & $\mathrm{n} / \mathrm{d}$ & $\begin{array}{r}-23.49 \\
23.29\end{array}$ & $\begin{array}{l}\mathrm{n} / \mathrm{d} \\
\mathrm{n} / \mathrm{d}\end{array}$ & $\begin{array}{l}-2.88 \\
9.95 \\
\end{array}$ \\
\hline $\begin{array}{c}\text { Direita } \\
\text { SIDIVE } \\
\text { Esq. }\end{array}$ & 5.251 & -0.415 & $\begin{array}{l}84.097 \\
89.130\end{array}$ & $\begin{array}{l}84.074 \\
90.271\end{array}$ & 0.320 & $\begin{array}{r}-22.885 \\
22.694\end{array}$ & $\begin{array}{l}-2.349 \\
-17.65 \\
\end{array}$ & $\begin{array}{l}-3.065 \\
10.334\end{array}$ \\
\hline $\begin{array}{r}\text { Direita } \\
\text { BARBOSA } \\
\text { Esq. }\end{array}$ & 4.906 & -0.420 & $\begin{array}{l}86.020 \\
87.205\end{array}$ & $\begin{array}{l}85.998 \\
88.475\end{array}$ & 0.319 & $\begin{array}{l}23.97 \\
23.79 \\
\end{array}$ & $\begin{array}{r}-2.22 \\
-17.78 \\
\end{array}$ & $\begin{array}{r}-2.988 \\
9.642 \\
\end{array}$ \\
\hline $\begin{array}{c}\text { Direita } \\
\text { ALMIIDA } \\
\text { Esq. }\end{array}$ & 5.010 & -0.400 & $\begin{array}{l}84.26 \\
88.97\end{array}$ & $\begin{array}{l}84.24 \\
90.42\end{array}$ & 0.2780 & $\begin{array}{r}-21.86 \\
21.71\end{array}$ & $\begin{array}{l}-2.13 \\
-17.75 \\
\end{array}$ & $\begin{array}{l}-2.94 \\
7.35\end{array}$ \\
\hline
\end{tabular}

Os resultados obtidos com o VAMPIRE levam a uma concordância de $6.5 \%$ com os valores das forças publicadas, como pode ser visto nas tabelas 3 e 4 . A posição lateral do rodeiro para as diversas publicações varia em torno de $4 \% \mathrm{em}$ função da posição da referência de coordenadas dos respectivos modelos, o que pode justificar essas variações.

A tabela 3 foi reunida pela primeira vez na obra de Barbosa, 1999. O objetivo é resumir através de uma apresentação direta e objetiva os resultados obtidos com o mesmo benchmark.

Na tabela 4 são apresentadas as variações percentuais das comparações entre os resultados obtidos com o VAMPIRE e outros pacotes numéricos. 
Tabela 4: Comparação percentual da Reação Vertical, $F_{x}, F_{y}$, e Força de contato

\begin{tabular}{c|c|c|c|c|c|c|c|c|}
\hline \multirow{2}{*}{} & \multicolumn{7}{c|}{ Comparaçäo dos resultados da tabela 3 com tabela 4 } \\
\hline \multirow{2}{*}{ Volta Reação Vertical [\%] } & \multicolumn{2}{|c|}{ Delta Fx [\%] } & \multicolumn{2}{|c|}{ Delta Fy [\%] } & \multicolumn{2}{c|}{ Delta Força contato [\%] } \\
\cline { 2 - 10 } & Esquerda & Direita & Esquerda & Direita & Esquerda & Direita & Esquerda & Direita \\
\cline { 2 - 10 } & 0.60 & 0.63 & 5.61 & 4.96 & 5.47 & 32.81 & 30.00 & 7.26 \\
\hline MEDINA & & & 6.42 & 5.78 & & & 35.53 & 10.91 \\
\hline RYVehsim & & & 7.22 & 7.41 & & & 23.83 & 11.98 \\
\hline Robotran & & & 6.78 & 6.94 & & & 26.13 & 2.08 \\
\hline SIDIVE & 0.18 & 0.19 & 4.34 & 4.48 & 0.57 & 9.32 & 28.88 & 4.08 \\
\hline BARBOSA & 2.02 & 2.05 & 8.74 & 8.80 & 0.17 & 4.05 & 23.77 & 1.61 \\
\hline MÉDIA & $\mathbf{0 . 9 3}$ & $\mathbf{0 . 9 5}$ & $\mathbf{6 . 5 2}$ & $\mathbf{6 . 3 9}$ & $\mathbf{2 . 0 7}$ & $\mathbf{1 5 . 3 9}$ & $\mathbf{2 8 . 0 2}$ & $\mathbf{6 . 3 2}$ \\
\hline
\end{tabular}

Os piores resultados aparecem na comparação dos resultados das forças de contato, na roda esquerda. A força na direção y da roda direita também apresenta uma margem elevada porque a comparação com o VOCO gerou uma margem de $32.81 \%$ de variação. Entretanto, os resultados da tabela 4 são bastante satisfatórios.

No próximo caso analisado, figura 44 e 45, a força lateral cresce a uma taxa igual a $50 \mathrm{kN} / \mathrm{s}$. Esse ensaio aborda o comportamento das forças no contato, do rodeiro (deslocamento lateral, yaw, inclinação) ao tocar o friso da roda no boleto do trilho. A resposta final de cada simulação é equivalente ao descarrilamento, sendo possível observar o comportamento das forças longitudinal, lateral, vertical que aparecem no contato.

A análise na figura 44 avalia o comportamento das forças nos contatos, ângulos de contato e posição do rodeiro até o descarrilamento para o coeficiente de 0.3. No VAMPIRE, a força lateral é de $68.3 \mathrm{kN}$. VOCO apresenta uma força no contato lateral de $24.3 \mathrm{kN}$. A força longitudinal no contato atinge $28.9 \mathrm{kN}$ na iminência ao descarrilamento no VOCO enquanto que o VAMPIRE apresenta o limite de $10.3 \mathrm{kN}$. A força vertical da simulação com o VOCO atinge $89.6 \mathrm{kN}$ comparada aos $146.9 \mathrm{kN}$. A força normal máxima na simulação do benchmark é de $192.9 \mathrm{kN}$ contra $229.7 \mathrm{kN}$ do VAMPIRE. 


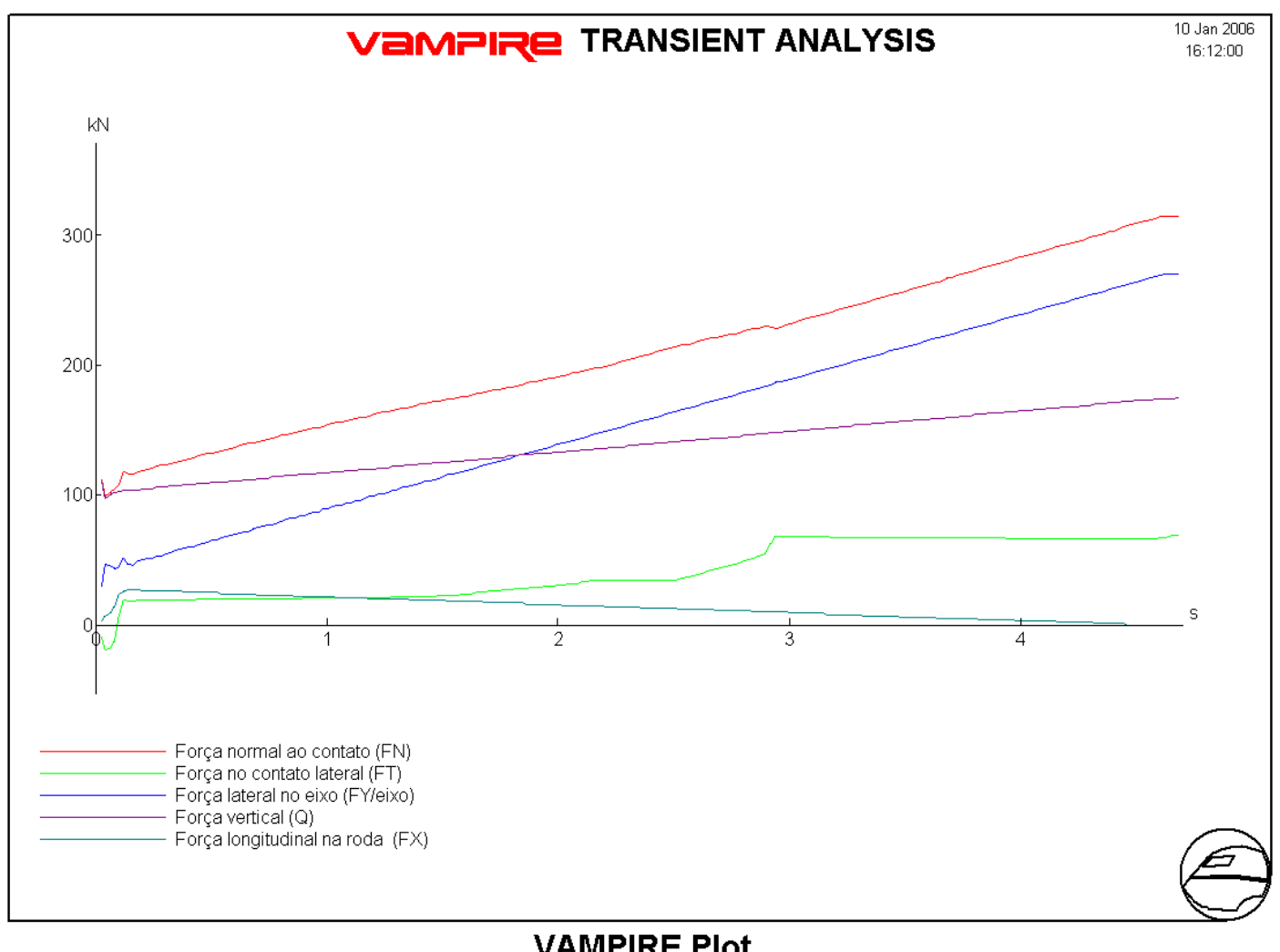

VAMPIRE PIot

Figura 44: Forças no Descarrilamento para coeficiente de atrito de 0.3

Ao encostar no friso, o modelo da figura 45 sofre uma perturbação em 0.16 segundos. Nesse instante, a força no contato lateral calculada pelo Vampire é de $24.3 \mathrm{kN}$ e no VOCO $32.3 \mathrm{kN}$. A força longitudinal na roda através do Vampire gera $54.1 \mathrm{kN}$ e no VOCO $68.3 \mathrm{kN}$. A força lateral (Y) no eixo é de $49.2 \mathrm{kN}$ contra $61 \mathrm{kN}$. O ângulo do plano de contato atinge 57.4 graus quando o cálculo com a ajuda do VOCO é de 45.3 graus. O contato com a parcela central do perfil da roda é transferido totalmente para o friso aos 2.2s. No VAMPIRE, o ângulo máximo do plano de contato é atingido na iminência ao descarrilamento nos 62.6 graus (figura 46) recebendo uma força lateral em torno de $68.7 \mathrm{kN}$. Pascal apresenta uma força lateral no contato de $50.1 \mathrm{kN}$. 


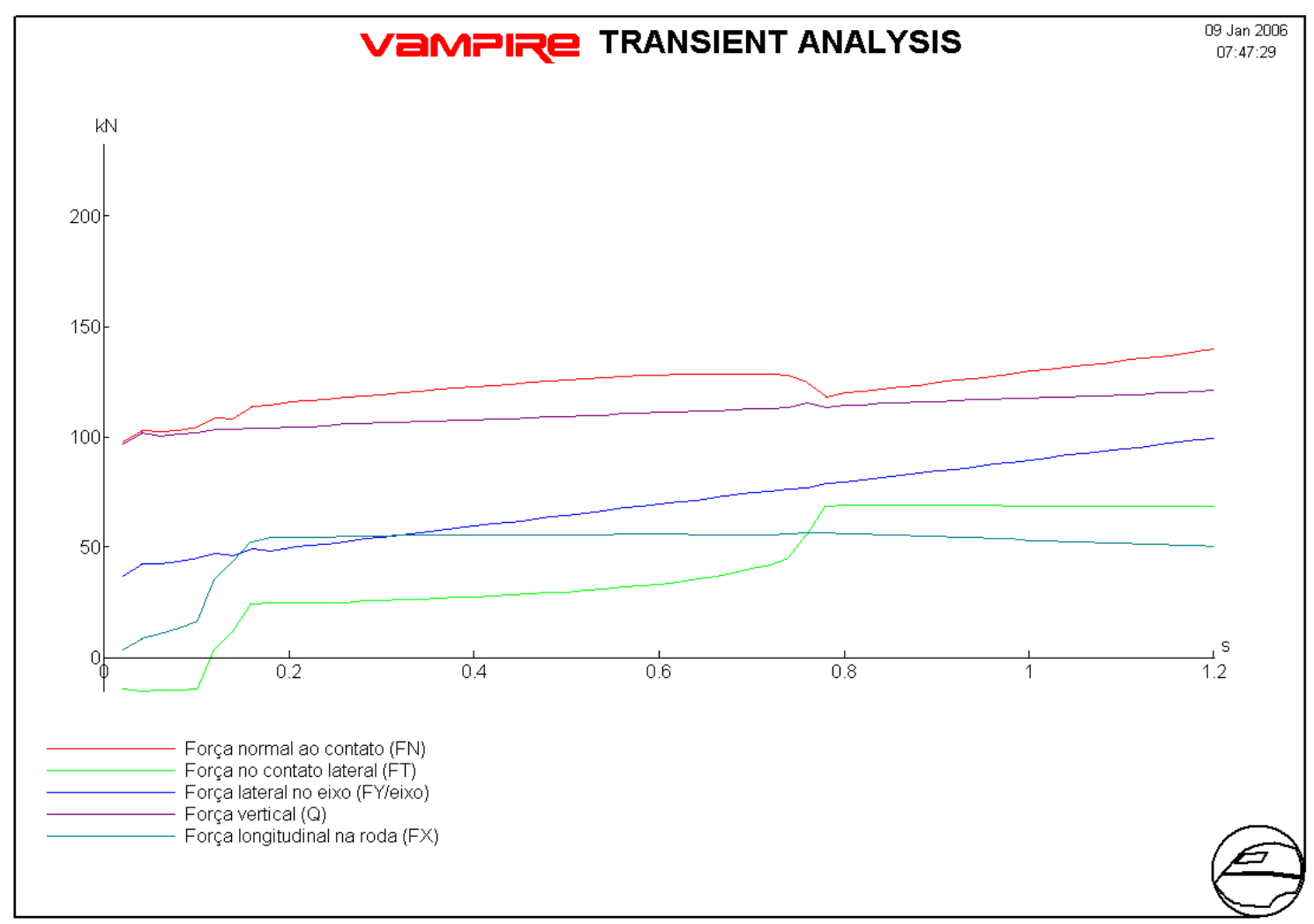

\section{VAMPIRE PIot}

Figura 45: Forças no Descarrilamento para coeficiente de atrito de 1

A força longitudinal no contato atinge $82.6 \mathrm{kN}$ na iminência ao descarrilamento no VOCO enquanto que o VAMPIRE apresenta o limite de $56.5 \mathrm{kN}$. O ângulo máximo no plano de contato é de 68.7 graus no VOCO. A força vertical Q através da simulação com o VOCO atinge $88.6 \mathrm{kN}$ comparada aos $114.9 \mathrm{kN}$. A força normal máxima através do benchmark é de $122.5 \mathrm{kN}$ contra $128.3 \mathrm{kN}$ do VAMPIRE. 


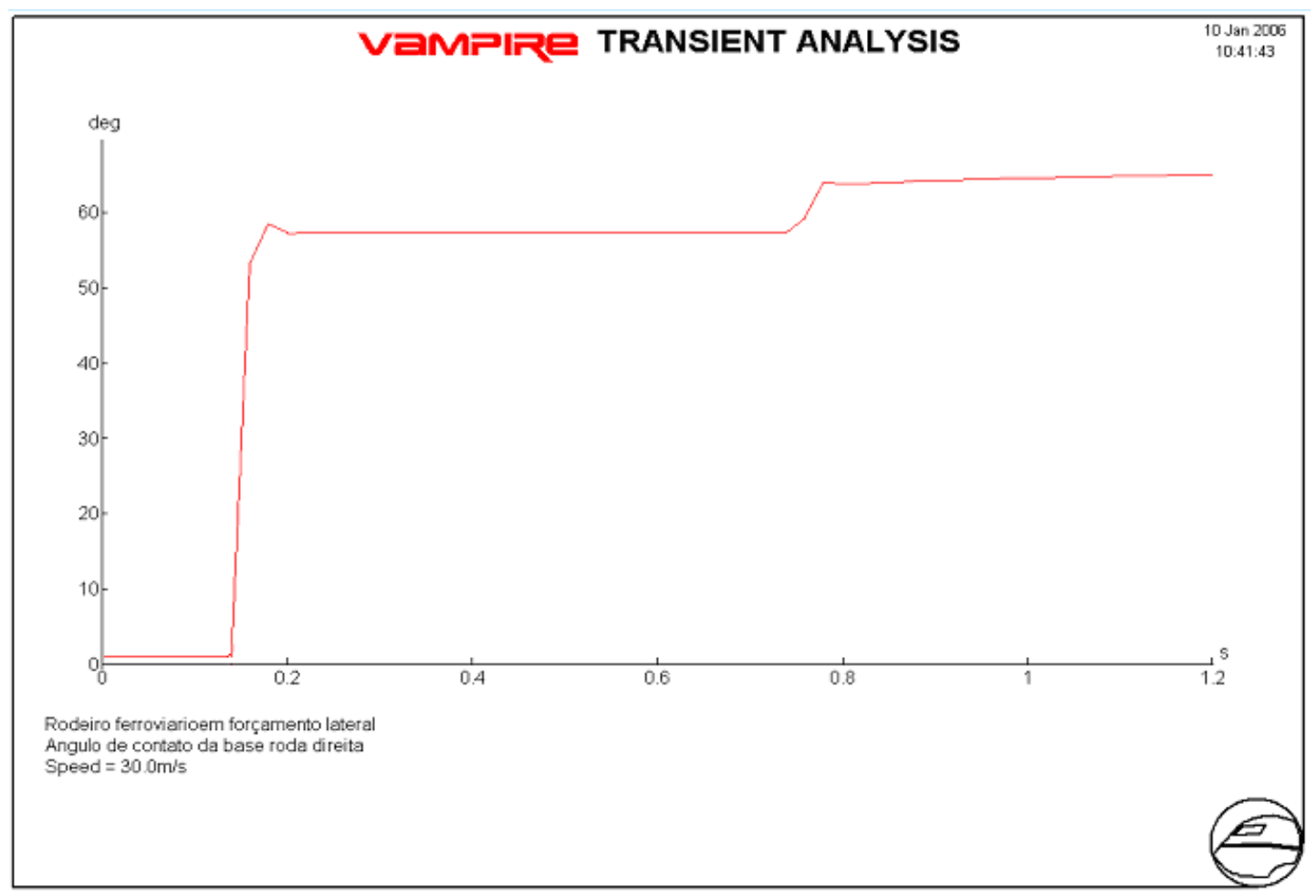

VAMPIRE Plot

Figura 46: Comportamento do ângulo do plano de contato $(M u=1)$

As relações de $\mathrm{L} / \mathrm{V}$, máxima força lateral nos trilhos e máxima força de contato tangencial para os diversos coeficientes de atrito na condição de iminência ao descarrilamento são apresentados na figura 47.

A curva L/V apresenta uma relação de 2.5 na simulação com os resultados publicados por Pascal. A curva L/V da figura 47 inicia com uma relação de 1.90. Para um coeficiente de atrito igual a 0.6, a relação da simulção do VOCO chega a 1.4. Vampire apresenta uma razão de 1.56. A máxima força transversal nos trilhos, apresentada por Pascal, começa com $222 \mathrm{kN}$ com um coeficiente de atrito 0.1 para chegar a $130 \mathrm{kN}$ com $\quad \mu$ igual a 0.6 . VAMPIRE tem $130.6 \mathrm{kN}$ com $\quad \mu$ igual a 0.1 e chega a $109.2 \mathrm{kN}$. A curva da força de contato tangencial começa com $9.5 \mathrm{kN}$ a um coeficientes de atrito de 0.1 e atinge $40 \mathrm{kN}$ no VOCO. A comparação com o VAMPIRE leva a $8.9 \mathrm{kN}$ com atrito de 0.1 e $55.5 \mathrm{kN}$ a 0.6 . 


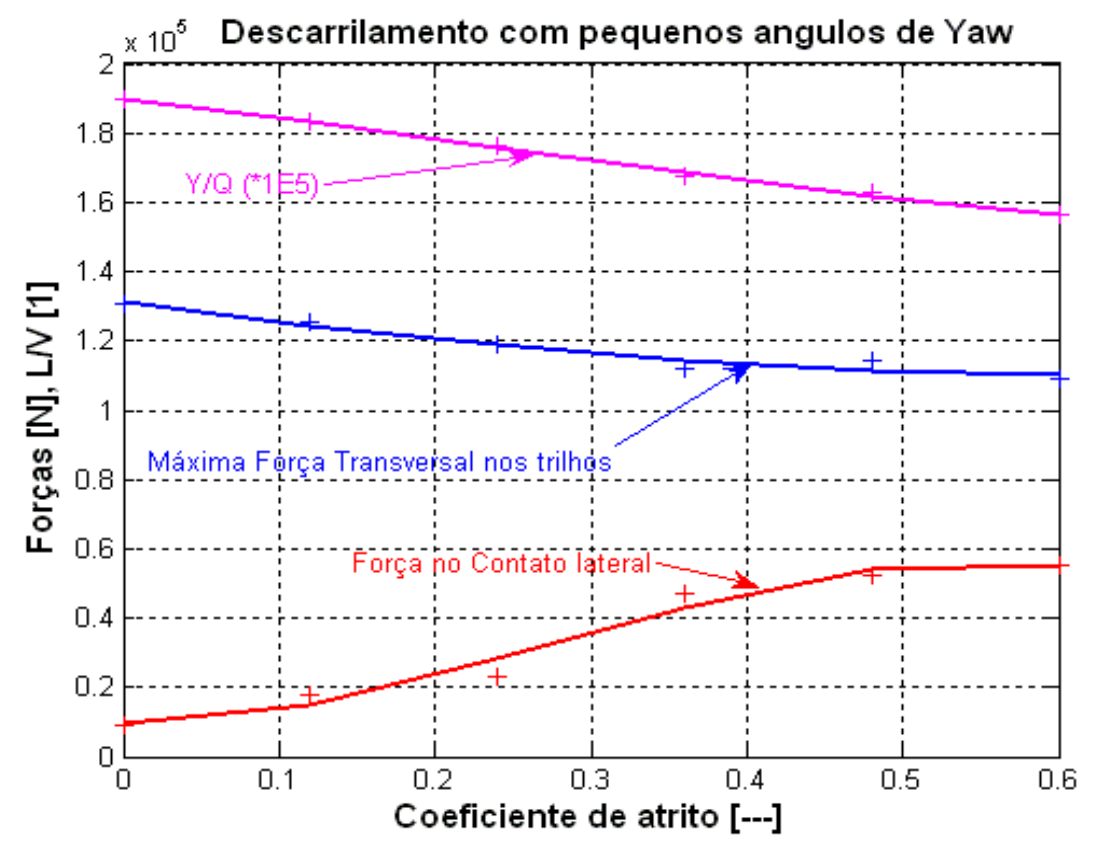

Figura 47: Máximas forcas e ralação $L / V$ na iminência ao descarrilamento

\subsection{Conclusões}

Os resultados obtidos da simulação do rodeiro no domínio do tempo mostram que o descarrilamento acontece ao 4.8s para a simulação com coeficiente de atrito de 0.3 ,conforme figura 44. A força de contato lateral esperada é de $24.3 \mathrm{kN}$ (Pascal) enquanto que o valor atingido é de $68.3 \mathrm{kN}$, conforme figura 44 . A força longitudinal decresce gradualmente a partir do momento que o contato é apenas no friso. As forças normais no contato são maiores que o esperado, $229.7 \mathrm{kN}$ pela figura 44 no descarrilamento. A força vertical (Q) variou bem pouco do início ao término da simulação, $22.2 \%$ acima do esperado.

Na simulação para o coeficiente de atrito igual a 1, a força de contato lateral é $37.1 \%$ maior. A força longitudinal atinge um valor máximo de $56.5 \mathrm{kN}, 20 \%$ menor que o esperado na simulação do benchmark. A força normal no contato é levemente maior que o esperado, porém a diferença de $6 \%$, é menor que a obtida por 
Barbosa(1999), em torno de 15\%. A força vertical (Q), para o coeficiente de atrito de 1, também variou bem pouco do início ao término da simulação, em torno de $20 \%$.

A curva L/V inicia com uma variação de $31.6 \%$ com atrito 0.1 e alcança variação de $10.3 \%$ dos resultados VAMPIRE com relação aos publicados por Pascal. A máxima força transversal nos trilhos varia $70.8 \%$ dos resultados do benchmarck no início da curva e atinge $19.0 \%$ na extremidade oposta e coeficiente de atrito 1 . A curva da força de contato tangencial começa com $6.7 \%$ de variação para o atrito $0.1 \mathrm{e}$ possui variação de $27.9 \%$ para coeficiente de atrito 1 . Dessa forma, os resultados obtidos na simulação do VAMPIRE são razoavelemente bons. 


\section{CONCLUSÃo}

Com o objetivo de apresentar ao leitor a evolução das teorias de contato roda trilho, fez-se uma revisão dos autores que contribuíram significativamente e suas idéias. Hoje, através de códigos gerados por computador, torna-se viável abordar problemas mais complexos sem a imposição de tantas simplificações do modelo real para análise. Percebe-se uma tendência de utilização da técnica de multicorpos para criação do modelo matemático e utilização da álgebra simbólica para criação das equações de movimento.

A teoria da mecânica de contato, necessária ao cálculo das forças de contato roda-trilho, foi apresentada detalhadamente, além da lei de saturação e das propriedades de contato. Desenvolveu-se o modelo do rodeiro ferroviário concentrando atenção para a determinação das velocidades relativas no contato, dos escorregamentos, determinação das forças de contato e saturação. Essas informações são de grande importância para a correta representação do modelo. Os resultados foram comparados com o benchmarck apresentando razoável concordância, conforme item 3.10 .

A análise modal do sistema linearizado ajudou a identificar a influência da velocidade nos autovalores e observar os modos de movimento. Os valores obtidos foram comparados havendo boa concordância com a obra de Barbosa (1996). Estes resultados encorajam o avanço dos estudos de modelo mais complexos com melhor detalhamento e verificações de imperfeições.

A influência da conicidade também pode ser registrada. Ao se variar a conicidade, a velocidade crítica e o amortecimento do sistema mostraram-se inversamente proporcionais enquanto que os autovalores de ambos os modos cresceram.

Um modelo não linear foi elaborado com base em uma proposta do Benchmark to test wheel/rail contact forces da International Association of Vehicle System Dynamics (IAVSD) utilizando-se a técnica de modelagem de sistemas multicorpos. A criação do modelo, obtenção das equações de movimento e a 
simulação do comportamento foram realizados e comparados com o benchmark havendo boa representatividade.

Como recomendação de novos estudos, sugere-se o estudo de mecanismos mais representativos utilizando técnica (truque, veículo completo), ou modelagem de sistemas mistos (FEA- Multicorpos). 


\section{ANEXO A}

\section{A. Equações de estados}

A solução do sistema de equações diferenciais começa com o relacionamento entre as equações de estado:

$$
\frac{d^{n}}{d t^{n}} c(t)+a_{n} \frac{d^{(n-1)}}{d t^{(n-1)}} c(t)+a_{(n-1)} \frac{d^{(n-2)}}{d t^{(n-2)}} c(t)+\ldots \ldots . .+a_{2} \frac{d}{d t} c(t)+a_{1} c(t)=r(t)
$$

em que $r(t)$ é a variável de entrada e $c(t)$ é a variável de saída, também conhecida como variável de deslocamento. Fazendo:

$$
\begin{gathered}
x_{1}(t)=c(t) \\
x_{2}(t)=\frac{d}{d t} c(t) \\
x_{3}(t)=\frac{d^{2}}{d t^{2}} c(t)=\frac{d}{d t} x_{2}(t) \\
\vdots \\
x_{n}(t)=\frac{d^{(n-1)}}{d t^{(n-1)}} c(t)=\frac{d}{d t} x_{(n-1)}(t)
\end{gathered}
$$

Relacionando tem-se:

$$
\begin{array}{r}
\frac{d}{d t} x_{1}(t)=x_{2} \\
\frac{d}{d t} x_{2}(t)=x_{3} \\
\vdots \\
\frac{d}{d t} x_{(n-1)}(t)=x_{n}
\end{array}
$$

Dessa forma, a expressão pode ser reescrita como:

$$
\begin{aligned}
& \frac{d^{n}}{d t^{n}} x_{1}(t)+a_{n} x_{n}+a_{(n-1)} x_{(n-1)}+\ldots \ldots . .+a_{2} x_{2}+a_{1} x_{1}=r(t) \\
& \frac{d^{n}}{d t^{n}} x_{1}(t)=-a_{n} x_{n}-a_{(n-1)} x_{(n-1)}-\ldots \ldots . .-a_{2} x_{2}-a_{1} x_{1}+r(t)
\end{aligned}
$$

Como $\frac{d}{d t} x_{n}(t)=\frac{d}{d t}\left[\frac{d^{(n-1)}}{d t} x_{1}(t)\right]=\frac{d^{n}}{d t^{n}} x_{1}(t)$ tem-se : 


$$
\frac{d}{d t} x_{n}(t)=-a_{n} x_{n}-a_{(n-1)} x_{(n-1)}-\ldots \ldots . .-a_{2} x_{2}-a_{1} x_{1}+r(t)
$$

em que $n=1 \ldots . . n$. Fazendo a somatória de todos os resultados tem-se:

$$
\begin{gathered}
\frac{d}{d t} x_{1}(t)=-a_{1} x_{1}+r(t) \\
\frac{d}{d t} x_{2}(t)=-a_{2} x_{2}-a_{1} x_{1}+r(t) \\
\vdots \\
\frac{d}{d t} x_{(n-1)}(t)=-a_{(n-1)} x_{(n-1)}-\ldots \ldots . . a_{2} x_{2}-a_{1} x_{1}+r(t) \\
\frac{d}{d t} x_{n}(t)=-a_{n} x_{n}-a_{(n-1)} x_{(n-1)}-\ldots \ldots . .-a_{2} x_{2}-a_{1} x_{1}+r(t)
\end{gathered}
$$

Reduzindo tem-se um sistema contínuo do tipo:

$$
\frac{d}{d t} X(t)=A X(t)+B r(t)
$$

onde $r(t)$ é a entrada do sistema também identificada como u(t). Assim:

$$
\dot{X}(t)=A X(t)+B u(t)
$$

Para o problema em questão, a matriz das variáveis de estado:

$$
\{x\}=\left\{\begin{array}{c}
\dot{u}_{y} \\
\dot{\varphi_{z}} \\
u_{y} \\
\varphi_{z}
\end{array}\right\}
$$

E sua derivada:

$$
\{\dot{x}\}=\left\{\begin{array}{c}
\ddot{u}_{y} \\
\ddot{\varphi}_{z} \\
\dot{u_{y}} \\
\dot{\varphi}_{z}
\end{array}\right\}
$$




\section{ANEXO B}

\section{B. Cálculo analítico dos autovalores e autovetores}

Seja o sistema calculado como:

$$
\begin{aligned}
\frac{d x(t)}{d t}= & A x(t)+B r(t) \\
& c(t)=D x(t)+\operatorname{Er}(t)
\end{aligned}
$$

onde $\mathrm{x}(\mathrm{t})=$ vetor de estado

$r(t)=$ vetor de entrada

$\mathrm{c}(\mathrm{t})=$ vetor de saída

e A,B,D e E são matrizes de dimensões apropriadas.

Tomando a transformada de Laplace em ambos os membros da Equação (B.1) e resultando para $X(s)$ temos:

$$
X(s)=(s I-A)^{-1} x(0)+(s I-A)^{-1} B R(s) .
$$

Calculando a transformada de Laplace da Equação (B.2) é

$$
C(s)=D X(s)+E R(s)
$$

Substituindo a Equação (B.3) na Equação.(B.4), temos:

$$
C(s)=D(s I-A)^{-1} x(0)+D(s I-A)^{-1} B R(s)+E R(s)
$$

Como as condições iniciais da função de transferência $x(0)$; assim a Eq.(B.5) se torna:

$$
C(s)=\left[D(s I-A)^{-1} B+E\right] R(s)
$$

Conseqüentemente, a função de transferência é definida como :

$$
G(s)=D(s I-A)^{-1} B+E
$$

que é uma matriz de "q" linhas e "p" colunas. Assim, a função de transferência $G(s)$ requer que a matriz $(s I-A)$ seja não linear.

A equação característica representa uma forma objetiva de se obter as raízes do problema de autovalor representado por A, B, C, D.

Seja o sistema linear abaixo apresentado: 
$\frac{d^{n} c}{d t^{n}}+a_{n} \frac{d^{n-1} c}{d t^{n-1}}+a_{n-1} \frac{d^{n-2} c}{d t^{n-2}}+\ldots+a_{2} \frac{d c}{d t}+a_{1 \mathrm{c}}=b_{n+1} \frac{d^{n} r}{d t^{n}}+b_{n} \frac{d^{n-1} r}{d t^{n-1}}+\ldots+b_{2} \frac{d_{r}}{d_{t}}+b_{1 \mathrm{r}}$

Definindo o operador $\mathrm{p}$ como:

$$
p^{g}=\frac{d^{g}}{d t^{g}} \quad \mathrm{~g}=1,2, \ldots \mathrm{n}
$$

a Eq. (51) é escrita da seguinte forma:

$$
\left(p_{n}+a_{n} p^{n-1}+a_{n-1} p^{n-2}+\ldots+a_{2} p+a_{1}\right) c=\left(b_{n+1} p^{n}+b_{n} p^{n-1}+\ldots+b_{2} p+b_{1}\right) r
$$

Então a equação característica do sistema é definida como:

$$
s^{n}+a_{n} s^{n-1}+a_{n-1} s^{n-2}+\ldots+a_{2} s+a_{1}=0
$$

que é a parte homogênea da Eq. (B.10) igualada a zero. Além do mais , o operador “p" é substituído pela variável "s" da transformada de Laplace e gera a seguinte equação para o cálculo da função de transferência:

$$
G(s)=\frac{C(s)}{R(s)}=\frac{b_{n+1} s^{n}+b_{n} s^{n-1}+\ldots+b_{2} s+b_{1}}{s^{n}+a_{n} s^{n-1}+\ldots+a_{2 s}+a_{1}}
$$

E a equação característica é obtida quando se iguala o denominador da função de transferência a zero.

Pela abordagem das variáveis de estado, podemos escrever a equação (B.13) como:

$$
G(s)=D \frac{\operatorname{adj}(s I-A)}{|s I-A|} B+E=\frac{D[\operatorname{adj}(s I-A)] B+|s I-A| E}{|s I-A|}
$$

Igualando a zero o denominador da matriz de função de transferência $G(s)$, obtemos a equação característica expressa como:

$$
|s I-A|=0
$$

que é uma forma alternativa da equação (B.11).

As raízes da equação característica são geralmente denominadas autovalores da matriz A. É interessante notar que se as equações de estado são representadas na forma canônica das variáveis de fase, os coeficientes da equação característica são dados diretamente pelos elementos da última linha da matriz A. 
Uma outra propriedade importante da equação característica e dos autovalores é que eles são invariante sobre uma transformação não singular $x=P_{y}$, de forma que :

$$
\hat{A}=P^{-1} A P
$$

então a equação característica e os autovalores de Â são idênticos aos de A. Isto é provado escrevendo-se:

$$
s I-\hat{A}=s I-P^{-1} A P
$$

ou $\quad s I-\hat{A}=s P^{-1} P-P^{-1} A P$

A equação característica de Â é:

$$
|s I-\hat{A}|=\left|s P^{-1} P-P^{-1} A P\right|=\left|P^{-1}(s I-A) P\right|
$$

Já que o determinante de um produto é igual ao produto dos determinantes, a equação se torna:

$$
|s I-\hat{A}|=\left|P^{-1}\right||s I-A||P|=|s I-A|
$$

$\mathrm{O}$ vetor $p_{i} n \times 1$ que satisfaz a equação matricial

$$
\left(\lambda_{i} I-A\right)_{p_{i}}=0
$$

Para um problema de autovalor de um sistema não amortecido, pode-se expressar a equação diferencial da seguinte forma polinomial:

$s^{2}+\lambda=0$ sendo as raízes $s_{1,2}= \pm \sqrt{\lambda}$

Em um sistema qualquer sem amortecimento, sendo $s_{1} e s_{2}$ as raízes de um modo qualquer, elas são complexas porque o valor de $\lambda$ é negativo. As raízes se localizam sobre o eixo imaginário das ordenadas e indicam o limite máximo para o sistema quanto a uma solicitação externa.

Se o sistema apresentasse amortecimento, suas raízes se localizariam colocadas mais para a esquerda do eixo real das abscissas, mais precisamente no lado negativo.

Dessa forma, a parcela real nas raízes de um sistema estarão presentes à medida que se aplicar amortecimento ao sistema e conforme o módulo do amortecimento cresce, as raízes, (que de início representam a propriedade de um sistema sem amortecimento) deixam de se colocar sobre os eixos imaginário das ordenadas ganhando parcela imaginária. Caso o amortecimento chegue a 1, ambas se 
encontram no mesmo ponto do espaço complexo mas sobre o eixo real. Do caminho o eixo imaginário das ordenadas até o eixo real das abscissas o amortecimento é maior que zero, porém menor que 1 . Tem-se um sistema sub amortecido e as raízes são diferentes entre si.

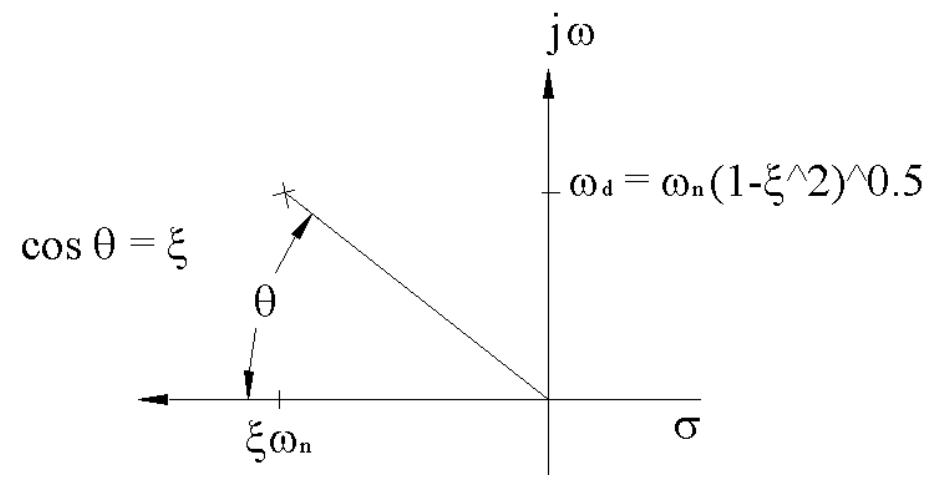

Figura 48: Gráfico Lugar das Raízes

No encontro das raízes, exatamente em cima do eixo real das abscissas, o amortecimento é igual a 1 e as raízes iguais. O sistema é criticamente amortecido. A partir desse valor de amortecimento, as raízes deixam de ser iguais e afastam-se da origem do sistema de coordenadas. Chama-se a esse sistema como sistema sobre amortecido.

O sistema mecânico amortecido é fornecido através das equações do movimento abaixo:

$$
[M] \ddot{q}(t)+[C] \dot{q}(t)+[K] q(t)=0
$$

E para esse sistema a raiz $S_{n 1,2}$ é dada como:

$$
s_{n 1,2}=-\xi w_{n} \pm \sqrt{\xi^{2}-1} w_{n}
$$

onde $\mathrm{n}=$ modo relacionado.

O comportamento do amortecimento influencia o descaimento da energia acumulada. Para $0<\xi<1$, a resposta apresenta um transiente oscilatório mas alcança a posição de equilíbrio.

$$
s_{n 1,2}=-\xi w_{n} \pm i \sqrt{1-\xi^{2}} w_{n}
$$


A parcela real é $-\xi w_{n}$ e se encontra do lado esquerdo na plotagem do plano complexo. A parcela imaginária, formada por um par conjugado, se encontra no eixo das ordenadas. A parcela $\sqrt{1-\xi^{2}} w_{n}$ representa a freqüência natural amortecida $w_{d}$. 


\title{
ANEXO C
}

\section{Benchmark to test wheel/rail contact forces}

Railway Benchmark \#1

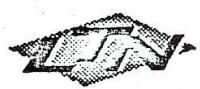

Noyember 1990

\author{
BENCHMARK TO TEST WHEEL/RAIL \\ CONTACT FORCES \\ ( proposed by Dr. J.P. Pascal of INRETS)
}

\begin{abstract}
$* * * * * * * * * * * * * *$
It seems necessary to compare the results of different codes at the very simple level of one single axle in order to demonstrate what is different in physical modelization of the
\end{abstract} wheel/rail contact itself.

\section{DATA}

One single axle of $1887 \mathrm{~kg}$ is loaded with a constant vertical force $\mathrm{Fz}$ (154715 N) applied to its center of gravity so as to apply a total vertical load of $173226 \mathrm{~N}$ to the track.

The axle is submitted to a constant transverse force Fy of $20000 \mathrm{~N}$ acting at the rail level (the point is supposed to coincisie with the theoretical contact point in central position of the axle where the rolling radius is $0.45 \mathrm{~m}$ ).

One single spring of $8.16 \mathrm{E} 7 \mathrm{~N} . \mathrm{m} / \mathrm{rad}$ limits the yaw angle around zero.

The rolling speed $\mathrm{Vx}$ is constant: $30 \mathrm{~m} / \mathrm{s}$.

The choice of the proposed datas (S1002 wheel profile - UIC60 rails - $1435 \mathrm{~mm}$ gauge: distance between inner points of rails located $14 \mathrm{~mm}$ under the track surface - 1/40 rail slant - $\mathrm{K}_{\mathrm{qz}}=8.16 \mathrm{E}^{7} \mathrm{~m} . \mathrm{N} / \mathrm{rad}$ ) has been guided by very well known wheel and rails theoretical profiles. Due to high yaw stiffness of springs, the yaw angles are limited and the contact is not completely samrated.

It is asked to compute two different equilibria:

1 - Axle position when submitted horizontally to $20 \mathrm{kN}$ at the rail level (theor. rolling radius)

The value of the force corresponds to equilibrium positions with contact between tread and flange, in an area of the wheel profile where spinceepage forces as well as gravity forces are fighting against each other and are important.

The results for 4 different friction coefficients : $0.1-0.2-0.3-0.4-$ corresponding to different saturation levels, should be analysed in order to separate, wheel by wheel, the contributions of normal forces, and creepage forces to assure the $20 \mathrm{kN}$ counterpar. It is proposed to present the results in the form of the following table of next page which gives the results of the "VOCO" code.

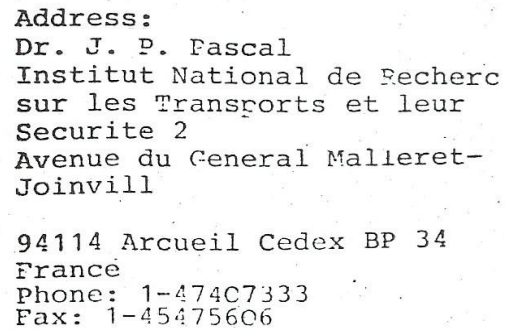


IAVSD - Benchmarks for Multibody Simulation Software

First Railway Benchmarik (Dr. Pascal's)

RESULTS of V'OCO

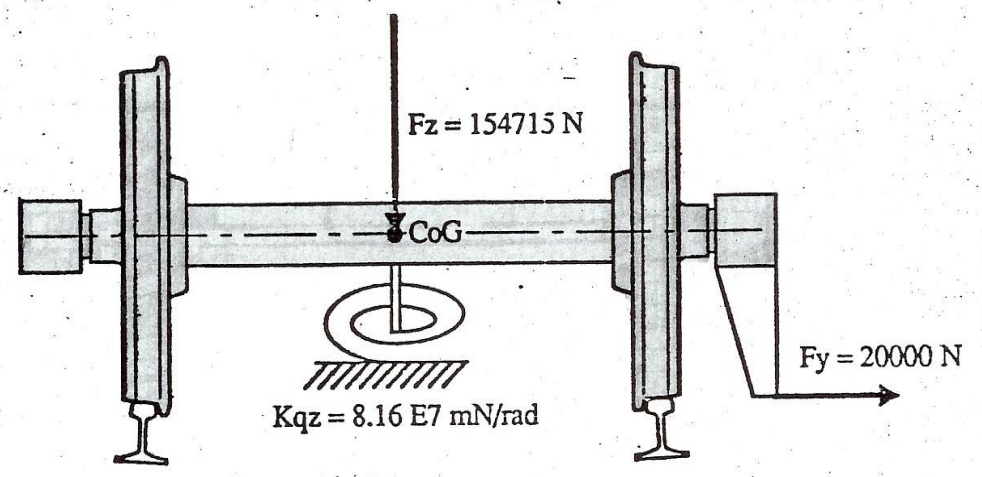

INRETS-LTN May 1991 


\begin{tabular}{|c|c|c|c|c|c|c|c|c|}
\hline admoelon & $\begin{array}{c}\text { Position } \\
\mathrm{mm}\end{array}$ & $\begin{array}{c}\text { yas } \\
\text { mpd }\end{array}$ & $\begin{array}{c}\text { or lood } \\
1+1\end{array}$ & $\underset{k M M}{\text { Norm.lond }}$ & Tang. Oam & $\underset{k H A}{F}$ & $\begin{array}{c}\text { Forese Fy } \\
\text { kN }\end{array}$ & $\begin{array}{c}\text { Fy croop } \\
\mathrm{kN}\end{array}$ \\
\hline $\begin{array}{c}\text { Right } \\
0.08 \\
\text { Loht }\end{array}$ & 4.92 & -0.0154 & $\begin{array}{l}84.388 \\
88.837 \\
\end{array}$ & $\begin{array}{l}84,445 \\
91,06 \\
\end{array}$ & 0.286 & 0,841 & $\begin{array}{c}-0,006 \\
-20 \\
-19.994\end{array}$ & $\begin{array}{r}-0.008 \\
0.08 \\
C .8 .18 \\
\end{array}$ \\
\hline & & $-0,157$ & $\begin{array}{l}84.389 \\
88,837 \\
\end{array}$ & $\begin{array}{l}84,445 \\
80,81 \\
\end{array}$ & 0.827 & 8.475 & $\begin{array}{c}-0.84 \\
-20 \\
-19.357 \\
\end{array}$ & $\begin{array}{r}-0,83 \\
0.83 i \\
1.586\end{array}$ \\
\hline$\bullet .2$ & 5.047 & -0.298 & $\begin{array}{l}84.389 \\
88.837 \\
\end{array}$ & $\begin{array}{r}84.445 \\
80.533 \\
\end{array}$ & 0.265 & 16.3 & $\begin{array}{l}-1.8 \\
-20 \\
-18.2 \\
\end{array}$ & $\begin{array}{r}-1.737 \\
3.178 \\
6.064 \\
\end{array}$ \\
\hline 0.8 & 5.214 & $-0,422$ & $\begin{array}{l}84,389 \\
88,837 \\
\end{array}$ & $\begin{array}{l}84,445 \\
89,847 \\
\end{array}$ & 0.387 & 23 & $\begin{array}{r}-2.8 \\
-20 \\
-17.1 \\
\end{array}$ & $\begin{array}{r}-2.91 \\
7.09 \\
1 . \\
\end{array}$ \\
\hline a.s... & $5 . \mathrm{A}$ & -0.528 & $\begin{array}{l}84,389 \\
88,837 \\
\end{array}$ & $\begin{array}{r}84.445 \\
88.6 \\
\end{array}$ & 0.38 & 28,6 & $\begin{array}{l}-4 \\
-20 \\
-16 \\
\end{array}$ & $\begin{array}{r}-4.02 \\
11.78 \\
15.8 \\
\end{array}$ \\
\hline 1 & 5.38 & -0.843 & $\begin{array}{l}84.389 \\
88.837\end{array}$ & $\begin{array}{c}84,445 \\
85.2\end{array}$ & 0.48 & 45.8 & $\begin{array}{r}-8.5 \\
-20 \\
-11.5 \\
\end{array}$ & $\begin{array}{r}-3,5 \\
16,2 \\
36,7 \\
\end{array}$ \\
\hline
\end{tabular}

\section{Maximum transverse force acceptable without derailing}

It is asked to compute the derailing limits of the same axle on the same tracl. as a ahesion. The could be presented in the form of a curve like the following fuin ion $O_{i}$ adhesion. The results could be presented in the $Y$ applied by the derailing wheel to

where the parameter $Y / Q$ is the ratio of the transverse force

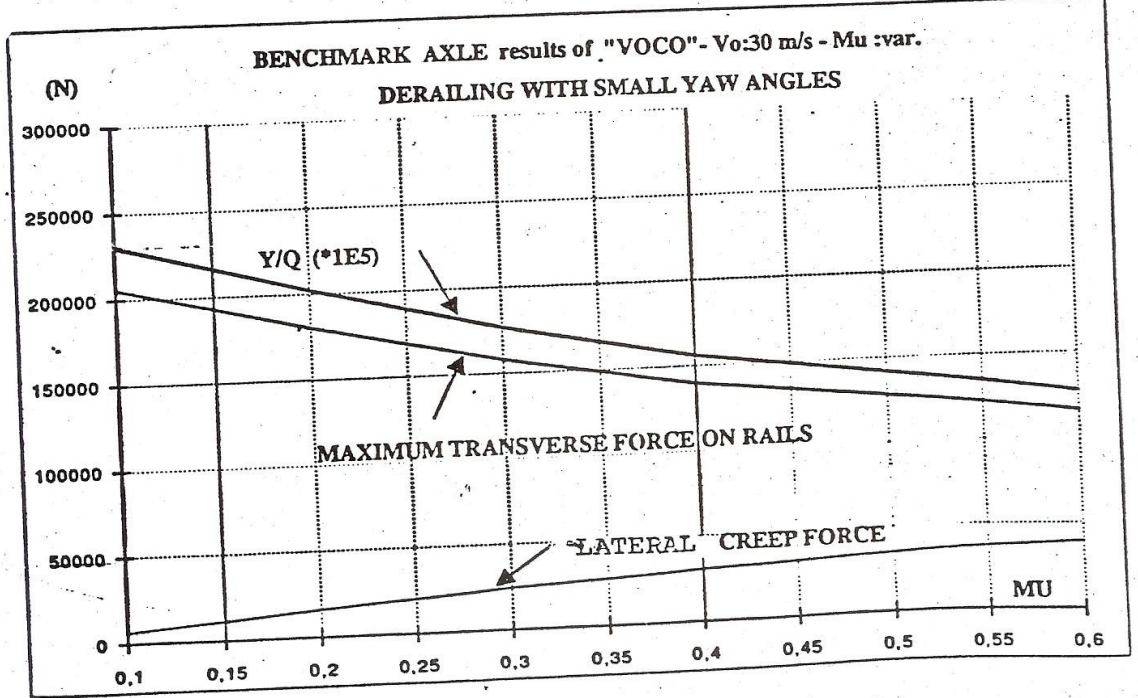


If a dynamic computation is possible, it could be interest inf to $u^{-r}$ senr onc vesult in the form of a diagram like the following which gives the evolution at 0.3 of adhesion when the applied transverse force is increasing at the rate of $50 \mathrm{kN} / \mathrm{sec}$. *

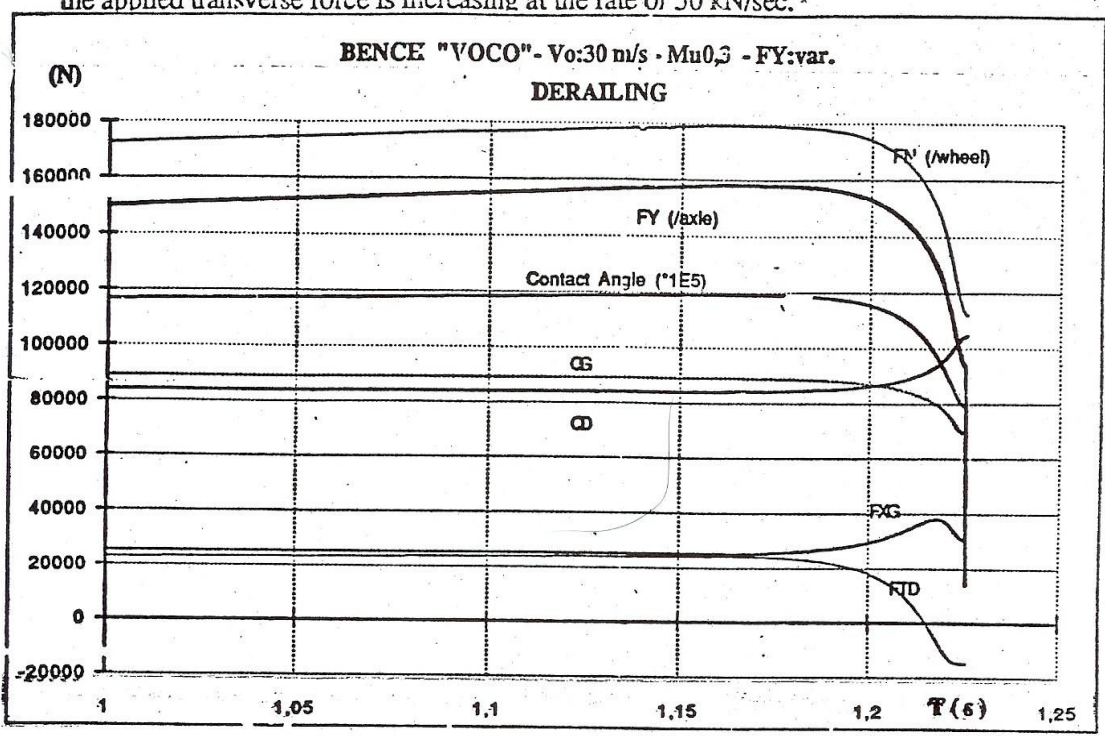

The next diagram, for an adhesion of 1 is given as ais example :

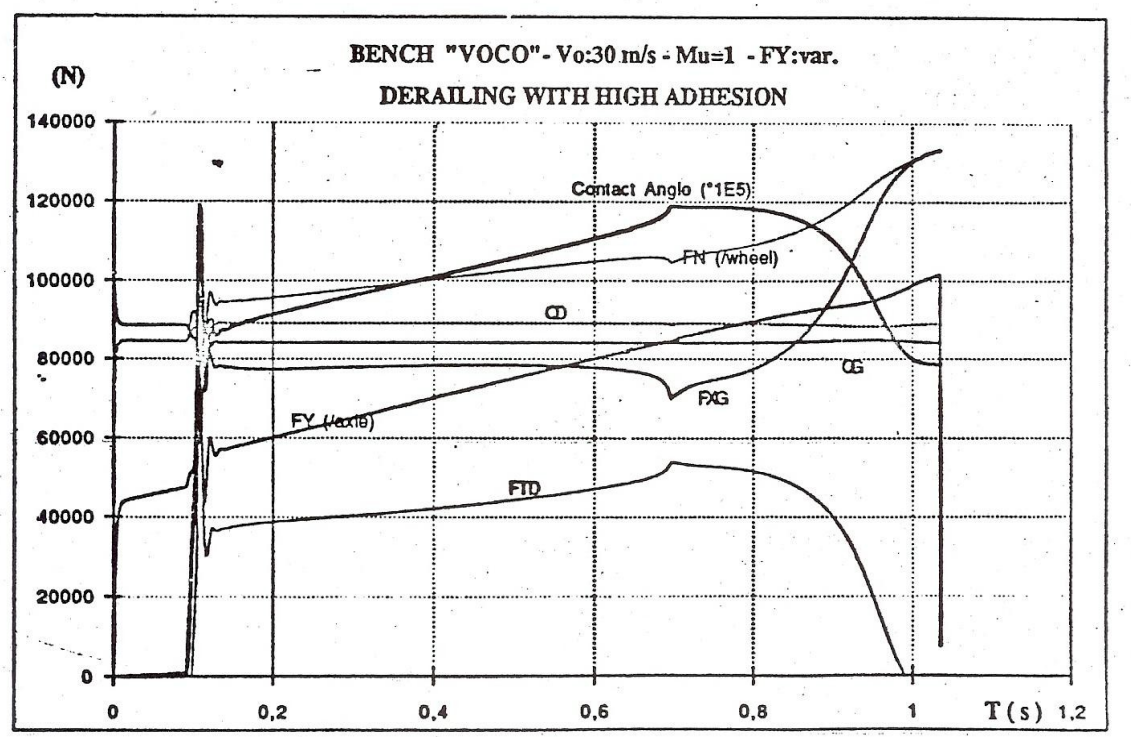

Annexes: S1002 and UIC60 profiles

Dr. J.P. PASCAL 
IAVSD - Benchmarks for Multibody Sirnulation Software

First Railway Benchmark (Dr. Pascal's)

RESULTS of VOCO

$* * * *$

A first set of results had been proposed as examples and here are presented the results of VOCO code simulation taking into account the last developments of multi contact theory ( 5 simultaneous contacts).

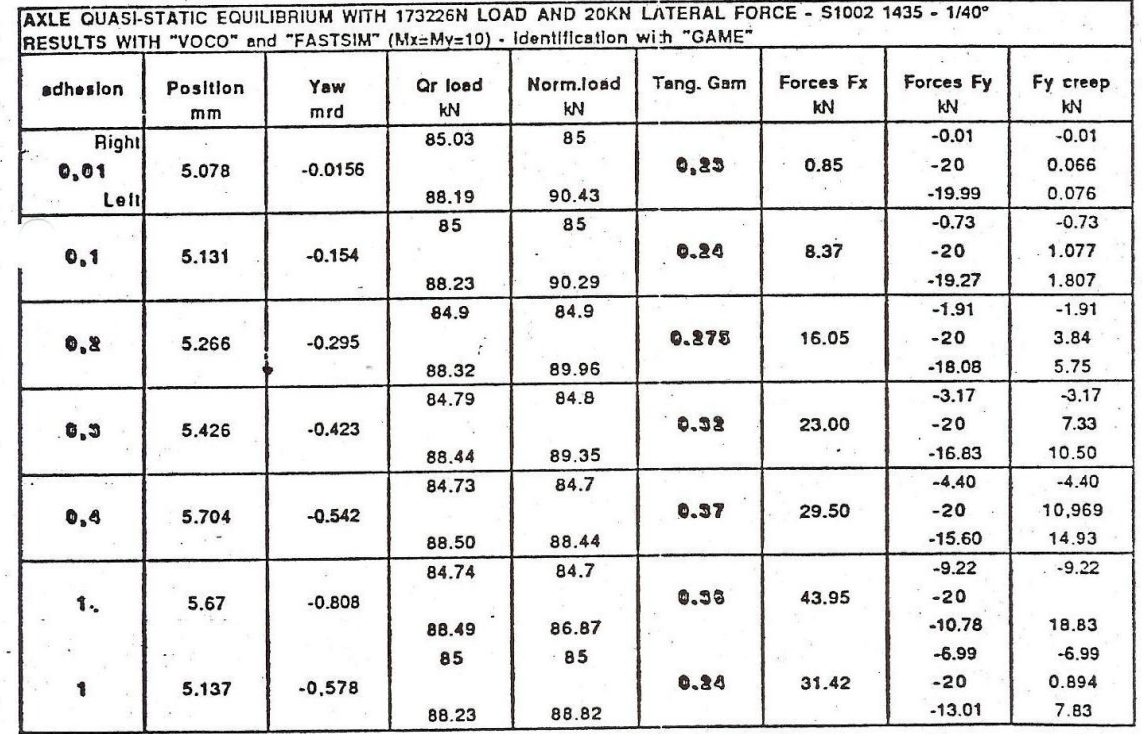

It should be noted that 2 different solutions have been found for the adhesion of 1 . According to initial conditions, it is possible to find one or the other. 
IAVSD - Benchmarks for Multibody Simulation Software
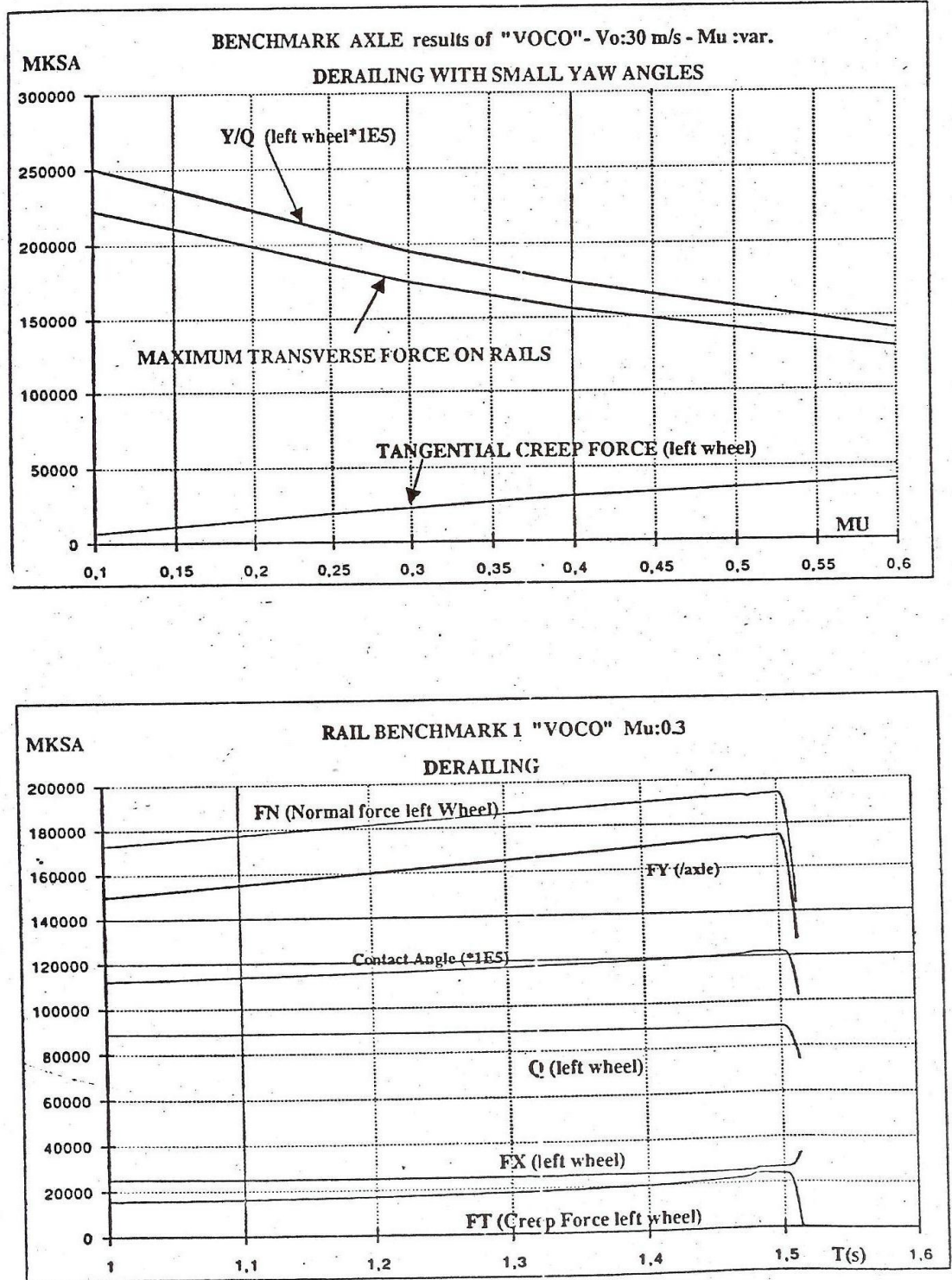

Results of "VOCO" May 1991 
IAVSD - Benchmarks for Multibody Simulation Software

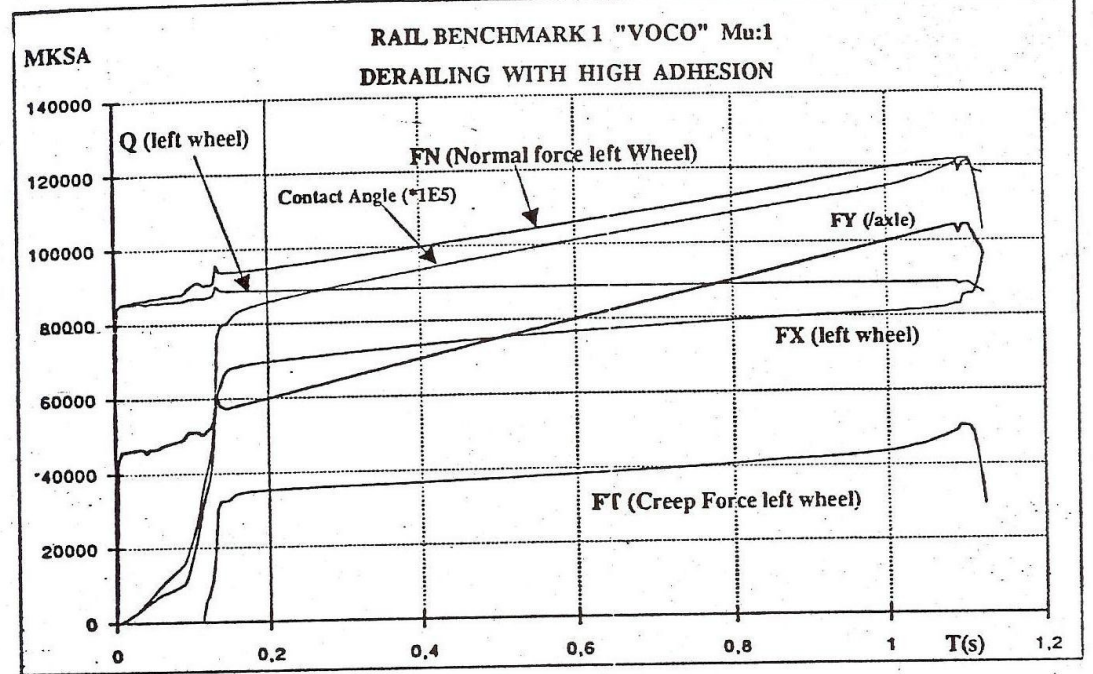

Results of "VOCO" May 1991 


\section{UIC-ORE S1002 PROFULE}

$Y$ IS THE TRANSVERSE COORDINATE (in $\mathrm{mm}$ )

$Z$ IS THE VERTICAL COORDINATE (in $\mathrm{mm}$ ) THE POINT $Y=0, Z=0$ IS THE CENTER ROLIING LINE

THE POINT $Y=-70$ IS THEE INNER FACE

TUE POINT $Y=+60$ IS THE OUTER FACE

ON THE AXIE, INNER FACES OF BOTh WHEELS ARE DISTANT OF $1360 \mathrm{~mm}$

FORTRAN DEFINITION :

IF(Y LE.60.DO.AND.Y.GT.32.15796D0) THEN

$Z=1.364323640 \mathrm{D0}-0.066666667 \mathrm{D} 0^{ \pm} \mathrm{Y}$

END IF

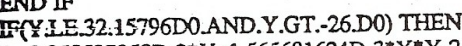

$\mathrm{Z}=3.358537058 \mathrm{D}-2^{*} \mathrm{Y}+1.565681624 \mathrm{D}-3^{*} \mathrm{Y}^{*} \mathrm{Y}-2.810427944 \mathrm{D}-5^{*} \mathrm{Y}^{* *} \mathrm{Z}$

$\&+5.844240864 \mathrm{D}-8^{*} \mathrm{Y}^{* * 4} 4-1.562379023 \mathrm{D}-8^{*} \mathrm{Y}^{* *} 5+5.309217349 \mathrm{D}-15^{*} \mathrm{Y}^{* *} 6$

\& $-5.957839843 \mathrm{D}-12 * Y^{* * 7+2.646656573 \mathrm{D}-13^{*} Y^{* * 8} 8}$

END IF

END IF 26 . DO.AND.Y.GT.-35.D0) THEN

IF YIE.-26.1063D3-1.038384026D3*Y-1.065501873D2*Y**2

$Z=-4.320221063 \mathrm{D} 3-1.038384026 \mathrm{D} 3^{*} \mathrm{Y}-1.065501873 \mathrm{D} 2^{*} \mathrm{Y}^{* *} 2$
$\&-6.051367875 \mathrm{D} 0^{*} \mathrm{Y}^{* *} 3-2.054332446 \mathrm{D}-\mathrm{1}^{*} \mathrm{Y}^{* * 4} 4-4.169739389 \mathrm{D}-3^{*} \mathrm{Y}^{* * 5}$

\& $-4.687195829 \mathrm{D}-5^{*} \mathrm{Y}^{* *} 6-2.252755540 \mathrm{D}-7^{*} \mathrm{Y}^{* *} 7$

END IF

IEIYI I -35 M.AND.Y.GT.-38.426669071D0) THEN

$\mathrm{Z}=16.446 \mathrm{DO}-\mathrm{DSQRT}\left(13 \mathrm{DO} 0^{*} 13 . \mathrm{DO}-(\mathrm{Y}+26.210665 \mathrm{DO})^{* * 2}\right.$ )

END IF

IF(YIE.-38.426669071D0.AND.Y.GT.-39.764473993D0) THEN

$Z=-93.576667419 \mathrm{DO}-2.747477419 \mathrm{DO} \mathrm{O}^{*} \mathrm{Y}$

END IF

IF(Y.LE.-39.764473993D0.AND.Y.GT.-49.662510381D0) THEN

$Z=8.834924130 \mathrm{DO}+\mathrm{DSQRT}\left(400 . \mathrm{DO}-(\mathrm{Y}+58.558326413 \mathrm{DO})^{\mathrm{*} * 2)}\right.$

END IF

END IF

$\mathrm{Z}=16 . \mathrm{D} 0+\mathrm{DSQRT}\left(144 . \mathrm{DO}-(\mathrm{Y}+55 . \mathrm{D} 0)^{* \neq 2} 2\right)$

END IF

IF(Y LE. -62.764705882D0.AND.Y.GE.-70.D0) THEN

$Z=9.519259302 D 0+D S Q R T(20.5 D 0 * 2-(Y+49.5 D 0) * * 2)$

END IF

NOTA : FIRST AND SECOND DERIVATIVES ARE CONIINUOUS 


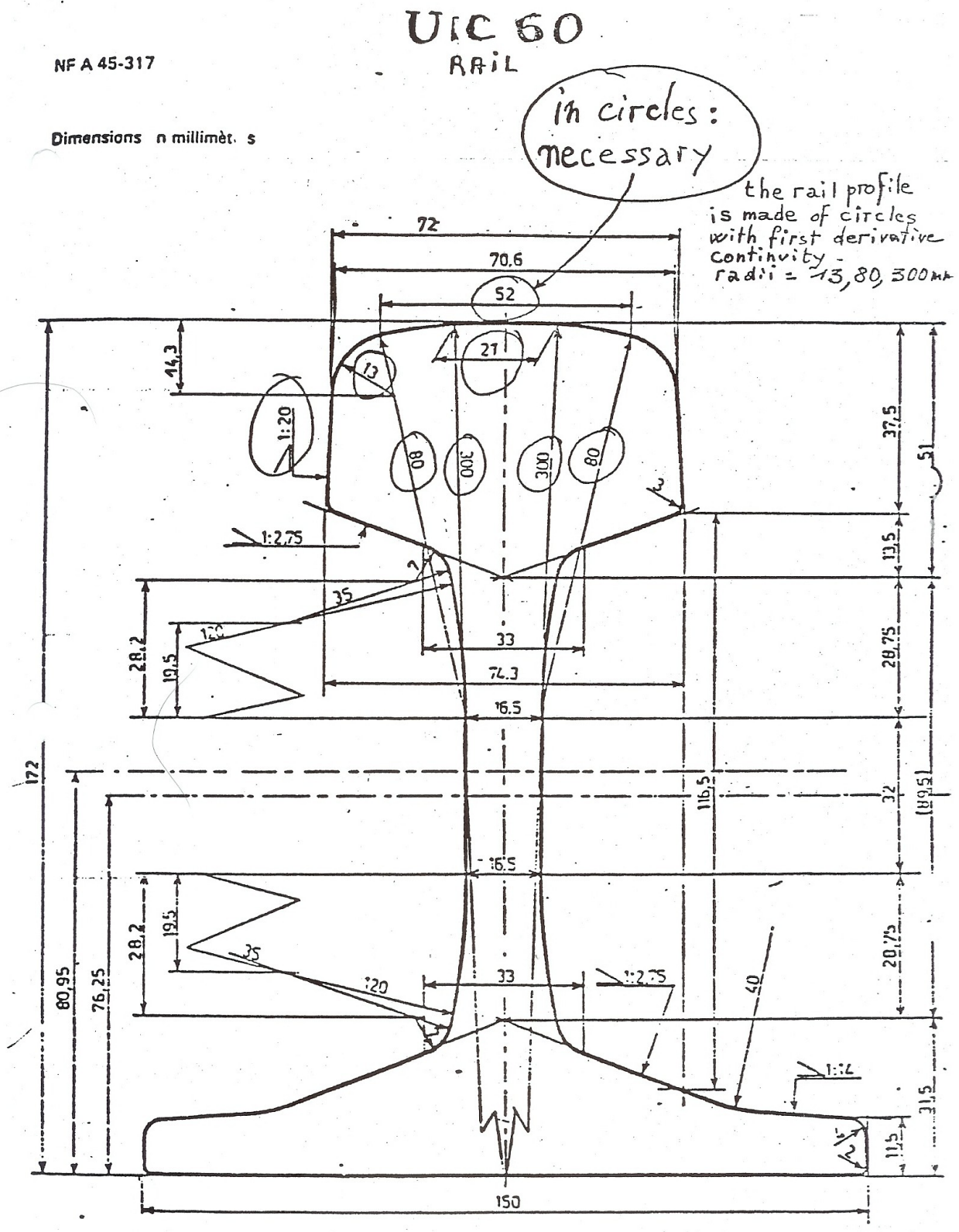

UIC 60 Pail

fullscale 


\section{REFERÊNCIA BIBLIOGRÁFICA}

AlMEIDA, M.T.; LABEGALINI, P.R.; OLIVEIRA,W.C.. Mecânica Geral Estática. São Paulo: Ed. Edgard Blücher ltda, 1984.

BARBOSA,R.S.. Estudo da Dinâmica Longitudinal do Trem. Dissertação de Mestrado da Universidade Estadual de Campinas. Orientação: Weber, H. I., 178 p., 1993.

BARBOSA,R.S.. Aplicação de Sistemas Multicorpos na Dinâmica de Veículos Guiados. Tese de Doutorado - Escola de Engenharia de São Carlos,Universidade de São Paulo,São Carlos. Orientação: Costa,A.,273p., 1999.

BARBOSA,R.S.. Safety Criterion for Railway Vehicle Derailment. Escola Politécnica da Universidade de São Paulo,São Paulo,Brasil, 7 p., 2005.

BARBOSA,R.S.;COSTA,A.. Dinâmica do rodeiro ferroviário. Revista Brasileira de sistemas mecânicos-ABCM. vol.XVIII,nº4, pp.318-329, 1996.

BARBOSA,R.S.;COSTA,A.. Safety Vehicle Traffic Speed Limit.. Paper presented on the IX International Symposium on Dynamic Problems of Mechanics, Basil, 2001.

BEER,F.P.;JOHNSTON JR,E.R.. Mecânica Vetorial para Engenheiros-Dinâmica; traduzido por Pinto, a.c.s.; Caldas,A... $3^{\mathrm{a} e d . v o l ~ I I . ~ S a ̃ o ~ P a u l o: ~ M c g r a w ~-~ H i l l ~ d o ~}$ Brasil, 1981.

BOYCE,W.E.;DiPRIMA,R.C.. Equações Diferenciais Elementares e Problemas

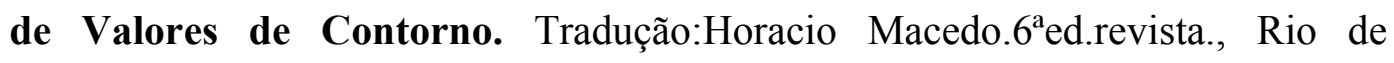
Janeiro:Livros Técnicos e Científicos Editora S.A., 1999. 
Choosing a Variable-Step Solver. Disponível em < $\underline{\text { http://www.mathworks.com> }}$. Acesso em:16/05/2005.

CLARK,R.A.. A review of numerical techniques for the integration of wheel-rail equations. Letter report (internal) of British Rails Research, 1992.

CLAUDIO,D.M.;MARINS, J.M.. Cálculo numérico computacional: teoria e prática. $3^{\mathrm{a} e d . S a ̃ o ~ P a u l o: ~ E d . ~ A t l a s, ~} 2000$.

COSTA,A.;CHERRY,A.S.;JONES,R.P.. An Integrated MBS Modeling Environment for Vehicle Motion Control Studies. Journal of Vehicle System Dynamics, Swets \& Zeitlinger, v.12,p.112-115. Supplement,1993 \& Mechanics, p.509, 1993.

DONG,R.G.;DUKKIPATI,R.V.. A finite element model of railway track and its application to the wheel flat problem. Journal of Rail and Rapid Transit, Institution of Mechanical Engineers - ImechE, part F, v.208, p.61-72. Proceedings, n.1, 1994.

DORF,R.C.; BISHOP,R.H.. Sistemas de controle modernos; traduzido por Silva Filho,B.S. Rio de Janeiro:LTC-Livros Técnicos e Científicos. Editora S.A., 2001.

DUFFEK,W.;JASCHINSKI,A.. Efficient Implementation of Wheel Rail Contact Mechanics in Dynamic Curving. Vehicle System Dynamics, Swets \& Zeitlinger, v.10, n.2/3, p.184-193, 1982.

DUKKIPATI,R.V.;et. el. Comparative Performance of Unconventional Railway Trucks. International Journal of Vehicle Designing, Inter science Enterprises Ltd, v.19, n.3, p.326-339, 1998. 
GARG,V.K.;DUKKIPATI, R.V.. Dynamics of Railway Vehicle Systems. Academic Press Canada, 1984.

GIMENEZ, J. G. et al.. Dynamic Vehicle Simulation "SIDIVE PROGRAM". Vehicle System Dynamics, Swets \& Zeitlinger, v. 22, p. 116-121. Supplement, 1993.

GIMENEZ, J. G. et al.. IAVSD Railway Benchmark \#2 SIDIVE AND VOCO, Code Solutions. In: $12^{\text {th }}$ IAVSD-SYMPOSIUM. Proceedings. Lyon, France, Swets \& Zeitlinger,v. 20, p. 172-184, 1991.

GIMENEZ, J. G.; KIK W.; Pascal, J. P.; Savage, G.. Simulation of the IAVSD Railway Vehicle Benchmark \#2 with MEDYNA, SIDIVE and VOCO. Vehicle System Dynamics, Multi body Computer Codes in Vehicle System Dynamics, Swets \& Zeitlinger, v. 22, p. 193-214, 1993.

IWNICKI, S.. Simulation of wheel-rail contact forces. Manchester Metropolitan University, Fatigue fract Engn Mater Struct v. 26, p. 887-900, 2003.

JASCHINSKI, A.. Multibody Simulation of Flexible Vehicles in Interaction with Flexible Guideways. Interaction of railway vehicles with the track and its substructure. Journal of Vehicle System Dynamics, Swets \& Zeitlinger, v.24, p.3144.Supplement, 1995. 
JASCHINSKI , A.; NETTER,H.. Non-Linear Dynamical Investigations By Using

Simplified Wheelset Models. In: $12^{\text {th }}$ IAVSD-SYMPOSIUM. Proceedings. Lyon, France,Swets \& Zeitlinger,v. 20,p. 284-298, 1991.

JOHNSON, K. L.. Contact Mechanics. Cambridge University Press, UK. 452p., 1985.

KALKER, J. J.. A Fast Algorithm for the Simplified Theory of Rolling Contact. Journal of Vehicle System Dynamics,Swets \& Zeitlinger,v. 11,p. 1-13, 1982.

KALKER， J. J.. Considerations on Rail Corrugation. Journal of Vehicle System Dynamics,Swets \& Zeitlinger,v. 23, p. 3-28, 1994.

KALKER, J. J.. Discretely Supported Rails Subjected to Transient Loads. Journal of Vehic1e System Dynamics, Swets \& Zeitlinger, v. 25, p. 71-88,n.1, 1996.

KALKER, J. J.. Survey of Wheel-Rail Rolling Contact Theory. Journal of Vehicle System Dynamics, Swets \& Zeitlinger, v. 8,p. 317-358, 1979.

KIK,W.;PASCAL,J.P.. Railway Benchmark Model \# 2:Bogie Vehicle. Vehicle System Dynamics,v.22,p.174-192, 1993. 
KUO,B.C.. Sistemas de controle automático;traduzido por Sales, R.M.; Leite, V.M.P. Rio de Janeiro:Prentice-Hall do Brasil, 1985.

Manual de Elaboração de Referências Bibliográficas(Norma ABNT). Disponível em: $<$ http://www.unijui.tche.br $>$ Acesso em:19/06/2005

MEIROVITCH, L.. Elements of Vibration Analysis. Tokyo, 1975.

OGATA, K.. Discrete-Time Control Systems. 2a Ed. New Jersey:Prentice Hall, 1995.

OGATA, K.. Modern Control Engineering. $4^{\text {a }}$ Ed. New Jersey: Prentice Hall, 2002.

OGATA, K. . System dynamics. $2^{\text {nd }}$ edition. Prentice\&Hall, USA,712 p., 1978.

PASCAL,J.P.. Benchmark to Test Wheel/Rail Contact Forces. 9 p., 1990.

PASCAL, J. P.; SAUVAGE, G. . Solution of the Multiple Wheel and Rail Contact Dynamic Problem. Journal of Vehicle System Dynamics, Swets \& Zeitlinger, v. 19 , n. 5 , p. $257-272,1990$ c.

PASCAL, J. P.; SAUVAGE,G. . New Method For Reducing The Multicontact Wheel/Rail Problem To One Equivalent Contact Patch. In: $12^{\text {th }}$ IAVSDSYMPASIUM, Lyon, France. Proceedings. Swets \& Zeitlinger, v. 20, p. ,475489, 1991. 
PASCAL, J. P. . About Multi-Hertzian-Contact Hypothesis and Equivalent Conicity in the Case of S1002 and UIC60 Analytical Wheel/Rail Profiles. Journal Vehicle System Dynamics,Swets \& Zeitlinger,v. 22, p. 57-78, 1993 a.

PASCAL, J. P.; SAUVAGE, G. . The Available Methods to Calculate the Wheel/Rail Forces in Non Hertzian Contact Patches and Rail Damaging. Journal of Vehicle System Dynamics,Swets \& Zeitlinger ,v. 22, p. 263-275, $1993 b$.

PASCAL, J. P.. The Railway Dynamic Codes “VOCO”. Journal of Vehicle System Dynamics, Swets\&Zeitlinger,v. 22, p. 137-139.Supplement, 1993d.

RUGGIERO,M.A.G.;LOPES,V.L.R..Cálculo numérico: aspectos teóricos e computacionais. $2^{\mathrm{a} e d . . S a ̃ o ~ P a u l o: M A K R O N ~ B o o k s, ~} 1996$.

SANTOS, I.F.. Dinâmica de Sistemas Mecânicos-Modelagem-SimulaçãoVisualização - Verificação. São Paulo: Makron Books, 2001.

SHABANA,A.A.;ZAAZAA,K.E.;ESCALONA,J.K.;SANY,J.R.. Development of elastic force model for wheel/Rail contact problems. Journal of Sound and Vibration, 31p, 2002.

SHABANA,A.A. ;BERZERI,M.; SANY,J.R.. Numerical Procedure for the Simulation of wheel/Rail Contact Dynamics. vol.123,pp.168-178, 2001.

THOMSON,W.T.;DAHLEH,M.D.. Theory of Vibration with Applications. $5^{\text {th }}$ ed. New Jersey: Prentice-Hall, 1998. 
URROZ, G.E.. Numerical and Statistical Methods with Scilab for Science and Engineering. vol I/II n³04/305. Greatunpublished.com, 2001.

VAMPIRE. User's reference manual, Version 4.31, 360 p., 2005.

WICKENS,A. H. .Dynamics of Actively Guided Vehicles. Vehicle System Dynamics Swets \& Zeitlinger, v. 20, n. 3/4, p. 219-242, 1991.

WICKENS, A. H. . Steering and stability of the bogie: vehicle dynamics and suspension design. Journal of Rail and Rapid Transit, London, Institution of Mechanical Engineers, v. 205, p. 109-122.Proceedings, 1991.

WICKENS, A. H..Railway Vehicles With Generic Bogies Capable of Perfect Steering. Vehicle System Dynamics .Swets \& Zeitlinger, V.25, N.6,p. 389-412, 1996.

WICKENS, A. H. . Static and Dynamic Instabilities of Bogie Railway Vehicles with Linkage Steered Wheelsets.. Vehicle System Dynamics. Swets\& Zeitlinger, v. 26,N.1, p. 1-16, 1996.

WICKENS, A. H.; IWNICKI, S. D. . Validation of a MATLAB Railway Vehicle Simulation Using a Scale Roller Rig. Vehicle System Dynamics.Swets \& Zeitlinger, v.30,n.3/4,p.257-270, 1998. 
ZILL,D.G.. Equações Diferenciais com Aplicações em Modelagem. Tradução: Cyro de Carvalho Patarra.. São Paulo:Pioneira Thomsom Learning, 2003. 